\title{
Stem and progenitor cells in preterm infants : role in the pathogenesis and potential for therapy
}

Citation for published version (APA):

Borghesi, A. (2015). Stem and progenitor cells in preterm infants : role in the pathogenesis and potential for therapy. [Doctoral Thesis, Maastricht University]. Maastricht University. https://doi.org/10.26481/dis.20150128ab

Document status and date:

Published: 01/01/2015

DOI:

10.26481/dis.20150128ab

Document Version:

Publisher's PDF, also known as Version of record

\section{Please check the document version of this publication:}

- A submitted manuscript is the version of the article upon submission and before peer-review. There can be important differences between the submitted version and the official published version of record.

People interested in the research are advised to contact the author for the final version of the publication, or visit the DOI to the publisher's website.

- The final author version and the galley proof are versions of the publication after peer review.

- The final published version features the final layout of the paper including the volume, issue and page numbers.

Link to publication

\footnotetext{
General rights rights.

- You may freely distribute the URL identifying the publication in the public portal. please follow below link for the End User Agreement:

www.umlib.nl/taverne-license

Take down policy

If you believe that this document breaches copyright please contact us at:

repository@maastrichtuniversity.nl

providing details and we will investigate your claim.
}

Copyright and moral rights for the publications made accessible in the public portal are retained by the authors and/or other copyright owners and it is a condition of accessing publications that users recognise and abide by the legal requirements associated with these

- Users may download and print one copy of any publication from the public portal for the purpose of private study or research.

- You may not further distribute the material or use it for any profit-making activity or commercial gain

If the publication is distributed under the terms of Article $25 \mathrm{fa}$ of the Dutch Copyright Act, indicated by the "Taverne" license above, 


\section{Stem and Progenitor Cells in Preterm Infants}

Role in the Pathogenesis and Potential for Therapy

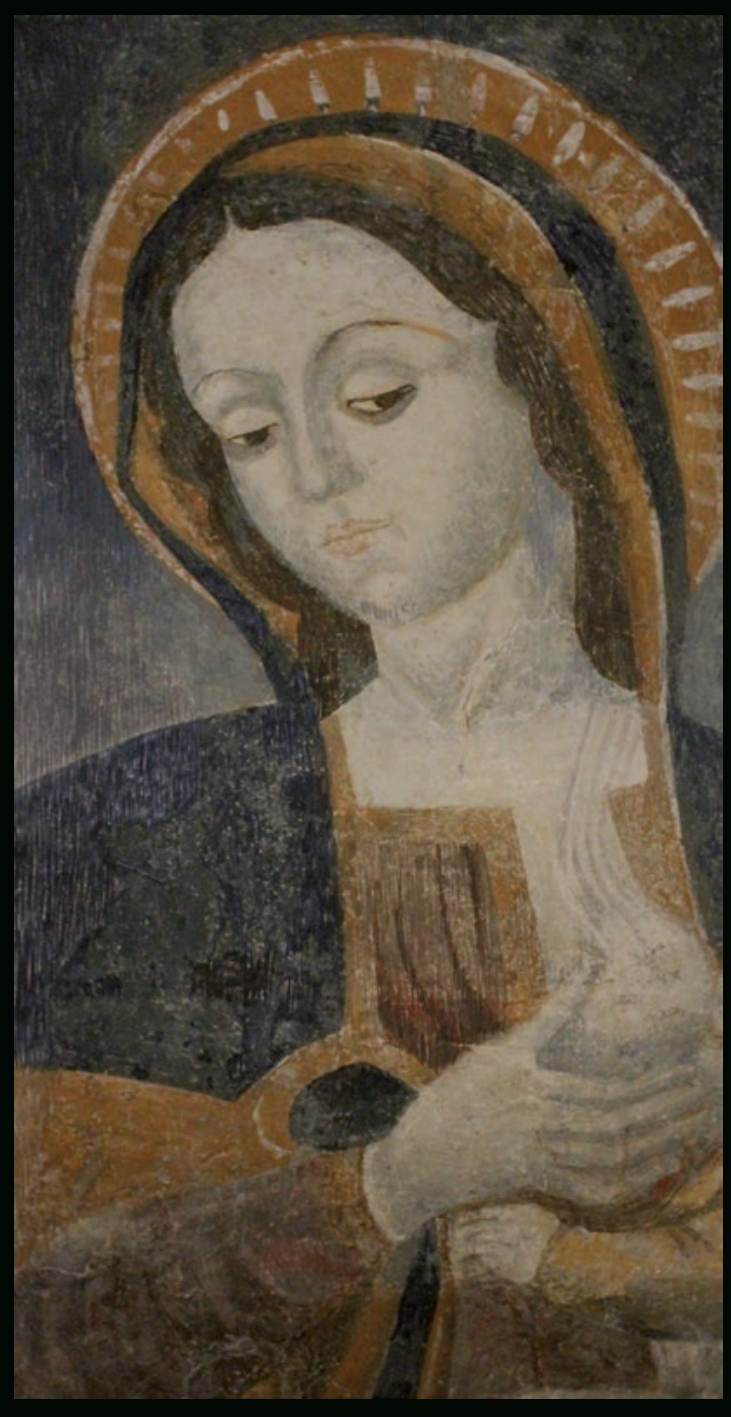


ISBN 9789461594051

(C) Copyright Alessandro Borghesi, Maastricht 2015

Production Datawyse / Universitaire Pers Maastricht Cover: Matonna te lu parete, chiesa di San Francesco d'Assisi, Gallipoli. 


\title{
Stem and Progenitor Cells in Preterm Infants Role in the Pathogenesis and Potential for Therapy
}

\author{
Dissertation
}

\author{
to obtain the degree of doctor at University Maastricht \\ on authority of the Rector Magnificus, \\ Prof. Dr. L.L.G. Soete \\ in accordance with the decision of the board of deans \\ to be defended in public \\ on Wednesday 28th of January 2015, at 14:00 hours
}

by

Alessandro Borghesi

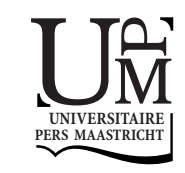




\section{Promotors}

Prof. dr. L.J.I. Zimmermann

Prof. dr. B.W. Kramer

\section{Co-promotors}

Dr. D. Gazzolo (Alessandria-Italy)

Dr. A.W.D. Gavilanes

\section{Assessment Committee}

Prof. dr. H. Steinbusch (chairman)

Prof. dr. V. Carnielli (Ancona-Italy)

Prof. dr. C. Dani (Florence-Italy)

Prof. dr. E. Dompeling 
To my niece, Victoria

Ce qu'un vrai médecin doit faire, c'est de s'instruire scientifiquement autant que possible, de comprendre que sa science est la plus belle de toutes et de se donner pour but de la perfectionner, de concourir à des progrès scientifiques, en même temps qu'on soulage les malades.

[...]

C'est dès le début qu'il faut prendre ce goût de la science qui ne vous abandonne jamais. Chaque malade aura pour vous un intérêt scientifique et un intérêt pratique. La science ne vous fera pas négliger les exigences morales du malade. Un homme d'esprit sait toujours parler à l'esprit de son semblable sans être obligé d'employer le mensonge et la tromperie indignes du malade et du médecin.

Si donc chaque jeune médecin est bien pénétré, en finissant ses études, de ce que la science possède actuellement et de la tendance qu'elle doit suivre, il remplira son rôle envers la société comme homme instruit et utile et son rôle envers la science parce qu'il fera tourner à son profit tout ce qu'il verra. Il fera ainsi sur tous les points des études, des observations qui seront imbues de l'esprit d'observation scientifique. L'humanité et la science trouveront leur profit; le médecin y trouvera le bonheur, car il n'y a d'heureux ici-bas que celui qui, en même temps que son corps, nourrit son intelligence. Or, quand on nourrit son esprit par l'observation et l'étude de la nature, l'aliment est inépuisable. Il faut nourrir son esprit et son corps.

Tel est donc le but que se doit proposer le médecin, c'est d'être utile à l'humanité souffrante actuellement et à la science dans l'avenir suivant la proportion qui lui sera possible. C'est un double devoir qu'il faut inculquer aux jeunes gens. Ils n'ont pas appris la médecine seulement pour vivre et gagner actuellement de l'argent; mais ils doivent contribuer aux progrès de l'humanité et ajouter chacun sa pierre à l'édifice scientifique que l'humanité élève dans son évolution.

Claude Bernard

PRINCIPES DE MÉDECINE EXPÉRIMENTALE ou de l'expérimentation appliquée à la physiologie, à la pathologie et à la thérapeutique. Chapitre XIV, Médecine actuelle, médecine future. 



\section{Table of contents}

Index of tables and figures

Abbreviation list

PART 1 GENERAL INTRODUCTION AND AIMS

Chapter 1. Introduction: Stem cell therapy for neonatal diseases associated with preterm birth

Chapter 2. Aims

PART 2. INVESTIGATING THE ROLE OF ENDOTHELIAL PROGENITOR CELLS AS BIOMARKERS

Chapter 3. Circulating endothelial progenitor cells in preterm infants with bronchopulmonary dysplasia

Chapter 4. Different subsets of circulating angiogenic cells do not predict bronchopulmonary dysplasia or other diseases of prematurity in preterm infants

Valorisation: ECFCs for early prediction of BPD

89

PART 3. BIOSAFETY PROFILE OF UMBILICAL CORD-MESENCHYMAL STROMAL CELLS 
Chapter 5. Genomic alterations in human umbilical cord-derived mesenchymal stromal cells call for stringent quality control before any possible therapeutic approach

Valorisation: Biosafety of umbilical cord-derived mesenchymal stromal cells (MSCs)

PART 4. DISCUSSION, FUTURE PERSPECTIVES AND CONCLUSIVE REMARKS 115

Chapter 6. Discussion

Chapter 7. Future perspectives and conclusive remarks

Acknowledgements

Curriculum vitae and scientific output 


\section{Index of tables and figures}

\section{Figures}

Figure 1. Timing of injury and sequelae associated with preterm birth.

Figure 2. Mechanisms of disease in prematurity.

Figure 3. Working hypothesis: lung stem/progenitor cells and/or ECFCs are depleted in infants developing BPD.

Figure 4. Working hypothesis on the role of ECFC depletion in preterm infants developing BPD.

Figure 5. Schematic representation of the mechanisms of white matter brain injury in diffuse PVL.

Figure 6. Working hypothesis: parallel between lung and brain injury, and potential for intervention.

Figure 7. Gating strategy for identification and enumeration of CD34+CD133+VEGFR-2+ and CD34+CD133-VEGFR-2+ cells.

Figure 8. Frequency of endothelial colony forming cells (ECFCs) in cord blood of preterm infants with or without BPD.

Figure 9. Correlation of endothelial colony forming cells (ECFCs) in cord blood with gestational age at birth.

Figure 10. One representative example of the gating strategy for assessment of the percentages of CD34+VEGFR-2+, CD34+CD133+VEGFR-2+, and CD45-CD34+CD133+VEGFR-2+ cells.

Figure 11. CD34+VEGFR-2+, CD34+CD133+VEGFR-2+, and CD45-

CD34+CD133+VEGFR-2+ cells in infants without BPD and in infants with mild or moderate-severe BPD.

Figure 12. Morphology and differentiation potential of BM- and UC- MSCs. 100

Figure 13. A representative flow cytometric analysis of UC-MSCs (top row) surface proteins and BM-MSCs (bottom row) at early passages.

Figure 14. Proliferative potential of BM- and UC-MSCs. 
Figure 15. Array-comparative genomic hybridization profile of the UC-MSC sample with chromosome 10 trisomy detected at late passages and not at the early ones.

Figure 16. Array-comparative genomic hybridization profile of the UC-MSC sample with $7 \mathrm{q} 35$ deletion of about $245 \mathrm{~Kb}$ [arr 7q35(146,856,474-147,101,307)x1 genomic assembly: hg19].

Figure 17. FISH analysis performed on the lot with chromosome 10 trisomy. 104

Figure 18. Methylcellulose-based anchorage-independent mesenchymal stromal cell growth assay.

Figure 19. Enumeration of cord blood ECFCs.

Figure 20. Cell surface phenotype of ECFCs, pro-angiogenic and nonangiogenic CPCs.

\section{Tables}

Table 1. Incidence of major diseases associated with preterm birth.

Table 2. Maternal, perinatal, and neonatal characteristics of the study infants.

Table 3. Median values of ECFCs in cord blood and of different CD34+ cell subsets at birth in infants with and without BPD.

Table 4. Maternal, perinatal, and neonatal characteristics of the study infants. 


\section{Abbreviation list}

$\begin{array}{ll}\text { BPD } & \text { bronchopulmonary dysplasia } \\ \text { PVL } & \text { periventricular leukomalacia } \\ \text { NEC } & \text { necrotizing enterocolitis } \\ \text { PDA } & \text { patent ductus arteriosus } \\ \text { ROP } & \text { retinopathy of prematurity } \\ \text { RDS } & \text { respiratory distress syndrome } \\ \text { NICU } & \text { neonatal intensive care unit } \\ \text { RIP } & \text { respiratory instability of prematurity } \\ \text { GMH-IVH } & \text { germinal matrix hemorrhage - intraventricular hemorrhage } \\ \text { PVHI } & \text { periventricular hemorrhagic infarction } \\ \text { ROS, RNS } & \text { reactive oxygen species, reactive nitrose species } \\ \text { VLBW } & \text { very low birth weight } \\ \text { GA } & \text { gestational age } \\ \text { COPD } & \text { chronic obstructive pulmonary disease } \\ \text { FEV1 } & \text { forced expiratory volume in } 1 \text { second } \\ \text { FEF25-75 } & \text { forced expiratory flow 25\%-75\% } \\ \text { pre-Ols } & \text { pre-oligodendrocytes } \\ \text { MSCs } & \text { mesenchymal stromal cells } \\ \text { EPCs } & \text { endothelial progenitor cells } \\ \text { CFU } & \text { colony forming unit } \\ \text { ECFC } & \text { endothelial colony forming cells } \\ \text { CD } & \text { cluster of differentiation } \\ \text { VEGFR-2 } & \text { vascular endothelial growth factor receptor-2 } \\ \text { CPCs } & \text { circulating progenitor cells } \\ \text { BM } & \text { bone marrow } \\ \text { TGF } & \text { transforming growth factor } \\ \text { UC } & \text { umbilical cord } \\ \text { BASCs } & \text { bronchioalveolar stem cells } \\ & \end{array}$





\section{Part 1 General introduction and aims}





\section{Chapter 1. Introduction:}

Stem cell therapy for neonatal diseases associated with preterm birth

Modified and integrated from:

Stem cell therapy for neonatal diseases associated with preterm birth.

Borghesi A, Cova C, Gazzolo D, Stronati M. J Clin Neonatol. 2013 Jan-Mar; 2(1):1-7. 


\subsection{General considerations}

Very and extremely preterm infants suffer from severe diseases associated with preterm birth, including bronchopulmonary dysplasia (BPD), periventricular leukomalacia (PVL), necrotizing enterocolitis (NEC), patent ductus arteriosus (PDA), sepsis, and retinopathy of prematurity (ROP).

All these diseases are strictly interrelated, are strongly associated, and share common risk factors and mechanisms of pathogenesis. Infection/ inflammation, ischemia/reperfusion, and oxidative stress, seem to be the main common pathogenic mechanisms underlying all these conditions.

During the nineties, the universal introduction of antenatal steroids and surfactant replacement as standard therapies for the prevention and treatment of neonatal respiratory distress syndrome (RDS) in the neonatal intensive care units (NICUs) has dramatically changed the natural history of diseases affecting prematurely born infants.

Indeed, together with a reduction in the severity of neonatal RDS, the sequelae of perinatal lung and brain injury profoundly changed: the old BPD and cystic PVL were replaced by newly emerging diseases, the so-called "new BPD" and "noncystic, diffuse PVL", respectively. These "new" sequelae differ from the old ones in severity (are usually less severe), pathogenesis, pathological features, and clinical presentation (1-6). In general, focal injury/necrosis and the consequent fibrosis/astrogliosis, the main components of old BPD and cystic PVL, appear to be milder and to contribute to a lesser extent to the pathogenesis of new BPD and noncystic PVL. Conversely, tissue simplification and developmental arrest (larger and fewer alveoli in the lungs, and hypomyelination with defective white matter development and neuronal abnormalities in the brain) are the key and predominant components of the new BPD and of the diffuse, noncystic form of PVL, and account, at least in part, for the different clinical correlates of these new conditions, both during the acute phase and at long term follow up $(3,6)$.

While surfactant replacement and prenatal steroids proved revolutionary in changing the destiny of preterm infants during the nineties by changing the natural history of old diseases, no preventive strategy is currently available to reduce the incidence of the new, emerging diseases. Consistently, the prevalence of all complications of prematurity has reached a steady state across the last decade (Table 1). 
Table 1. Incidence of major diseases associated with preterm birth.

\begin{tabular}{lccc}
\hline & 2000 & 2005 & 2010 \\
\hline Necrotizing enterocolitis & $4.9 \%$ & $5.3 \%$ & $5.1 \%$ \\
Bronchopulmonary dysplasia & $27.3 \%$ & $26.3 \%$ & $23.5 \%$ \\
IVH grade III-IV & $5.8 \%$ & $6 \%$ & $5.4 \%$ \\
Periventricular Leukomalacia & $3 \%$ & $2.8 \%$ & $2.8 \%$ \\
n. of involved centers & 20,000 & 30,000 & 44,000 \\
\hline
\end{tabular}

Data are extrapolated from the Vermont Oxford Network database and are related to a population of very low birth weight infants (VLBW, < $1500 \mathrm{~g}$ ). The numbers indicates the percentage of very low birth weight infants who developed the disease.

Overall, the sequelae of prematurity still represent a burden for neonatal medicine and global health. The rate of preterm birth has risen in most industrialized countries in the last decades, with reported rates of preterm delivery $(<37$ weeks gestational age) ranging from $5-9 \%$ in Europe to $12-13 \%$ in the USA (7-9), and with estimated costs in the USA of $\$ 26$ billion a year (http://www.iom.edu/Reports/2006/Preterm-Birth-Causes-Consequences-and-Prevention.aspx, accessed November 24, 2013). Importantly, preterm births account for $75 \%$ of perinatal mortality and more than half of the long-term morbidity: preterm infants who survive are at increased risk of neurodevelopmental impairment and respiratory and gastrointestinal complications (7).

Therefore, the understanding of the pathological bases of the pathogenic processes associated with preterm birth and the research and development of new tools for the prevention of the sequelae resulting from prematurity are imperatives.

\subsection{Epidemiology, pathology, and long term outcomes of BPD, PVL and other diseases of prematurity}

Pre- and perinatal pathogenic factors work during the perinatal period and during the first weeks of life to cause acute injury to the immature neonatal preterm tissues; tissue damage and repair constitute the bases for subsequent sequelae featuring as chronic diseases (Figure 1).

Major sequelae associated with prematurity include (but are not limited to): i) respiratory sequelae following RDS and/or respiratory instability of prematurity (RIP), resulting in the clinical, radiological and pathological picture of BPD $(1,3)$; ii) neurodevelopmental sequelae following acute brain injury resulting in variable combinations of PVL and neuronal/axonal abnormalities (the so-called encephalo- 
pathy of prematurity), and sequelae following severe germinal matrix hemorrhage - intraventricular hemorrhage (GMH-IVH) with periventricular hemorrhagic infarction (PVHI) $(6,10,11)$; iii) sequelae following NEC (12) (Figure 1).

\begin{tabular}{|c|c|c|c|c|}
\hline & Ac & Ite disease & & Sequela \\
\hline & & RDS & & \\
\hline & r & ــ & & BPD \\
\hline Preterm & $1^{\mathrm{st}}$ & $2^{\text {nd }}$ & 36 w PMA & \\
\hline Birth & week & week & & \\
\hline & IVH & 3-4, brain injury & & $\begin{array}{l}\text { Cystic and } \\
\text { non-cystic }\end{array}$ \\
\hline & 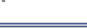 & 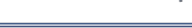 & & \\
\hline Preterm & $1^{\text {st }}$ & $2^{\text {nd }}$ & 36 w PMA & \\
\hline Birth & week & week & & \\
\hline & & NEC & & Bowel \\
\hline & $r$ & 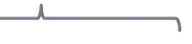 & & sequelae \\
\hline $\begin{array}{l}\text { Preterm } \\
\text { Birth }\end{array}$ & $\begin{array}{c}1^{\text {st }} \\
\text { week }\end{array}$ & $\begin{array}{c}2^{\text {nd }} \\
\text { week }\end{array}$ & 36 w PMA & \\
\hline
\end{tabular}

Figure 1. Timing of injury and sequelae associated with preterm birth. $\mathrm{RDS}=$ respiratory distress syndrome; $\mathrm{BPD}=$ bronchopulmonary dysplasia IVH = intraventricular hemorrhage; PVL = periventricular leukomalacia NEC = necrotizing enterocolitis.

Emphasis in this thesis will be given to these conditions: the thesis is maximally focused on BPD (this latter presently being the most likely to benefit from prevention/treatment with stem cells), partially on cerebral injury associated with preterm birth, and minimally on other conditions (e.g. NEC); conversely, other sequelae of prematurity that are of equal importance (as, for instance, ocular sequelae following ROP) will not be matter of this thesis.

Although in origin the project of the present thesis was focused on BPD only, and aimed at understanding the pathogenesis of BPD and at developing therapies for its prevention or attenuation, during the $\mathrm{PhD}$ study period it became more and more clear that: i) the preterm infant as a whole is exposed to risk/pathogenic factors that work in the immature tissues of different organs to cause injury (for instance, prolonged mechanical ventilation is a risk factor for both BPD and PVL, and the exposure to free radical species of oxygen and nitrogen - ROS, RNS -, deriving at least in part from exposure to high oxygen concentrations, is a pathogenic mechanism working in both conditions; similarly, infants with NEC are at higher risk of cerebral white matter injury); ii) in parallel with these considerations, any cell therapy given to a preterm newborn infant to target a specific organ (e.g. the 
lungs) will inevitably sort effects in many other tissues and organs (e.g. the brain and the bowel).

It would be therefore reductive here to limit the dissertation to BPD without mentioning, at least briefly, other major diseases associated with preterm birth (in the present section and in the "Discussion" section); and it will be similarly important, when the time for translation to clinics will come, to remember that treating BPD will mean treating and preventing PVL and NEC and other diseases; and viceversa.

\subsection{1. $B P D$}

BPD is a chronic lung disease affecting very and extremely preterm infants, following mechanical ventilation and oxygen administration for neonatal RDS/RIP $(1,3$, 13). BPD affects up to $43 \%$ of infants with very low birth weight (VLBW; $\leq 1500 \mathrm{~g}$ ) $(3,14)$, with infants born at less than 28 weeks gestational age (GA) being at higher risk. BPD is characterized by arrested alveolar and lung vascular growth (15), leading to chronic need of oxygen supplementation until late in infancy and disturbances in lung function and neurodevelopment in older children and adults.

Pathological changes occurring early in life following preterm birth disrupt lung architecture and function, and may persist across childhood and into adulthood, facilitating the occurrence of early onset emphysema and pulmonary hypertension in young adults (16-18). Changes affect both the lung vascular bed and the pulmonary parenchyma and airways.

Lung vascular bed. Vascular changes in the lung have been classically reported as "dysmorphic lung vascular growth" $(19,20)$. More recently, Galambos et al. reported histologic evidence of intrapulmonary vessels that bridge pulmonary arteries and veins in the distal lungs of infants dying with severe BPD, appearing similar to "misaligned pulmonary veins" described in the lethal form of the congenital lung disorder, alveolar capillary dysplasia. These vessels work as precapillary arteriovenous anastomoses in the more severe forms of BPD and, possibly persisting and expanding, may provide the anatomic basis for intrapulmonary shunt and hypoxemia in the more severe forms of BPD (21). When surviving, at pre-school age, infants with BPD have decreased pulmonary artery acceleration time and higher left and right ventricular myocardial performance indexes, consistent with higher pulmonary pressures and impaired biventricular systolic and diastolic functions at preschool ages (22). The pathogenesis of lung vascular disruption in BPD is largely unknown.

Pulmonary parenchyma and airways. Pulmonary function is also impaired in infants surviving BPD throughout childhood and until adulthood. Vollsæter et al. performed a controlled and population-based study on the longitudinal development of lung function from childhood to adulthood after extremely preterm birth, 
and found that airway obstruction was present from mid-childhood to adulthood after extremely preterm birth, most evident after neonatal BPD, underlining the risk of early onset chronic obstructive pulmonary disease (COPD) in this population. Importantly, the two examined cohorts in this study consisted of infants born in the years 1982-1985 and 1991-1992 (23).

Gough et al. recently reported a study on lung function and quality of life on 72 adult BPD survivors evaluated at $24.1 \pm 4.0$ years (gestational age $-\mathrm{GA}$ - at birth: $27.1 \pm 2.1 \mathrm{wks}$ ) compared to 57 non-BPD controls evaluated at $25.3 \pm 4.0$ years (GA at birth $31.0 \pm 2.5 \mathrm{wks}$ ) and 78 full term controls; in their study, BPD subjects were twice as likely to report wheeze and three times more likely to use asthma medication than controls, and at spirometry had significantly lower FEV1 and FEF25-75 than both the preterm non-BPD and full term controls (all $p<0.01$ ) (24). These data were relative to subjects born in the years 1978-1993. The results of this study were similar to those reported in another, less recent study, showing that VLBW subjects with BPD in the newborn period have poorer lung function in late adolescence than those without BPD; again, the cohort consisted of infants born in the years 1977-1982 (25).

All the above reported studies on pulmonary function were performed on cohorts of infants born before 1993; therefore, the question remains open whether similar pulmonary long term dysfunction may be present in infants born in the last 10-15 years, that is, after changes in clinical practice that entered the NICUs worldwide (including surfactant, prenatal steroids, and more gentle ventilator approaches for the management of respiratory diseases of preterm infants). Importantly, a study from the EPIcure study group assessed, at 11 years of age, a cohort of infants born at 25 completed weeks GA or less in 1995. The goal of the study was to understand whether infants born in more recent years, who are generally more immature than their predecessors, but have been exposed to less aggressive ventilatory support, are equally at risk of persistent respiratory morbidity. In their study, Fawke et al. reported that, at 11 years of age, $56 \%$ of children born before 25+6 weeks GA had abnormal baseline spirometry, $27 \%$ had a positive bronchodilator response, and $25 \%$ had a diagnosis of asthma (twice that observed in classmates). Among the $65 \%$ of extremely preterm children who had been asymptomatic over the previous 12 months, 48\% had abnormal baseline spirometry, of whom $81 \%$ had prior bronchopulmonary dysplasia, emphasizing the need for continued monitoring of these children (26).

Of interest are the results of a recent work, by Narayanan et al., analyzing a population of infants with BPD and suggesting that, in survivors of extremely preterm birth, deranged alveolar development (considered the hallmark of BPD on the basis of histological studies of fatal cases in early childhood) may be compensated within the first decade of life, probably by later alveolarization; although the years of recruitment are not reported, the authors suggest that, given the high rates of 
prenatal steroids and postnatal surfactant, infants could be better classified as having been affected by "new", rather than "old", BPD. Importantly, and consistently with previous studies, extremely preterm infants in this study had lower $\mathrm{FEV}_{1}$ compared with term-born and mild preterm children $(P=0.017)$ suggesting that infants with new BPD, while compensating during childhood for defective alveolarization, may be in any case at higher risk of early onset COPD $(27,28)$. Additionally, abnormal ventilatory responses to hypoxia and hyperoxia have been described in adults with a history of preterm birth, possibly due to disrupted chemoreceptor development (29).

Extra-pulmonary effects of lung disease. Infants with BPD are subject to prolonged exposure to mechanical ventilation and supplemental oxygen and are at high risk for an adverse neurodevelopment (4).

Altogether, it is intuitive that the reduction of the incidence of BPD would be a key step to reduce the detrimental consequences of prolonged ventilation and oxygen exposure including i) the long term pulmonary and ii) the lung vascular features of BPD (pulmonary hypertension and increased risk of COPD), and could indirectly reduce iii) the incidence of other, extra-pulmonary diseases as ROP and PVL with, possibly, a reduction of the overall morbidity in preterm infants.

In the last years, the way of ventilating infants has profoundly changed, giving hope for a dramatic reduction in the incidence of respiratory sequelae of prematurity. In fact, preterm infants seem to benefit from less aggressive respiratory care strategies (30-33), and the trend towards a slightly reduction in the incidence of BPD over the last decade goes along with the introduction of these more gentle ways to ventilate infants (Table 1). A recent meta-analysis included randomized controlled trials published in peer-reviewed journals since the year 2000, and compared preterm infants born at $<30$ weeks GA treated by using a strategy that aimed at avoiding endothracheal mechanical ventilation, with a control group in which mechanical ventilation via an endotracheal tube was performed at an earlier stage. The combined odds ratio (95\% confidence interval) of death or BPD was 0.83 (0.71-0.96), with study results remarkably homogeneous. The authors conclude that strategies aiming at avoiding endotracheal mechanical ventilation in infants $<30$ weeks GA have a small but significant beneficial impact on preventing BPD (34). Another meta-analysis reported comparable results (35).

It is likely that, with the increased use of "gentle" and non-invasive ventilation as a first choice strategy for neonatal RDS/RIP, the incidence of BPD will undergo further reduction in the upcoming years; however, most likely, we are far from eradicating new BPD (less strictly related to ventilation than old BPD) with interventions limited to changing respiratory care and without the introduction in clinical practice of new and more effective preventive tools.

Thus, given i) the absence of specific therapies for BPD in the present landscape; ii) the inability of currently available preventive strategies to minimize the 
risk of developing BPD (including ventilatory strategies); and iii) the failure of some promising drugs, such as nitric oxide, to effectively prevent BPD in clinical trials (36); it seems essential, and urgent, the search of novel and safe strategies to prevent or repair lung injury in preterm infants. In this context, the use of exogenously administered stem/progenitor cells is a promising option.

\subsubsection{Major diseases associated with prematurity other than BPD}

PVL - encephalopathy of prematurity. A series of excellent review articles by Joseph J. Volpe have well summarized, in the last years, the major acquisitions in the field of neonatal neurology and specifically in the field of brain injury following extremely preterm birth. From those reviews, we can point out the following concepts:

- Brain injury is extremely common following preterm birth. Of the approximately surviving $90 \%$ of VLBW infants, brain abnormalities account for the subsequent occurrence of cognitive, behavioral, attentional, and socialization defects in $25 \%-50 \%$ of infants, and of major motor deficits (e.g., cerebral palsy) in 5\%-10\% of infants (11); in infants with birth weight < $1000 \mathrm{~g}$ (with survival rates approaching $70 \%$ ), more than $50 \%$ of the survivors exhibit subsequent disability (11);

- Neuropathological lesions include: i) GMH-IVH, particularly with PVHI (occurring in only approximately 5\% of the VLBW infants, but up to $20-30 \%$ in infants < $750 \mathrm{~g}$ ) (10); and ii) encephalopathy of prematurity (imaging studies indicate that $50 \%$ or more of infants with VLBW show findings consistent with PVL, with the accompanying neuronal/axonal deficits involving the cerebral white matter, thalamus, basal ganglia, cerebral cortex, brainstem, and cerebellum) (37);

- $\quad$ PVL refers to injury to cerebral white matter, classically with two components: focal and diffuse (10). The focal component consists of localized necrosis deep in periventricular white matter, with loss of all cellular elements, and can be i) macroscopic in size evolving over several weeks to multiple cystic lesions (cystic PVL, affecting less than 5\% of infants with VLBW) (10); and ii) microscopic in size and evolving over several weeks to glial scars that are not readily seen by neuroimaging ("noncystic" PVL). The diffuse component consists of marked astrogliosis and microgliosis, and initially by a decrease in premyelinating oligodendrocytes (pre-OLs); in PVL, these latter cells seem not to have the capacity for full differentiation to mature myelin producing cells, and hypomyelination with ventriculomegaly is the later sequela $(6,10,11,38,39)$. The cause of the apparent disturbance of pre-OL maturation is currently unknown, but the failure of the regenerating oligodendroglial progenitors to differentiate into mature oligodendrocytes has been well documented in a neona- 
tal animal model of PVL (40). In this animal model, pre-OLs are exquisitely vulnerable to an hypoxic-ischaemic insult, a common feature in premature infants.

- In addition, neuronal/axonal disease is a previously under-recognized accompaniment of PVL. The regions of involvement include the cerebral white matter (axons and subplate neurons), thalamus, basal ganglia, cerebral cortex, brainstem, and cerebellum.

- $\quad$ Regarding clinico-pathological correlations, cystic PVL probably accounts for the small group of infants who show spastic diplegia, while non-cystic PVL together with neuronal/axonal disease account for the cognitive, attentional, behavioral, and socialization deficits observed later, usually in the absence of major motor deficits (10).

The complex and multifactorial origin of perinatal brain injury has prevented the development of specific treatments. The burden due to long-term neurological morbidity, and the high prevalence of perinatal brain damage, prompts the search for novel and effective treatments, currently not available, for brain protection and repair. Among others, stem cell therapy has the potential to be safe and effective (41-43).

NEC. Recent comprehensive reviews about NEC are available in the literature. Here we can summarize few key concepts:

- $\quad$ NEC is an inflammatory disease of the bowel (44-46) occurring in about 7\% of VLBW infants (12);

- $\quad$ Long term consequences of NEC may affect the bowel, (with severity depending on the severity of the NEC and on the extent of bowel resection if necessary), or extra-intestinal organs including the brain, with an increased risk of adverse neurodevelopment (12, 47-49).

The term "necrotizing enterocolitis" comprises a spectrum of different intestinal conditions differing in pathogenesis. These include:

i) classical NEC of the extremely preterm infant;

ii) NEC of the late preterm and term infant, associated or not with other conditions (infections, maternal illicit drug use, intestinal anomalies such as aganglionosis or atresias, congenital heart disease, and perinatal stress that may affect mesenteric blood flow);

iii) spontaneous/focal intestinal perforation.

- $\quad$ Strategies aiming at preventing NEC should aim at: i) early identifying infants at risk of each of these conditions; ii) developing preventive strategies for each specific condition. At present, there is no way to predict which infants will develop NEC and by which mechanism (the physician at the bedside, beyond few risk factors not always present, is almost invariably unable to explain at the level of single individuals why an infant developed NEC, and why other infants 
with overlapping clinical conditions did not); and there is no way, consequently, to prevent the disease (early enteral feeding with human breast milk and probiotics have slightly reduced, but not eradicated NEC) and no specific treatment is available.

NEC is mainly an inflammatory disease $(44,45,50)$, and, at least hypothetically, immunomodulation with mesenchymal stromal cells (MSCs) could represent, in the future, a suitable option (see later).

Other conditions. Beyond the three major sequelae of prematurity, other conditions occurring during the neonatal age, associated or not with preterm birth, could benefit in the future from stem/progenitor cell therapy. The dissertation about these conditions goes beyond the scope of the present thesis. In chapter $7, \mathrm{a}$ short comment about these diseases is provided.

\subsection{Stem cell loss as a common mechanism of pathogenesis in different diseases associated with preterm birth}

The extremely preterm infant as a whole is exposed to an array of risk factors exerting different pathogenic effects on different organs, depending, at least in part, on the sensitivity of the target tissues.

Sequelae of preterm birth often result from exposure to factors causing injury maximally during the days immediately preceeding birth and/or during the first days up to two to three weeks of life (51). These pre-, peri- and post-natal factors occur during a temporal developmental window in which organ expansion and development of architectural complexity reach their maximum (Figure 1).

The exact definition of the timing of tissue injury after preterm birth is fundamental not only for the understanding of the pathogenic mechanisms underlying diseases of prematurity, but also to design effective strategies for prevention and treatment. The ultimate goal of a preventing approach should aim at limiting damage during the acute phase by intervening before the sequelae are established or even before acute injury is established; in the context of stem/progenitor cell therapy, providing protection to the developing organs should be the goal, rather than regenerating tissues after the damage is established.

Risk factors for BPD and brain injury ultimately contribute to tissue damage by two main mechanisms: ischemia/reperfusion and infection/inflammation, both promoting the production of ROS/RNS causative of oxidative stress. In addition, tissue damage is enhanced by deprivation of maternal/placental protective growth factors and molecules (e.g. estrogens) and by a (probably) weak, still not fully demonstrated $(52,53)$, genetic predisposition $(54,55)$. The final effect of these pathogenic mechanisms is the development, at a variable extent, of scarring and 
fibrosis and, importantly, cell loss or altered cell development $(6,56)$ resulting in tissue simplification and organ developmental arrest (Figure 2).

Although the understanding of the mechanisms underlying tissue simplification is still incomplete, it is admitted that exposure to ROS and RNS is detrimental to stem and progenitor cells, which are exquisitely sensitive to oxidative stress, while their terminally differentiated counterparts are more resistant to oxidative damage $(6,57-59)$. Therefore, the combination of risk factors cited above, including oxidative stress, genetic predisposition and deprivation of maternal/placental molecules, may contribute to tissue simplification by directly damaging stem/progenitor cells and the developing, differentiating cells, during a welldefined temporal or developmental window (Figure 2).

Stem/progenitor cell depletion could be a common mechanism of pathogenesis at least in PVL and BPD, and possibly in other diseases of prematurity, representing, in each affected tissue, a point of convergence of several risk factors to which the infant is exposed; the scheme "risk factor $\rightarrow$ stem cell depletion/biased differentiation $\rightarrow$ tissue simplification/fibrosis" could be a common (although simplified) scheme to explain many conditions associated with prematurity.

Data emerging from the literature support this hypothesis (see next sections) and open new paths of study for the upcoming years.

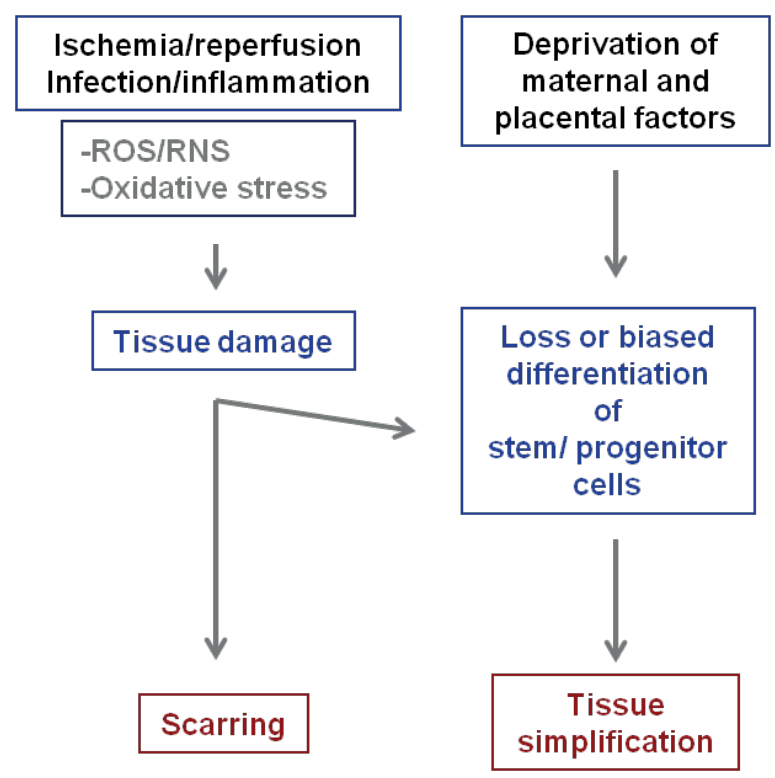

Figure 2. Mechanisms of disease in prematurity.

Schematic representation of the common mechanisms of pathogenesis underlying tissue damage in diverse diseases of prematurity. ROS/RNS indicates reactive oxygen and nitrogen species. 


\subsection{Stem/progenitor cell loss in BPD: initial evidence}

Many risk factors are known to predispose ventilated preterm infants with respiratory distress syndrome to the development of BPD, including exposure to high airway pressures and high inspired oxygen concentrations, the presence of a symptomatic PDA, and systemic infections $(3,60)$. In addition to environmental risk factors, genetic susceptibility also may play a major role (55). However, the cellular and molecular bases of the development of BPD are still poorly understood.

As stated above, alveolar simplification is predominant over fibrosis in the "new BPD" compared to old BPD, and changes in ventilation or respiratory support in order to minimize lung injury have only slightly changed the incidence of BPD (30-34). These observations suggest that, beyond ventilation-induced injury, specific developmental pathways, or cell populations, are disrupted in infants developing BPD in the post-surfactant era. Currently, the contribution of progenitor cells to normal pulmonary development or to lung protection from injury remain unclear; circulating or resident endothelial progenitor cells (EPC) and MSCs are thought to contribute to lung development, but their physiological roles are unproven (61). Recent studies, of maximal importance in creating the rationale for future studies focused on BPD, have started to elucidate the role of resident stem cell populations involved in lung development, homeostasis and repair, and the molecular signaling pathways that are crucial for lung epithelial differentiation and regeneration in vivo and for endothelial-epithelial cross-talk $(62,63)$.

As explained in the following paragraphs, initial evidence supports the hypothesis that, at the cellular level, stem/progenitor cell depletion, disruption or abnormal differentiation may be major pathogenic mechanisms of lung tissue simplification and alveolar development arrest in infants with BPD; this initial evidence represents the basis to further dissect the role of diverse stem/progenitor cell populations during lung development and after injury, and constitutes the rationale for using stem/progenitor cells for therapy or prevention.

\subsubsection{EPC depletion}

Experimental models and clinical data have clarified that structural changes of the capillaries and decreased angiogenesis in the lung vasculature contribute, together with infection/inflammation, to the pathogenesis of BPD (20,64-66). An important question remains the role of endothelial progenitors (circulating or lung resident) and of angiogenic cells in the impaired lung capillary formation observed in infants with BPD. 
Experimental and clinical studies have been performed in support of the view that loss of endothelial progenitors could be a mechanism underlying the abnormal vascular growth in BPD.

The term "EPC" encompasses a wide range of cell populations with angiogenic properties.

Circulating EPCs were first isolated from human peripheral blood in 1997 by Asahara et al. (67). Thereafter, during the last decade, multiple techniques have been developed to isolate and quantify human EPCs, including a) in vitro adhesion and colony forming assays (68) and b) enumeration by cell surface phenotype using different combinations of surface markers (69).

The clonogenic assays include i) the method first described by Asahara et al. (67), ii) a second method described by Ito et al. (70), which was further modified by iii) Hill et al. (71); this latter is commercially available (and identifies the socalled colony forming unit-Hill cells, CFU-Hill). All these methods identify cells that have been considered putative EPCs, but are of hematopoietic origin, displaying pro-angiogenic activity but not fulfilling all the criteria to define an EPC (68). Conversely, another clonogenic method identifies late outgrowth endothelial colony forming cells (ECFCs), an additional subtype of EPC. ECFCs define a rare population of circulating cells that can be isolated by in vitro colony formation assay from bone marrow, umbilical cord blood or adult peripheral blood (72). ECFCs do not express the hematopoietic surface antigen CD45 or the CD14, do not ingest bacteria, display clonal proliferative properties, high telomerase activity, a hierarchical pathway of differentiation, in vitro capillary-like tube formation, and in vivo vessel formation upon implantation in immunodeficient mice $(68,73)$. At present, this population is the only EPC subtype recognized to belong to the endothelial lineage.

Flow cytometry has been used to define an EPC based on the expression of cell surface markers.

The so-called triple positive, circulating CD34+CD133+VEGFR-2+ cells, and other closely related cells (CD34+VEGFR-2+ cells and other) have been tagged as EPCs, due to their angiogenic capacity; however, they are of hematopoietic origin and are not able to undergo endothelial differentiation in vitro and in vivo, but probably contribute to vascularization as bystander cells or by orchestrating endothelial cell growth and differentiation $(68,74,75)$. Before this concept became clear, EPCs have been identified in many studies as triple-positive circulating CD34+CD133+VEGFR-2+ mononuclear cells enumerated by flow cytometry (69).

Other polychromatic flow cytometry protocols have been recently developed (76); these protocols identify hematopoietic cell populations (a population of circulating progenitor cells, CPCs) as well as the rare, ECFC-containing, CD34+CD45cell population. These new protocols may be more useful for the identification and enumeration of specific cell populations directly involved in lung vascular development. See also chapter 6. 
In parallel to the efforts to identify the putative EPCs, a number of studies have applied all these methodologies to investigate the number and function of circulating EPCs in adult diseases characterized by vascular dysfunction, including cardiovascular disease and type 2 diabetes mellitus $(71,77,78)$. Interestingly, adult studies reported an inverse correlation between the number of in vitro enumerated EPCs (CFU-Hill cells) and the Framingham risk factor score (71), and an inverse correlation between circulating levels of CD34+VEGFR-2+ cells (EPCs studied by surface phenotype) and future adverse cardiovascular outcome (77), bringing forth the concept of using EPC enumeration as a clinical biomarker.

While a large number of studies have reported correlation of EPC number and function with adult diseases, very little is known about different subtypes of EPCs during gestation, during the neonatal age or in neonatal diseases. Initial evidence supports the hypothesis that circulating angiogenic cells may play an important role during development, and attention has particularly focused on clarifying the function of EPCs in lung vascular development, and the role of the impairment of EPC mobilization and homing in hyperoxia-induced lung injury characteristic of BPD.

In a mouse model of BPD, Balasubramaniam et al. found that exposure to hyperoxia decreases pulmonary vascular density, simplifies distal lung structure, and reduces EPCs (the authors actually studied angiogenic cells of hematopoietic origin enumerated by flow cytometry) in blood, bone marrow, and lungs suggesting a role of mobilization, recruitment, and engraftment of these cells to the lung in maintaining or repairing lung structure (79). However, these findings are not consistent with human studies, in which this heterogeneous population (identified by flow cytometry with the expression of CD34, CD133 (AC133), VEGFR-2, CD45, and CD144 surface markers in different combinations) does not correlate with the development of BPD neither at birth nor some days after birth (80-82) (see also chapter 3).

Much less clinical work has been done, conversely, to correlate the "true" EPCs, that is, ECFCs, with clinical disease states. And thus, despite remarkable progress in our understanding of their biological in vitro and in vivo properties since their first description (83), little is known about ECFC number and function during normal development and during disease.

Importantly, cord blood circulating ECFCs (that is, EPCs of endothelial origin, enumerated as number of colonies developing from cord blood mononuclear cells), have been shown, in two independent studies (one from our group), to be lower in cord blood from infants who later develop BPD compared to infants without BPD $(80,84)$ (see also chapter 3 ). Although both studies suggest that loss of circulating ECFCs may be implicated in the pathogenesis of lung vascular disruption typical of BPD, none of the two studies provides a mechanistic link. Interestingly, a very recent study by Alphonse et al. demonstrates that lung resident ECFCs from rats 
exposed to hyperoxia are functionally impaired (have compromised proliferative, clonogenic and in vitro vessel forming potential), suggesting that oxygen-induced depletion of lung resident ECFCs may be a possible mechanism underlying arrested lung vascular growth in BPD $(18,85,86)$. Several in vitro studies demonstrated that ECFCs are highly sensitive to oxidative stress, a major contributor to the pathogenesis of BPD, thus indirectly sustaining the idea that their disruption under oxidative conditions (hyperoxia and infection/inflammation) may be linked to the pathogenesis of BPD (57-59). Further human and animal studies are needed to definitely establish a link between loss of lung resident and/or circulating ECFCs and the development of BPD in preterm infants. Figure 3 and Figure 4 schematically explain a possible working hypothesis for these studies.

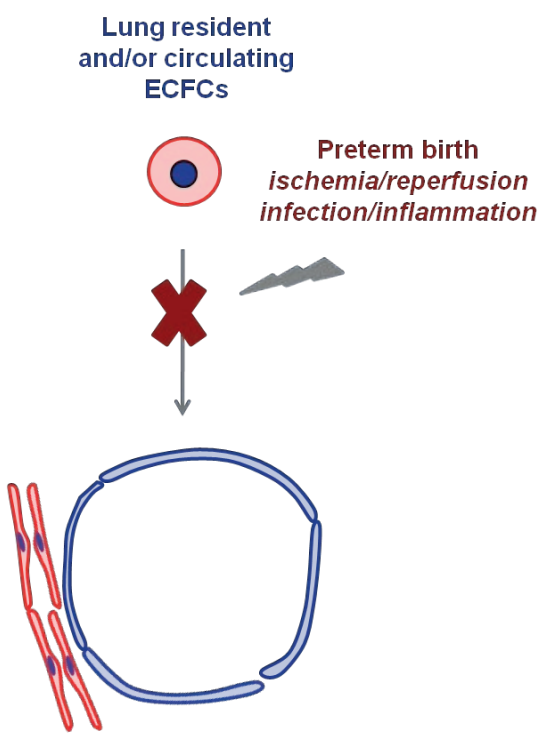

Figure 3. Working hypothesis: lung stem/progenitor cells and/or ECFCs are depleted in infants developing BPD.

ECFC indicates resident or circulating endothelial colony forming cells. 

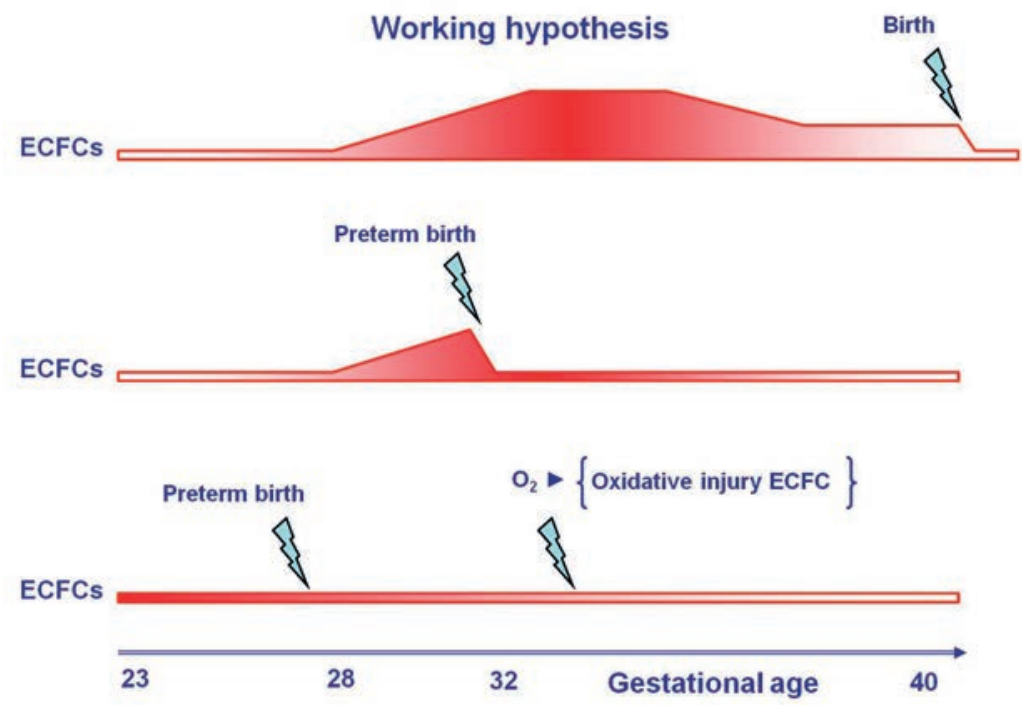

Figure 4. Working hypothesis on the role of ECFC depletion in preterm infants developing BPD.

Accordingly, endothelial proliferation increase, possibly with the contribution of circulating and resident ECFCs, during a specific temporal window in order to create vascular networks in organs and tissues; preterm birth itself is accompanied by a reduction in all circulating CD34+ cell subsets, which include the circulating, ECFC-containing, CD34+CD45- cell subset; risk factors associated with preterm birth would further impair circulating and/or resident ECFCs by reducing their number and their clonogenic and proliferative capacity, thus disrupting endothelial proliferation and reducing the contribution of ECFCs to vessel formation in the lungs and in other tissues. ECFC indicates resident or circulating endothelial colony forming cells.

\subsubsection{MSC depletion}

MSCs are cells of mesenchymal origin able to differentiate into mesoderm-derived cells (87). MSCs can be isolated from the bone marrow and many other tissues, including adipose tissue and fetal annexes (umbilical cord, placenta, amniotic sac). The existence of lung resident MSCs that reside and self-renew in the adult lung has been demonstrated (88-90); Lama et al. investigated cells derived from bronchoalveolar lavage up to 11 years after human lung allografts, and found the presence of MSCs of donor sex identity in sex-mismatched lung transplant recipients even years after transplantation $(90,91)$.

Whether a depletion of lung resident MSCs may underlie the pathological changes characteristic of BPD is unclear.

The hypothesis that the loss of resident MSCs in the lung stroma may contribute to the development of BPD is supported by one experimental study. In a rat model of BPD, van Haaften et al. demonstrated that after 2 weeks of exposure to 
hyperoxia, the histological pattern of alveolar simplification was associated with a reduced number of circulating and lung resident MSCs (92).

However, contrasting results emerge from human studies. Recently, Popova et al., collected the tracheal aspirates from fifty-six ventilated preterm infants for isolation of MSCs; in their study, the presence of MSCs in the tracheal aspirate increased the adjusted odds of BPD by nearly 22 times (93). Of note, the studied cells were able to acquire a myofibroblast phenotype, different from human bone marrow(BM)-derived MSCs that do not undergo myofibroblastic differentiation in response to transforming growth factor (TGF)- $\beta 1$; the difference in the studied cell populations may account for the contrasting results between the rat and the human studies (85). Indeed, these lung MSCs isolated from the neonatal tracheal aspirates, distinct from lung fibroblasts in terms of clonogenic and differentiation capacities, demonstrated a pattern of lung-specific gene expression (different from cord blood MSCs) (94), spontaneously expressed genes of a myofibroblast progenitor cell phenotype, and underwent myofibroblastic changes in response to autocrine and exogenous TGF- $\beta 1$, different from BM-MSCs which were resistant to TGF- $\beta 1$-induced myofibroblastic differentiation (95).

Hennrick et al. also found that fibroblast-like cells expressing MSC markers can be isolated from the tracheal aspirates of premature infants undergoing mechanical ventilation for respiratory distress syndrome; infants from whom MSCs could be isolated seemed to have worse outcomes in terms of days of mechanical ventilation, days of oxygen supplementation, and incidence of BPD compared with infants that did not have MSCs in the tracheal aspirates $(90,96)$.

All these findings seem contrasting with loss of lung resident MSCs after exposure to hyperoxia in the experimental model (92) and with therapeutic experimental data demonstrating that BM-and umbilical cord(UC)-MSCs protect the lung of rats and mice from developing BPD-like disease when exposed to hyperoxia, see later $(92,97-99)$.

Pierro and Thebaud (90) suggest that the finding of the resistance of BM-MSCs to undergo myofibroblastic differentiation in response to TGF- $\beta 1$, different from neonatal lung MSCs which undergo TGF- $\beta 1$-driven myofibroblastic differentiation, emphasizes distinct properties between these two populations of MSCs ("not all MSCs are equal") and opens new paths for the understanding of the contribution of different cell populations in normal lung development and in the pathogenesis of BPD. Consistently, TGF- $\beta 1$ is a growth factor responsible for several fibrotic disorders (100), is elevated in the tracheal aspirate of ventilated preterm babies that go on to develop BPD (101), and the abrogation of its signaling prevents arrested lung growth in experimental BPD $(90,102)$.

The bias towards myofibroblastic differentiation of lung resident MSCs may clarify some points of the pathogenesis of BPD, and may help to explain the mechanisms of altered endothelial growth, abnormal epithelial-stromal interactions, defective 
elastogenesis, extracellular matrix remodeling and may account for reduced protection of alveolar cells, for consequent increased vulnerability of epithelial cells to acute injury and for reduced antifibrotic activity in the lungs, thus leading to alveolar simplification and fibrotic changes, the hallmarks of BPD.

The contribution of myofibroblast-biased or unbiased lung resident MSCs under homeostatic/developmental conditions and/or after lung injury will be therefore a central issue in future research.

Further, the possible (still hypothetical, not demonstrated) contribution to lung protection of circulating or migrating BM-derived MSCs homing to the lung, still needs to be investigated.

Future studies in these directions may make more robust the rationale for using BM- or UC-MSCs in the setting of prematurity.

\subsection{Pre-oligodendrocyte loss and neuronal developmental abnormalities in encephalopathy of prematurity}

The neuropathological lesions underlying encephalopathy of prematurity have been described above (39). White matter damage is a cell-specific injury that appears to be caused by preferential death of pre-OLs during a developmental window of vulnerability $(6,37)$. Pre-OLs are abundant in the brain of preterm (but not term) infants and progressively differentiate into mature OLs between 28 and 40 weeks gestational age to form the myelin sheath. Both ischemia and infection contribute to the production of ROS and RNS, at least in part through the activation of microglia.

It is known that pre-OLs, but not mature OLs, are highly vulnerable to oxidative stress, and are preferentially lost upon exposure to pathogenic factors associated with prematurity. These considerations support the notion that progenitor cell depletion (pre-OL depletion), occurring during the process of myelin formation, might result in developmental arrest and tissue simplification (hypomyelination in central cerebral white matter and - possibly secondary - neuronal abnormalities), the hallmarks of the diffuse component of encephalopathy of prematurity (Figure 5).

The mechanism underlying neuronal/axonal disease and loss of cortical volume in preterm infants is less clear. Possible explanations are: i) cortical volume loss is a product of neuronal loss of function and death (primary neuronal degeneration) possibly accompanied by so-called secondary retrograde neuro-axonal degeneration, resulting from primary injury to immature white matter; ii) cortical volume loss arises because of a failure of neuronal maturation rather than cell death or axonal degeneration; iii) a third hypothesis implies neither neuronal de- 
generation nor aborted maturation, but rather that altered growth in the thalami would result in secondary alterations in cortical development (56).

Recently published studies suggest that not only quantitative neuronal deficit (103), but also maturational and developmental disruption of neurons (disturbances in the dendritic arbor and synapse formation of cortical neurons) $(104,105)$, underlie cognitive and learning disabilities after preterm birth.

All these considerations are of fundamental importance when considering the use of systemically administered stem cell therapies in preterm infants, either targeted to the brain or not. Cell therapies aiming at preventing brain injury associated with preterm birth should, indeed, focus on protecting the developing cell populations (pre-OLs and cortical neurons); cell therapies aiming at reducing the risk of other diseases (e.g. BPD) should take in account the importance of assessing brain maturation with imaging studies. Also, cell therapy targeted to the brain should take advantage from the possibility of exploiting or promoting endogenous neuronal repair or regeneration (106).

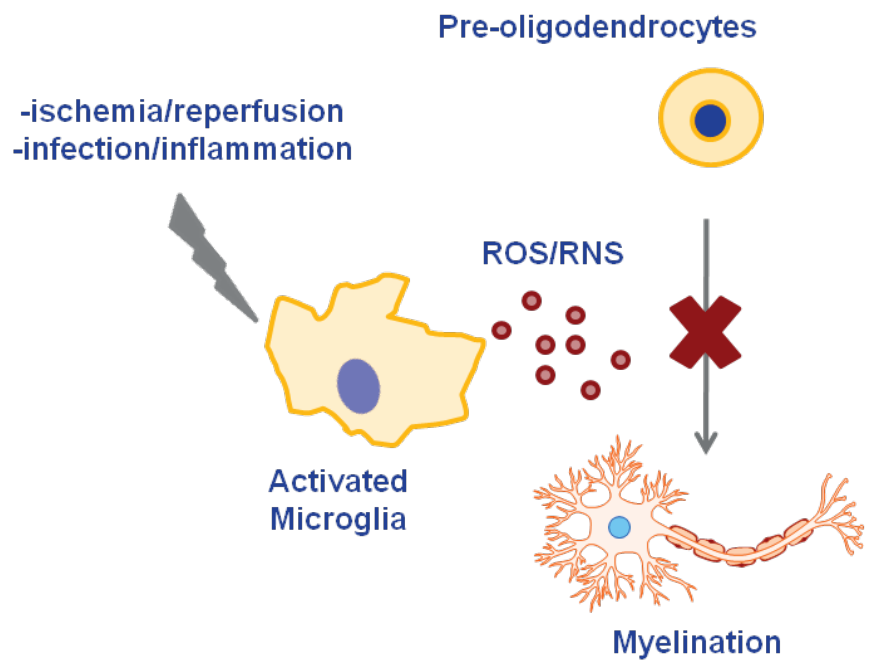

Figure 5. Schematic representation of the mechanisms of white matter brain injury in diffuse PVL.

ROS/RNS indicate reactive oxygen and nitrogen species.

\subsection{Stem cell loss in other neonatal conditions}

Whether other diseases associated with prematurity may be caused by loss or altered differentiation program of stem/progenitor cells is currently unknown. 
Recent discoveries have shed light on intestinal regeneration in physiological and pathological conditions. Indeed, the intestinal epithelium undergoes continuous self-renewal, and this process seems to be maintained by distinct populations of cells meeting the criteria to be defined resident stem cells, located in different positions in the crypts, and critical for the maintenance of epithelial turnover (107109). Advances in the understanding of the mechanisms of intestinal regeneration in homeostatic conditions and after injury point out that a population Lgr5- intestinal stem cells maintain intestinal homeostasis, while Lgr5+ intestinal stem cells seem dispensable in homeostasis; conversely, Lgr5+ cells are dispensable after radiation induced injury, pointing out a different sensitivity of the two cell populations to radiation, and different roles in intestinal regeneration after injury or self renewal under homeostatic conditions (110). This recent knowledge will be invaluable for future studies on NEC, in order to understand the cell populations involved in intestinal epithelial regeneration in the preterm infant with our without NEC, and to understand whether a depletion of intestinal stem cells and consequently a defective self-renewal of the immature intestine may underlie vulnerability to the pathogenic factors that are responsible for NEC.

The scheme "risk factor $\rightarrow$ stem cell depletion/biased differentiation $\rightarrow$ tissue simplification/fibrosis", in parallel for BPD and PVL, is reported in Figure 6. Similar considerations could be made for NEC.
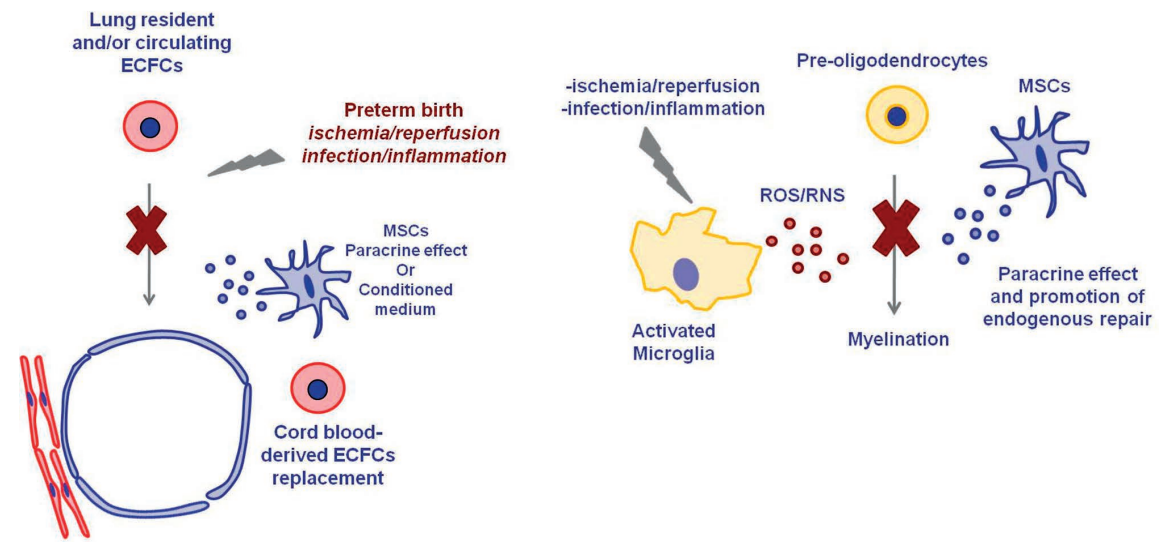

Figure 6. Working hypothesis: parallel between lung and brain injury, and potential for intervention.

Left panel: Possible interventions to prevent bronchopulmonary dysplasia (BPD). Based on the hypothesis that lung epithelial stem/progenitor cells and/or ECFCs are depleted in infants developing BPD, administration of mesenchymal stem cells (MSCs) (or their conditioned medium) for tissue protection, or ECFC replacement, could be suitable options to prevent lung injury.

Right panel: White matter brain injury in diffuse PVL: MSC-based treatments may protect the developing brain or stimulate endogenous repair.

ECFCs = endothelial colony forming cells; MSCs = mesenchymal stromal cells; ROS/RNS = reactive oxygen and nitrogen species. 


\subsection{Animal models for cell therapy in neonatal lung injury}

\subsubsection{General aspects}

The field of harnessing stem/progenitor cells to protect or repair organs in the preterm (and term) neonate is in its beginning, and question marks are more numerous than affirmative points. To the present knowledge, the main goals of a cell based therapy for treatment or prevention of neonatal diseases associated with preterm birth include i) replacement of depleted stem/progenitor cells, ii) reduction of inflammation and fibrosis, iii) protection of cells (both mature cells and resident stem/progenitor cells) from injury associated with infection, ischemia and oxidative stress.

Specific issues regarding the bench-to-bedside translation of stem cell therapy in neonatal lung and extra-lung diseases are not matter of the present manuscript, and will not discussed here (111). Here we will only focus on general issues regarding the potential of different stem cell types in reducing the incidence and the severity of neonatal diseases.

Neonatal diseases associated with preterm birth are complex and multifactorial diseases, and a combination of the above mentioned goals could be favorable to achieve tissue protection and optimal organ development.

The present thesis is mostly focused on some issues regarding the most promising cell-based approaches for BPD, with only few notes regarding the effects that the same cell types suitable for preventing or treating BPD could exert in infants developing other diseases of prematurity, mainly encephalopathy of prematurity and NEC.

\subsubsection{Potential stem cell-based treatments}

MSC-based treatments. Recently published pre-clinical studies on animal models of BPD showed a benefit from the administration, either intratracheal or systemic, of MSCs or their conditioned medium $(92,97)$. In these seminal studies, and in other subsequent works based on rodent (mouse and rat) models of BPD (99, 112114), administration of BM- or UC- or umbilical cord blood-MSCs or their conditioned medium improved survival and exercise tolerance, reduced alveolar loss and lung inflammation, attenuated lung vascular injury and prevented pulmonary hypertension. In a subsequent study by Hansmann et al., one single intravenous dose of the conditioned medium from cultured mouse BM-MSCs, administered after two weeks of exposure to hyperoxia (FiO2 0.75), reversed the hyperoxiainduced parenchymal fibrosis and peripheral pulmonary artery devascularization (pruning), partially reversed alveolar injury, normalized lung function (airway resistance, dynamic lung compliance); most importantly, the MSC conditioned 
medium fully reversed the moderate pulmonary hypertension and right ventricular hypertrophy and attenuated the peripheral pulmonary artery muscularization associated with hyperoxia-induced BPD (115), with part of the effects being mediated by MSC-derived exosomes (116). In another study, aiming at defining whether the beneficial effects of MSCs are ascribable to the activation of endogenous lung epithelial stem cells, systemic treatment of neonatal hyperoxia-exposed mice with MSCs or their conditioned medium led to a significant increase in bronchioalveolar stem cells (BASCs), an adult lung stem cell population capable of self-renewal and differentiation in culture, suggesting that the beneficial response from the MSCs is at least in part due to stimulation of BASCs to play a role in the repair of alveolar lung injury found in BPD and in the restoration of distal lung cell epithelia (117).

MSCs display a wide variety of properties, including immunomodulatory and regenerative capacity, as well as the ability to provide paracrine anti-apoptotic, pro-angiogenic and anti-scarring (anti-fibrotic) stimuli (118-121). Exogenously administered bone marrow-derived MSCs have been demonstrated to be able to protect lung epithelial cells against acute lung injury, by restituting alveolar cell bioenergetics through the transfer of mitochondria to lung epithelial cells (98). In addition, MSCs appear to display anti-infective properties that make them an attractive therapy also in the setting of neonatal infection or infection-related inflammation (122-125).

By using a unique translational Escherichia coli pneumonia model in an ex vivo perfused human lung, Lee et al. tested the therapeutic effects of MSCs on lung fluid balance, acute inflammation, and bacterial clearance, in order to define whether MSCs's immunomodulatory properties may have detrimental effects if targeted toward infectious etiologies of lung injury (bacterial-induced acute lung injury). In their experiments, human MSCs restored alveolar fluid clearance to a normal level, decreased inflammation and were associated with increased bacterial killing and reduced bacteremia, in part through increased alveolar macrophage phagocytosis and secretion of anti-microbial factors, among which the keratinocyte growth factor (125).

All these properties of MSCs make them suitable for cell therapy in the preterm infant, particularly for the prevention of BPD and PVL. Their regenerative potential and immunomodulatory properties have been previously exploited in other MSC-based clinical protocols, including allogenic hematopoietic stem cell transplantation to reduce the incidence or severity of acute graft-versus-host disease (118-120, 126-129).

The use of BM-MSCs has several advantages over the use of other stem/progenitor cell populations:

- $\quad$ MSCs have been previously used in clinical (pediatric and adult) protocols, and have been demonstrated to be safe; 
- Their biological behavior (at least for BM-derived MSCs) has been extensively investigated in in vitro and animal models;

- MSCs display multiple beneficial properties, including immunomodulatory capacity, antifibrosis activity, anti-apoptotic and growth promoting activity, and ability to restore the bioenergetic balance through transfer of mitochondria to lung epithelial cells;

- MSCs have already been demonstrated to be effective in animal models of neonatal diseases, including BPD and hypoxic-ischemic encephalopathy, and their administration could have a "multiorgan" beneficial effect, not limited to lungs and brain.

EPC-based treatments. The rationale for using angiogenic cells (either EPCs of hematopoietic origin or true endothelial progenitors, namely ECFCs) for the prevention of BPD is based on the following observations:

- $\quad$ Lung vascular growth is disrupted in infants with BPD: indeed, arrested vascular growth, one of the major features of BPD, strongly contributes to pulmonary hypertension and to the clinical outcome in preterm neonates;

- Low numbers of ECFCs in cord blood correlate with subsequent development of BPD, suggesting a role for ECFC depletion in the pathogenesis of lung vascular disruption $(80,84)$ (see chapter 3 ).

- In an oxygen-induced BPD mouse model, Balasubramaniam et al. showed restoration of the alveolar structure and vessel density in mice treated with bone marrow myeloid progenitor cell population (bone marrow-derived angiogenic cells), a novel myeloid cell population with angiogenic properties (130).

- $\quad$ More recently, Baker et al. also demonstrated the beneficial effects of ECFCs ore their conditioned medium on lung cells in vitro and in vivo in an experimental neonatal lung injury (131). The authors used human umbilical cord blood ECFCs from preterm and full-term newborns and demonstrated that both term and preterm ECFC-conditioned medium promoted cell growth and angiogenesis in vitro (on sheep fetal pulmonary artery endothelial cell proliferation and function as well as alveolar type 2 cell growth); however, in line with previous works $(59,132)$, when ECFC-conditioned medium was collected during exposure to mild hyperoxia, the benefit of preterm ECFC-conditioned medium was no longer observed, while the conditioned medium of hyperoxia exposed term ECFCs still retained their effect. Additionally, in a bleomycin model of BPD, treatment with conditioned medium from ECFCs or from mature ECs effectively decreased the right ventricular hypertrophy, but had no effect on alveolar septation. The authors conclude that term ECFC-conditioned medium is beneficial both in vitro and in experimental BPD, but during oxidative stress preterm ECFC-conditioned medium, but not term ECFC-conditioned medium, loses its benefit. However, the authors add a note of caution, also 
suggesting that the inability of term ECFC-conditioned medium to promote alveolarization may limit its therapeutic potential.

- In addition, interesting data by Alphonse et al. show that intra-jugular administration of human umbilical cord-derived ECFCs (that is, EPCs of endothelial origin) improved lung function, preserved alveolar development, attenuated pulmonary hypertension (improved pulmonary artery acceleration times and decreased right ventricular hypertrophy) in hyperoxia-exposed mouse pups, suggesting that human umbilical cord blood-derived ECFCs may offer a new therapeutic option for BPD, by replacing depleted ECFCs or by restoring their function $(18,85,86)$.

Umbilical cord stem cells-based treatments. The use of the whole mononuclear fraction of the umbilical cord blood has been proposed as a possible way to administer the stem/progenitor cell populations contained in the cord blood without need for manipulation or expansion in culture. However, recent studies suggest that its role may be limited, and not without risks (42).

Human amnion epithelial cell (hAEC)-based treatments. Given their availability from human amniotic membranes, hAECs could be a good candidate for cell replacement. In the developing lung, hAEC have been shown to prevent ventilation-induced injury and injury related to infection in ovine models, mainly via modulation of the inflammatory response, rather than by engraftment. Further studies will clarify the therapeutic potential of hAEC in $\operatorname{BPD}(133,134)$.

Other. Other cell populations may be suitable for stem cell therapy in neonatal medicine, in the future, including neural stem cells, intestinal stem cells, iPS cells. Harnessing iPS could provide tools to cure diseases associated or not with prematurity, and even genetic diseases.

Which cell type will be the most suitable for the treatment and/or prevention of specific neonatal diseases, which is the best route of administration, and which is the adequate number of cells to be infused, are still open questions, and will be discussed later (see chapter 7).

\subsubsection{Additional considerations}

PVL. Whether stem cell therapy targeted to BPD could be beneficial in attenuating the complications of PVL is still matter of investigation. Animal models are rather focused on the use of MSCs in the recovery process after brain injury following birth asphyxia or stroke (135-141); recently, intravenously administered MSCs have been demonstrated, in a preclinical large animal (sheep) model, to protect against white matter injury following global hypoxia-ischemia, at least in part via 
induction of T-cell tolerance (142). These results are promising and encouraging for future clinical application in the setting of both hypoxic ischemic encephalopathy and encephalopathy of prematurity.

NEC. Regarding stem cell therapy for NEC, a series of observations suggest a potential role for stem cell therapy in preventing or treating NEC. First, MSCs have been demonstrated to enhance the viability and proliferation of human fetal intestinal epithelial cells following hypoxic injury, via paracrine mechanisms (143); second, a study has evaluated the effectiveness of BM-MSCs in a neonatal rat NEC model, and MSCs reduced significantly the histopathological damage (144); third, MSCs have proven effective in clinical settings in treating adult bowel inflammatory diseases (145); finally, other cell types (iPS-derived intestinal stem cells) may be transplanted to achieve regeneration of the intestinal epithelium after injury (146).

Further animal and in vitro studies, in addition to those already published, will accurately address all these issues.

\subsubsection{Safety considerations on the use of stem and progenitor cells and possible sources of cells}

Cell therapy must be riskless, and the potential of tumoral transformation should be carefully and exactly calculated before any cell type is used in regenerative therapies. Further, the way a cell population works with the immune system of the host must be predictable before cells are infused for treatment.

Adult (BM- and adipose tissue-derived) MSCs have been extensively characterized, but the use of these cells raises ethical issues regarding the source for cell obtainment. MSCs can be better obtained from other "easy-access sources" (UC-, decidua-, amniotic fluid-, and amniotic sac-derived MSCs), but these cells have been much less studied. Similarly, very little is known about the genetic stability and about the immunological behavior and immunogenicity of adult and cord blood-derived ECFCs.

a) Risk of tumorigenesis. Adult human MSCs, different from mouse MSCs, are apparently resistant to oncogenic transformation during in vitro expansion $(147,148)$. These results are consistent with previous observations from our group which showed genetic stability on 10 samples of bone marrow-derived MSCs (149). In contrast, Tarte et al., by karyotype analysis, found donordependent chromosomal abnormalities in BM-derived MSCs which however did not confer a selective advantage to the affected clone (150). An important question is whether human MSCs from sources different from bone marrow are prone to acquire genetic alteration and tumoral phenotype upon in vitro expansion. This question has been addressed during the PhD study period, and is reported in chapter 5 . 
b) Interaction with the immune system of the host. Open questions are whether UC-, decidua-, and amniotic sac-derived MSCs display immuomodulatory capacity comparable to that of bone marrow-derived MSCs; and whether MSCs and cord-blood derived ECFCs, in the context of an allogenic transplantation (the most likely to be used in newborn infants), are susceptible to cytotoxicity by the allogenic T lymphocytes or NK cells of the host.

c) Senescence. Senescence should be avoided, and population doublings should be kept to a minimum, to avoid unpredictable side effect, and to avoid the risk of inefficiency (151).

As stated above, growing interest is focusing on exploiting the paracrine effect of stem cells. Without completely abrogating the possible side effects of stem cells, the use of the conditioned medium may provide an array of protective factors, without the possible adverse effects strictly related to cell administration and cellto-cell contact, and biased stem cell differentiation in the "sick" environment of preterm organs, which are exposed to several detrimental agents such as free radicals, abnormal oxygen and $\mathrm{CO} 2$ concentrations, and infectious agents or microbial products, and in which specific cell populations (e.g. the activated microglia in the brain) could limit the beneficial effect of stem cells or even biase their action towards unwanted effects.

A way to limit damage while maintaining efficiency relies on exploiting the paracrine effect of stem cells by using growth factors produced by stem cells without administering stem cells themselves. Some researchers are indeed focusing on understanding which of the specific factors contained in the conditioned medium could be more beneficial to preterm infants, or which are the signaling pathways that are crucial for survival and regeneration of the cell populations that are preferentially lost in diseases of the preterm infant. Interestingly, the keratinocyte growth factor seemed to be the molecule mediating at least part of the effects of MSCs (restored alveolar fluid clearance, reduced inflammation, antimicrobial activity) in an E. coli-injured lung model $(124,125)$; in another study, Scafidi et al. demonstrated that, in a mouse model of very preterm brain injury, intranasal administration of heparin-binding epidermal growth factor immediately after injury decreases oligodendroglial death, enhances generation of new OLs from progenitor cells and promotes functional recovery (152).

Pierro and Thebaud, in a recent editorial, well recapitulate the present stateof-the-art of stem cell therapy for lung disease (90). They well underline how stem cell research for lung diseases is clamped in the vise, between the urgent need of patients for accelerating translation from the bench to the bedside, and the need of researchers to determine the most efficient reparative cell-based strategy with the least possible side effects. Possible risks of lung stem cell therapy include the potential tumor formation and other possible adverse effects such as fibrosis for- 
mation (see above: myofibroblastic-biased differentiation of MSCs); these issues should be addressed in preclinical studies which should include robust short- and long-term efficacy and safety data to accelerate and enhance the success of clinical trials. Taking into account that stem cell therapy must be regulated as tightly as whatever drug therapy, translation of stem cell knowledge and technology into neonatal clinical medicine will be only possible through the integration of the clinical standpoint, the scientific perspective, and the regulatory point of view (148, 153, 154). 


\section{References}

1. Bancalari EH, Jobe $\mathrm{AH}$. The respiratory course of extremely preterm infants: a dilemma for diagnosis and terminology. J Pediatr. 2012 Oct;161(4):585-8.

2. Jobe AH, Bancalari E. Bronchopulmonary dysplasia. Am J Respir Crit Care Med. 2001 Jun;163(7):1723-9.

3. Bancalari E, Claure N, Sosenko IR. Bronchopulmonary dysplasia: changes in pathogenesis, epidemiology and definition. Semin Neonatol. 2003 Feb;8(1):63-71.

4. Hamrick SE, Miller SP, Leonard C, Glidden DV, Goldstein R, Ramaswamy V, et al. Trends in severe brain injury and neurodevelopmental outcome in premature newborn infants: the role of cystic periventricular leukomalacia. J Pediatr. 2004 Nov;145(5):593-9.

5. Huppi PS. Immature white matter lesions in the premature infant. J Pediatr. 2004 Nov;145(5):5758.

6. Volpe JJ. Cerebral white matter injury of the premature infant-more common than you think. Pediatrics. 2003 Jul;112(1 Pt 1):176-80.

7. Goldenberg RL, Culhane JF, Iams JD, Romero R. Epidemiology and causes of preterm birth. Lancet. 2008 Jan 5;371(9606):75-84.

8. Slattery MM, Morrison JJ. Preterm delivery. Lancet. 2002 Nov 9;360(9344):1489-97.

9. Martin JA, Hamilton BE, Ventura SJ, Osterman MJ, Kirmeyer S, Mathews TJ, et al. Births: final data for 2009. Natl Vital Stat Rep. 2011 Nov 3;60(1):1-70.

10. Volpe JJ. Brain injury in premature infants: a complex amalgam of destructive and developmental disturbances. Lancet Neurol. 2009 Jan;8(1):110-24.

11. Volpe JJ. The encephalopathy of prematurity--brain injury and impaired brain development inextricably intertwined. Semin Pediatr Neurol. 2009 Dec;16(4):167-78.

12. Neu J, Walker WA. Necrotizing enterocolitis. N Engl J Med. 2011 Jan 20;364(3):255-64.

13. Kinsella JP, Greenough A, Abman SH. Bronchopulmonary dysplasia. Lancet. 2006 Apr 29;367(9520):1421-31.

14. Darlow BA, Cust AE, Donoghue DA. Improved outcomes for very low birthweight infants: evidence from New Zealand national population based data. Arch Dis Child Fetal Neonatal Ed. 2003 Jan;88(1):F23-8.

15. Coalson JJ. Pathology of bronchopulmonary dysplasia. Semin Perinatol. 2006 Aug;30(4):179-84.

16. Baraldi E, Carraro S, Filippone M. Bronchopulmonary dysplasia: definitions and long-term respiratory outcome. Early Hum Dev. 2009 Oct;85(10 Suppl):S1-3.

17. Carraro S, Filippone M, Da Dalt L, Ferraro V, Maretti M, Bressan S, et al. Bronchopulmonary dysplasia: the earliest and perhaps the longest lasting obstructive lung disease in humans. Early Hum Dev. 2013 Oct;89 Suppl 3:S3-5.

18. Alphonse RS, Rajabali S, Thebaud B. Lung injury in preterm neonates: the role and therapeutic potential of stem cells. Antioxid Redox Signal. 2012 Oct 1;17(7):1013-40.

19. Abman SH. The dysmorphic pulmonary circulation in bronchopulmonary dysplasia: a growing story. Am J Respir Crit Care Med. 2008 Jul 15;178(2):114-5.

20. Thebaud B, Abman SH. Bronchopulmonary dysplasia: where have all the vessels gone? Roles of angiogenic growth factors in chronic lung disease. Am J Respir Crit Care Med. 2007 May 15;175(10):978-85.

21. Galambos C, Sims-Lucas S, Abman SH. Histologic evidence of intrapulmonary anastomoses by three-dimensional reconstruction in severe bronchopulmonary dysplasia. Ann Am Thorac Soc. 2013 Oct;10(5):474-81.

22. Koroglu OA, Yalaz M, Levent E, Akisu M, Kultursay N. Cardiovascular consequences of bronchopulmonary dysplasia in prematurely born preschool children. Neonatology. 2013;104(4):2839. 
23. Vollsaeter M, Roksund OD, Eide GE, Markestad T, Halvorsen T. Lung function after preterm birth: development from mid-childhood to adulthood. Thorax. 2013 Aug;68(8):767-76.

24. Gough A, Linden M, Spence D, Patterson CC, Halliday HL, McGarvey LP. Impaired lung function and Health Status in Adult Survivors of Bronchopulmonary Dysplasia. Eur Respir J. 2013 Jul 30.

25. Doyle LW, Faber B, Callanan C, Freezer N, Ford GW, Davis NM. Bronchopulmonary dysplasia in very low birth weight subjects and lung function in late adolescence. Pediatrics. 2006 Jul;118(1):108-13.

26. Fawke J, Lum S, Kirkby J, Hennessy E, Marlow N, Rowell V, et al. Lung function and respiratory symptoms at 11 years in children born extremely preterm: the EPICure study. Am J Respir Crit Care Med. 2010 Jul 15;182(2):237-45.

27. Narayanan M, Beardsmore CS, Owers-Bradley J, Dogaru CM, Mada M, Ball I, et al. Catch-up alveolarization in ex-preterm children: evidence from (3)He magnetic resonance. Am J Respir Crit Care Med. 2013 May 15;187(10):1104-9.

28. Jobe AH. Good news for lung repair in preterm infants. Am J Respir Crit Care Med. 2013 May 15;187(10):1043-4.

29. Bates ML, Farrell ET, Eldridge MW. Abnormal ventilatory responses in adults born prematurely. $\mathrm{N}$ Engl J Med. 2014 Feb 6;370(6):584-5.

30. Finer NN, Carlo WA, Walsh MC, Rich W, Gantz MG, Laptook AR, et al. Early CPAP versus surfactant in extremely preterm infants. N Engl J Med. 2010 May 27;362(21):1970-9.

31. Morley CJ. CPAP and low oxygen saturation for very preterm babies? N Engl J Med. 2010 May 27;362(21):2024-6.

32. Morley CJ, Davis PG, Doyle LW, Brion LP, Hascoet JM, Carlin JB. Nasal CPAP or intubation at birth for very preterm infants. N Engl J Med. 2008 Feb 14;358(7):700-8.

33. Vaucher YE, Peralta-Carcelen M, Finer NN, Carlo WA, Gantz MG, Walsh MC, et al. Neurodevelopmental outcomes in the early CPAP and pulse oximetry trial. N Engl J Med. 2012 Dec 27;367(26):2495-504.

34. Fischer HS, Buhrer C. Avoiding endotracheal ventilation to prevent bronchopulmonary dysplasia: a meta-analysis. Pediatrics. 2013 Nov;132(5):e1351-60.

35. Schmolzer GM, Kumar M, Pichler G, Aziz K, O’Reilly M, Cheung PY. Non-invasive versus invasive respiratory support in preterm infants at birth: systematic review and meta-analysis. BMJ. 2013;347:f5980.

36. Donohue PK, Gilmore MM, Cristofalo E, Wilson RF, Weiner JZ, Lau BD, et al. Inhaled nitric oxide in preterm infants: a systematic review. Pediatrics. 2011 Feb;127(2):e414-22.

37. Khwaja 0, Volpe JJ. Pathogenesis of cerebral white matter injury of prematurity. Arch Dis Child Fetal Neonatal Ed. 2008 Mar;93(2):F153-61.

38. Volpe JJ. Systemic inflammation, oligodendroglial maturation, and the encephalopathy of prematurity. Ann Neurol. 2011 Oct; 70(4):525-9.

39. Volpe JJ, Kinney HC, Jensen FE, Rosenberg PA. The developing oligodendrocyte: key cellular target in brain injury in the premature infant. Int J Dev Neurosci. 2011 Jun;29(4):423-40.

40. Segovia KN, McClure M, Moravec M, Luo NL, Wan Y, Gong X, et al. Arrested oligodendrocyte lineage maturation in chronic perinatal white matter injury. Ann Neurol. 2008 Apr;63(4):520-30.

41. Dalous J, Larghero J, Baud 0. Transplantation of umbilical cord-derived mesenchymal stem cells as a novel strategy to protect the central nervous system: technical aspects, preclinical studies, and clinical perspectives. Pediatr Res. 2012 Apr;71(4 Pt 2):482-90.

42. Dalous J, Pansiot J, Pham H, Chatel P, Nadaradja C, D'Agostino I, et al. Use of human umbilical cord blood mononuclear cells to prevent perinatal brain injury: a preclinical study. Stem Cells Dev. 2013 Jan 1;22(1):169-79.

43. Titomanlio L, Kavelaars A, Dalous J, Mani S, El Ghouzzi V, Heijnen C, et al. Stem cell therapy for neonatal brain injury: perspectives and challenges. Ann Neurol. 2011 Nov;70(5):698-712.

44. Gaudin A, Farnoux C, Bonnard A, Alison M, Maury L, Biran V, et al. Necrotizing enterocolitis (NEC) and the risk of intestinal stricture: the value of C-reactive protein. PLoS One. 2013;8(10):e76858. 
45. Abreu MT. The Ying and Yang of bacterial signaling in necrotizing enterocolitis. Gastroenterology. 2010 Jan;138(1):39-43.

46. Walsh MC, Kliegman RM. Necrotizing enterocolitis: treatment based on staging criteria. Pediatr Clin North Am. 1986 Feb;33(1):179-201.

47. Volpe JJ. Postnatal sepsis, necrotizing entercolitis, and the critical role of systemic inflammation in white matter injury in premature infants. J Pediatr. 2008 Aug;153(2):160-3.

48. Shah DK, Doyle LW, Anderson PJ, Bear M, Daley AJ, Hunt RW, et al. Adverse neurodevelopment in preterm infants with postnatal sepsis or necrotizing enterocolitis is mediated by white matter abnormalities on magnetic resonance imaging at term. J Pediatr. 2008 Aug;153(2):170-5, 5 e1.

49. Hintz SR, Kendrick DE, Stoll BJ, Vohr BR, Fanaroff AA, Donovan EF, et al. Neurodevelopmental and growth outcomes of extremely low birth weight infants after necrotizing enterocolitis. Pediatrics. 2005 Mar;115(3):696-703.

50. Young CM, Kingma SD, Neu J. Ischemia-reperfusion and neonatal intestinal injury. J Pediatr. 2011 Feb;158(2 Suppl):e25-8.

51. Volpe JJ. Electroencephalography may provide insight into timing of premature brain injury. Pediatrics. 2009 Sep;124(3):e542-4.

52. Shaw GM, O'Brodovich HM. Progress in understanding the genetics of bronchopulmonary dysplasia. Semin Perinatol. 2013 Apr;37(2):85-93.

53. Wang H, St Julien KR, Stevenson DK, Hoffmann TJ, Witte JS, Lazzeroni LC, et al. A genome-wide association study (GWAS) for bronchopulmonary dysplasia. Pediatrics. 2013 Aug;132(2):290-7.

54. McCurnin DC, Pierce RA, Willis BC, Chang LY, Yoder BA, Yuhanna IS, et al. Postnatal estradiol upregulates lung nitric oxide synthases and improves lung function in bronchopulmonary dysplasia. Am J Respir Crit Care Med. 2009 Mar 15;179(6):492-500.

55. Lavoie PM, Pham C, Jang KL. Heritability of bronchopulmonary dysplasia, defined according to the consensus statement of the national institutes of health. Pediatrics. 2008 Sep;122(3):479-85.

56. Molnar Z, Rutherford M. Brain maturation after preterm birth. Sci Transl Med. 2013 Jan 16;5(168): 168 ps2.

57. Baker CD, Ryan SL, Ingram DA, Seedorf GJ, Abman SH, Balasubramaniam V. Endothelial colonyforming cells from preterm infants are increased and more susceptible to hyperoxia. Am J Respir Crit Care Med. 2009 Sep 1;180(5):454-61.

58. Ingram DA, Krier TR, Mead LE, McGuire C, Prater DN, Bhavsar J, et al. Clonogenic endothelial progenitor cells are sensitive to oxidative stress. Stem Cells. 2007 Feb;25(2):297-304.

59. Fujinaga H, Baker CD, Ryan SL, Markham NE, Seedorf GJ, Balasubramaniam V, et al. Hyperoxia disrupts vascular endothelial growth factor-nitric oxide signaling and decreases growth of endothelial colony-forming cells from preterm infants. Am J Physiol Lung Cell Mol Physiol. 2009 Dec;297(6):L1160-9.

60. Gonzalez A, Sosenko IR, Chandar J, Hummler H, Claure N, Bancalari E. Influence of infection on patent ductus arteriosus and chronic lung disease in premature infants weighing 1000 grams or less. J Pediatr. 1996 Apr;128(4):470-8.

61. Baker CD, Abman SH. Umbilical cord stem cell therapy for bronchopulmonary dysplasia: ready for prime time? Thorax. 2013 May;68(5):402-4.

62. Desai TJ, Brownfield DG, Krasnow MA. Alveolar progenitor and stem cells in lung development, renewal and cancer. Nature. 2014 Feb 5.

63. Lee JH, Bhang DH, Beede A, Huang TL, Stripp BR, Bloch KD, et al. Lung Stem Cell Differentiation in Mice Directed by Endothelial Cells via a BMP4-NFATc1-Thrombospondin-1 Axis. Cell. 2014 Jan 30;156(3):440-55.

64. Bhatt AJ, Pryhuber GS, Huyck H, Watkins RH, Metlay LA, Maniscalco WM. Disrupted pulmonary vasculature and decreased vascular endothelial growth factor, Flt-1, and TIE-2 in human infants dying with bronchopulmonary dysplasia. Am J Respir Crit Care Med. 2001 Nov 15;164(10 Pt 1):1971-80. 
65. Maniscalco WM, Watkins RH, Pryhuber GS, Bhatt A, Shea C, Huyck H. Angiogenic factors and alveolar vasculature: development and alterations by injury in very premature baboons. Am J Physiol Lung Cell Mol Physiol. 2002 Apr;282(4):L811-23.

66. Thebaud B. Angiogenesis in lung development, injury and repair: implications for chronic lung disease of prematurity. Neonatology. 2007;91(4):291-7.

67. Asahara T, Murohara T, Sullivan A, Silver M, van der Zee R, Li T, et al. Isolation of putative progenitor endothelial cells for angiogenesis. Science. 1997 Feb 14;275(5302):964-7.

68. Hirschi KK, Ingram DA, Yoder MC. Assessing identity, phenotype, and fate of endothelial progenitor cells. Arterioscler Thromb Vasc Biol. 2008 Sep;28(9):1584-95.

69. Peichev M, Naiyer AJ, Pereira D, Zhu Z, Lane WJ, Williams M, et al. Expression of VEGFR-2 and AC133 by circulating human CD34(+) cells identifies a population of functional endothelial precursors. Blood. 2000 Feb 1;95(3):952-8.

70. Ito H, Rovira, II, Bloom ML, Takeda K, Ferrans VJ, Quyyumi AA, et al. Endothelial progenitor cells as putative targets for angiostatin. Cancer Res. 1999 Dec 1;59(23):5875-7.

71. Hill JM, Zalos G, Halcox JP, Schenke WH, Waclawiw MA, Quyyumi AA, et al. Circulating endothelial progenitor cells, vascular function, and cardiovascular risk. N Engl J Med. 2003 Feb 13;348(7): 593-600.

72. Ingram DA, Mead LE, Tanaka H, Meade V, Fenoglio A, Mortell K, et al. Identification of a novel hierarchy of endothelial progenitor cells using human peripheral and umbilical cord blood. Blood. 2004 Nov 1;104(9):2752-60.

73. Yoder MC, Ingram DA. The definition of EPCs and other bone marrow cells contributing to neoangiogenesis and tumor growth: is there common ground for understanding the roles of numerous marrow-derived cells in the neoangiogenic process? Biochim Biophys Acta. 2009 Aug;1796(1):504.

74. Case J, Mead LE, Bessler WK, Prater D, White HA, Saadatzadeh MR, et al. Human CD34+AC133+ VEGFR-2+ cells are not endothelial progenitor cells but distinct, primitive hematopoietic progenitors. Exp Hematol. 2007 Jul;35(7):1109-18.

75. Prater DN, Case J, Ingram DA, Yoder MC. Working hypothesis to redefine endothelial progenitor cells. Leukemia. 2007 Jun;21(6):1141-9.

76. Chang DV, Tiller CJ, Kisling JA, Case J, Mund JA, Haneline LS, et al. Membrane and Capillary Components of Lung Diffusion and Pro-Angiogenic Cells in Infants. Eur Respir J. 2013 May 16.

77. Werner N, Kosiol S, Schiegl T, Ahlers P, Walenta K, Link A, et al. Circulating endothelial progenitor cells and cardiovascular outcomes. N Engl J Med. 2005 Sep 8;353(10):999-1007.

78. Tepper OM, Galiano RD, Capla JM, Kalka C, Gagne PJ, Jacobowitz GR, et al. Human endothelial progenitor cells from type II diabetics exhibit impaired proliferation, adhesion, and incorporation into vascular structures. Circulation. 2002 Nov 26;106(22):2781-6.

79. Balasubramaniam V, Mervis CF, Maxey AM, Markham NE, Abman SH. Hyperoxia reduces bone marrow, circulating, and lung endothelial progenitor cells in the developing lung: implications for the pathogenesis of bronchopulmonary dysplasia. Am J Physiol Lung Cell Mol Physiol. 2007 May;292(5):L1073-84.

80. Borghesi A, Massa M, Campanelli R, Bollani L, Tzialla C, Figar TA, et al. Circulating endothelial progenitor cells in preterm infants with bronchopulmonary dysplasia. Am J Respir Crit Care Med. 2009 Sep 15;180(6):540-6.

81. Paviotti G, Fadini GP, Boscaro E, Agostini C, Avogaro A, Chiandetti L, et al. Endothelial progenitor cells, bronchopulmonary dysplasia and other short-term outcomes of extremely preterm birth. Early Hum Dev. 2011 Jul;87(7):461-5.

82. Safranow K, Kotowski M, Lewandowska J, Machalinska A, Dziedziejko V, Czajka R, et al. Circulating endothelial progenitor cells in premature infants: is there an association with premature birth complications? J Perinat Med. 2012 Jun;40(4):455-62.

83. Lin Y, Weisdorf DJ, Solovey A, Hebbel RP. Origins of circulating endothelial cells and endothelial outgrowth from blood. J Clin Invest. 2000 Jan;105(1):71-7. 
84. Baker CD, Balasubramaniam V, Mourani PM, Sontag MK, Black CP, Ryan SL, et al. Cord blood angiogenic progenitor cells are decreased in bronchopulmonary dysplasia. Eur Respir J. 2012 Dec;40(6):1516-22.

85. O'Reilly M, Thebaud B. Cell-based strategies to reconstitute lung function in infants with severe bronchopulmonary dysplasia. Clin Perinatol. 2012 Sep;39(3):703-25.

86. Alphonse RS, Vadivel A, Fung M, Shelley WC, Critser PJ, Ionescu L, et al. Existence, Functional Impairment and Lung Repair Potential of Endothelial Colony Forming Cells in Oxygen-Induced Arrested Alveolar Growth. Circulation. 2014 Apr 7.

87. Dominici M, Le Blanc K, Mueller I, Slaper-Cortenbach I, Marini F, Krause D, et al. Minimal criteria for defining multipotent mesenchymal stromal cells. The International Society for Cellular Therapy position statement. Cytotherapy. 2006;8(4):315-7.

88. in 't Anker PS, Noort WA, Scherjon SA, Kleijburg-van der Keur C, Kruisselbrink AB, van Bezooijen $\mathrm{RL}$, et al. Mesenchymal stem cells in human second-trimester bone marrow, liver, lung, and spleen exhibit a similar immunophenotype but a heterogeneous multilineage differentiation potential. Haematologica. 2003 Aug;88(8):845-52.

89. Sabatini F, Petecchia L, Tavian M, Jodon de Villeroche V, Rossi GA, Brouty-Boye D. Human bronchial fibroblasts exhibit a mesenchymal stem cell phenotype and multilineage differentiating potentialities. Lab Invest. 2005 Aug;85(8):962-71.

90. Pierro M, Thebaud B. Mesenchymal stem cells in chronic lung disease: culprit or savior? Am J Physiol Lung Cell Mol Physiol. 2010 Jun;298(6):L732-4.

91. Lama VN, Smith L, Badri L, Flint A, Andrei AC, Murray S, et al. Evidence for tissue-resident mesenchymal stem cells in human adult lung from studies of transplanted allografts. J Clin Invest. 2007 Apr;117(4):989-96.

92. van Haaften T, Byrne R, Bonnet S, Rochefort GY, Akabutu J, Bouchentouf M, et al. Airway delivery of mesenchymal stem cells prevents arrested alveolar growth in neonatal lung injury in rats. Am J Respir Crit Care Med. 2009 Dec 1;180(11):1131-42.

93. Popova AP, Bozyk PD, Bentley JK, Linn MJ, Goldsmith AM, Schumacher RE, et al. Isolation of tracheal aspirate mesenchymal stromal cells predicts bronchopulmonary dysplasia. Pediatrics. 2010 Nov;126(5):e1127-33.

94. Bozyk PD, Popova AP, Bentley JK, Goldsmith AM, Linn MJ, Weiss DJ, et al. Mesenchymal stromal cells from neonatal tracheal aspirates demonstrate a pattern of lung-specific gene expression. Stem Cells Dev. 2011 Nov;20(11):1995-2007.

95. Popova AP, Bozyk PD, Goldsmith AM, Linn MJ, Lei J, Bentley JK, et al. Autocrine production of TGFbeta1 promotes myofibroblastic differentiation of neonatal lung mesenchymal stem cells. Am J Physiol Lung Cell Mol Physiol. 2010 Jun;298(6):L735-43.

96. Hennrick KT, Keeton AG, Nanua S, Kijek TG, Goldsmith AM, Sajjan US, et al. Lung cells from neonates show a mesenchymal stem cell phenotype. Am J Respir Crit Care Med. 2007 Jun 1;175(11):1158-64.

97. Aslam M, Baveja R, Liang OD, Fernandez-Gonzalez A, Lee C, Mitsialis SA, et al. Bone marrow stromal cells attenuate lung injury in a murine model of neonatal chronic lung disease. Am J Respir Crit Care Med. 2009 Dec 1;180(11):1122-30.

98. Islam MN, Das SR, Emin MT, Wei M, Sun L, Westphalen K, et al. Mitochondrial transfer from bonemarrow-derived stromal cells to pulmonary alveoli protects against acute lung injury. Nat Med. 2012 May;18(5):759-65.

99. Pierro M, Ionescu L, Montemurro T, Vadivel A, Weissmann G, Oudit G, et al. Short-term, long-term and paracrine effect of human umbilical cord-derived stem cells in lung injury prevention and repair in experimental bronchopulmonary dysplasia. Thorax. 2012 Dec 15.

100. Gauldie J, Kolb M, Ask K, Martin G, Bonniaud P, Warburton D. Smad3 signaling involved in pulmonary fibrosis and emphysema. Proc Am Thorac Soc. 2006 Nov;3(8):696-702. 
101. Kotecha S, Wangoo A, Silverman M, Shaw RJ. Increase in the concentration of transforming growth factor beta-1 in bronchoalveolar lavage fluid before development of chronic lung disease of prematurity. J Pediatr. 1996 Apr;128(4):464-9.

102. Nakanishi H, Sugiura T, Streisand JB, Lonning SM, Roberts JD, Jr. TGF-beta-neutralizing antibodies improve pulmonary alveologenesis and vasculogenesis in the injured newborn lung. Am J Physiol Lung Cell Mol Physiol. 2007 Jul;293(1):L151-61.

103. Kinney HC, Haynes RL, Xu G, Andiman SE, Folkerth RD, Sleeper LA, et al. Neuron deficit in the white matter and subplate in periventricular leukomalacia. Ann Neurol. 2012 Mar;71(3):397-406.

104. Dean JM, McClendon E, Hansen K, Azimi-Zonooz A, Chen K, Riddle A, et al. Prenatal cerebral ischemia disrupts MRI-defined cortical microstructure through disturbances in neuronal arborization. Sci Transl Med. 2013 Jan 16;5(168):168ra7.

105. Vinall J, Grunau RE, Brant R, Chau V, Poskitt KJ, Synnes AR, et al. Slower postnatal growth is associated with delayed cerebral cortical maturation in preterm newborns. Sci Transl Med. 2013 Jan 16;5(168):168ra8.

106. Haynes RL, Xu G, Folkerth RD, Trachtenberg FL, Volpe JJ, Kinney HC. Potential neuronal repair in cerebral white matter injury in the human neonate. Pediatr Res. 2011 Jan;69(1):62-7.

107. Powell AE, Wang Y, Li Y, Poulin EJ, Means AL, Washington MK, et al. The pan-ErbB negative regulator Lrig1 is an intestinal stem cell marker that functions as a tumor suppressor. Cell. $2012 \mathrm{Mar}$ 30;149(1):146-58.

108. Sangiorgi E, Capecchi MR. Bmi1 is expressed in vivo in intestinal stem cells. Nat Genet. 2008 Jul;40(7):915-20.

109. Takeda N, Jain R, LeBoeuf MR, Wang Q, Lu MM, Epstein JA. Interconversion between intestinal stem cell populations in distinct niches. Science. 2011 Dec 9;334(6061):1420-4.

110. Metcalfe C, Kljavin NM, Ybarra R, de Sauvage FJ. Lgr5(+) stem cells are indispensable for radiationinduced intestinal regeneration. Cell Stem Cell. 2014 Feb 6;14(2):149-59.

111. Matthay MA, Anversa P, Bhattacharya J, Burnett BK, Chapman HA, Hare JM, et al. Cell therapy for lung diseases. Report from an NIH-NHLBI workshop, November 13-14, 2012. Am J Respir Crit Care Med. 2013 Aug 1;188(3):370-5.

112. Liang OD, Mitsialis SA, Chang MS, Vergadi E, Lee C, Aslam M, et al. Mesenchymal stromal cells expressing heme oxygenase-1 reverse pulmonary hypertension. Stem Cells. 2011 Jan;29(1):99107.

113. Chang YS, Choi SJ, Sung DK, Kim SY, Oh W, Yang YS, et al. Intratracheal transplantation of human umbilical cord blood-derived mesenchymal stem cells dose-dependently attenuates hyperoxiainduced lung injury in neonatal rats. Cell Transplant. 2011;20(11):1843-54.

114. Ionescu L, Byrne RN, van Haaften T, Vadivel A, Alphonse RS, Rey-Parra GJ, et al. Stem cell conditioned medium improves acute lung injury in mice: in vivo evidence for stem cell paracrine action. Am J Physiol Lung Cell Mol Physiol. 2012 Dec;303(11):L967-77.

115. Hansmann G, Fernandez-Gonzalez A, Aslam M, Vitali SH, Martin T, Mitsialis SA, et al. Mesenchymal stem cell-mediated reversal of bronchopulmonary dysplasia and associated pulmonary hypertension. Pulm Circ. 2012 Apr-Jun;2(2):170-81.

116. Lee C, Mitsialis SA, Aslam M, Vitali SH, Vergadi E, Konstantinou G, et al. Exosomes mediate the cytoprotective action of mesenchymal stromal cells on hypoxia-induced pulmonary hypertension. Circulation. 2012 Nov 27;126(22):2601-11.

117. Tropea KA, Leder E, Aslam M, Lau AN, Raiser DM, Lee JH, et al. Bronchioalveolar stem cells increase after mesenchymal stromal cell treatment in a mouse model of bronchopulmonary dysplasia. Am J Physiol Lung Cell Mol Physiol. 2012 May 1;302(9):L829-37.

118. Bernardo ME, Pagliara D, Locatelli F. Mesenchymal stromal cell therapy: a revolution in Regenerative Medicine? Bone Marrow Transplant. 2012 Feb;47(2):164-71.

119. Le Blanc K. Mesenchymal stromal cells: Tissue repair and immune modulation. Cytotherapy. 2006;8(6):559-61. 
120. Avanzini MA, Bernardo ME, Cometa AM, Perotti C, Zaffaroni N, Novara F, et al. Generation of mesenchymal stromal cells in the presence of platelet lysate: a phenotypic and functional comparison of umbilical cord blood- and bone marrow-derived progenitors. Haematologica. 2009 Dec;94(12):1649-60.

121. Singer NG, Caplan AI. Mesenchymal stem cells: mechanisms of inflammation. Annu Rev Pathol. 2011;6:457-78.

122. Krasnodembskaya A, Samarani G, Song Y, Zhuo H, Su X, Lee JW, et al. Human mesenchymal stem cells reduce mortality and bacteremia in gram-negative sepsis in mice in part by enhancing the phagocytic activity of blood monocytes. Am J Physiol Lung Cell Mol Physiol. 2012 May 15;302(10):L1003-13.

123. Krasnodembskaya A, Song Y, Fang X, Gupta N, Serikov V, Lee JW, et al. Antibacterial effect of human mesenchymal stem cells is mediated in part from secretion of the antimicrobial peptide LL37. Stem Cells. 2010 Dec;28(12):2229-38.

124. Lee JW, Fang X, Krasnodembskaya A, Howard JP, Matthay MA. Concise review: Mesenchymal stem cells for acute lung injury: role of paracrine soluble factors. Stem Cells. 2011 Jun;29(6):913-9.

125. Lee JW, Krasnodembskaya A, McKenna DH, Song Y, Abbott J, Matthay MA. Therapeutic effects of human mesenchymal stem cells in ex vivo human lungs injured with live bacteria. Am J Respir Crit Care Med. 2013 Apr 1;187(7):751-60.

126. Le Blanc K, Frassoni F, Ball L, Locatelli F, Roelofs H, Lewis I, et al. Mesenchymal stem cells for treatment of steroid-resistant, severe, acute graft-versus-host disease: a phase II study. Lancet. 2008 May 10;371(9624):1579-86.

127. Matthay MA, Thompson BT, Read EJ, McKenna DH, Jr., Liu KD, Calfee CS, et al. Therapeutic potential of mesenchymal stem cells for severe acute lung injury. Chest. 2010 0ct;138(4):965-72.

128. Salem HK, Thiemermann C. Mesenchymal stromal cells: current understanding and clinical status. Stem Cells. 2010 Mar 31;28(3):585-96.

129. Sensebe L, Bourin P. Mesenchymal stem cells for therapeutic purposes. Transplantation. 2009 May 15;87(9 Suppl):S49-53.

130. Balasubramaniam V, Ryan SL, Seedorf GJ, Roth EV, Heumann TR, Yoder MC, et al. Bone marrowderived angiogenic cells restore lung alveolar and vascular structure after neonatal hyperoxia in infant mice. Am J Physiol Lung Cell Mol Physiol. 2010 Mar;298(3):L315-23.

131. Baker CD, Seedorf GJ, Wisniewski BL, Black CP, Ryan SL, Balasubramaniam V, et al. Endothelial colony-forming cell conditioned media promote angiogenesis in vitro and prevent pulmonary hypertension in experimental bronchopulmonary dysplasia. Am J Physiol Lung Cell Mol Physiol. 2013 Jul 1;305(1):L73-81.

132. Baker CD, Ryan SL, Ingram DA, Seedorf GJ, Abman SH, Balasubramaniam V. Endothelial Colony Forming Cells from Preterm Infants are Increased and More Susceptible to Hyperoxia. Am J Respir Crit Care Med. 2009 May 29.

133. Vosdoganes P, Hodges RJ, Lim R, Westover AJ, Acharya RY, Wallace EM, et al. Human amnion epithelial cells as a treatment for inflammation-induced fetal lung injury in sheep. Am J Obstet Gynecol. 2011 Aug;205(2):156 e26-33.

134. Hodges RJ, Jenkin G, Hooper SB, Allison B, Lim R, Dickinson H, et al. Human amnion epithelial cells reduce ventilation-induced preterm lung injury in fetal sheep. Am J Obstet Gynecol. 2012 May;206(5):448 e8-15.

135. van Velthoven CT, Kavelaars A, van Bel F, Heijnen CJ. Mesenchymal stem cell transplantation changes the gene expression profile of the neonatal ischemic brain. Brain Behav Immun. 2011 Oct;25(7):1342-8.

136. van Velthoven CT, Kavelaars A, van Bel F, Heijnen CJ. Nasal administration of stem cells: a promising novel route to treat neonatal ischemic brain damage. Pediatr Res. 2010 Nov;68(5):419-22. 
137. van Velthoven CT, Kavelaars A, van Bel F, Heijnen CJ. Repeated mesenchymal stem cell treatment after neonatal hypoxia-ischemia has distinct effects on formation and maturation of new neurons and oligodendrocytes leading to restoration of damage, corticospinal motor tract activity, and sensorimotor function. J Neurosci. 2010 Jul 14;30(28):9603-11.

138. van Velthoven CT, Kavelaars A, van Bel F, Heijnen CJ. Mesenchymal stem cell treatment after neonatal hypoxic-ischemic brain injury improves behavioral outcome and induces neuronal and oligodendrocyte regeneration. Brain Behav Immun. 2010 Mar;24(3):387-93.

139. van Velthoven CT, Kavelaars A, van Bel F, Heijnen CJ. Regeneration of the ischemic brain by engineered stem cells: fuelling endogenous repair processes. Brain Res Rev. 2009 Jun;61(1):1-13.

140. Kim ES, Ahn SY, Im GH, Sung DK, Park YR, Choi SH, et al. Human umbilical cord blood-derived mesenchymal stem cell transplantation attenuates severe brain injury by permanent middle cerebral artery occlusion in newborn rats. Pediatr Res. United States2012. p. 277-84.

141. Gortner L, Felderhoff-Muser U, Monz D, Bieback K, Kluter H, Jellema R, et al. Regenerative therapies in neonatology: clinical perspectives. Klin Padiatr. 2012 Jul;224(4):233-40.

142. Jellema RK, Wolfs TG, Lima Passos V, Zwanenburg A, Ophelders DR, Kuypers E, et al. Mesenchymal stem cells induce T-cell tolerance and protect the preterm brain after global hypoxia-ischemia. PLoS One. 2013;8(8):e73031.

143. Weil BR, Markel TA, Herrmann JL, Abarbanell AM, Meldrum DR. Mesenchymal stem cells enhance the viability and proliferation of human fetal intestinal epithelial cells following hypoxic injury via paracrine mechanisms. Surgery. 2009 Aug;146(2):190-7.

144. Tayman C, Uckan D, Kilic E, Ulus AT, Tonbul A, Murat Hirfanoglu I, et al. Mesenchymal stem cell therapy in necrotizing enterocolitis: a rat study. Pediatr Res. 2011 Nov;70(5):489-94.

145. Ciccocioppo R, Bernardo ME, Sgarella A, Maccario R, Avanzini MA, Ubezio C, et al. Autologous bone marrow-derived mesenchymal stromal cells in the treatment of fistulising Crohn's disease. Gut. 2011 Jun;60(6):788-98.

146. Fordham RP, Yui S, Hannan NR, Soendergaard C, Madgwick A, Schweiger PJ, et al. Transplantation of expanded fetal intestinal progenitors contributes to colon regeneration after injury. Cell Stem Cell. 2013 Dec 5;13(6):734-44.

147. Aguilar S, Nye E, Chan J, Loebinger M, Spencer-Dene B, Fisk N, et al. Murine but not human mesenchymal stem cells generate osteosarcoma-like lesions in the lung. Stem Cells. 2007 Jun;25(6):1586-94.

148. Barkholt L, Flory E, Jekerle V, Lucas-Samuel S, Ahnert P, Bisset L, et al. Risk of tumorigenicity in mesenchymal stromal cell-based therapies-Bridging scientific observations and regulatory viewpoints. Cytotherapy. 2013 Apr 18.

149. Bernardo ME, Zaffaroni N, Novara F, Cometa AM, Avanzini MA, Moretta A, et al. Human bone marrow derived mesenchymal stem cells do not undergo transformation after long-term in vitro culture and do not exhibit telomere maintenance mechanisms. Cancer Res. 2007 Oct 1;67(19):9142-9.

150. Tarte K, Gaillard J, Lataillade JJ, Fouillard L, Becker M, Mossafa H, et al. Clinical-grade production of human mesenchymal stromal cells: occurrence of aneuploidy without transformation. Blood. Feb 25;115(8):1549-53.

151. Sensebe L. Beyond genetic stability of mesenchymal stromal cells. Cytotherapy. 2013 Nov;15(11):1307-8.

152. Scafidi J, Hammond TR, Scafidi S, Ritter J, Jablonska B, Roncal M, et al. Intranasal epidermal growth factor treatment rescues neonatal brain injury. Nature. 2014 Feb 13;506(7487):230-4.

153. Zon L. Translational research: the path for bringing discovery to patients. Cell Stem Cell. 2014 Feb 6;14(2):146-8.

154. Mendicino M, Bailey AM, Wonnacott K, Puri RK, Bauer SR. MSC-Based Product Characterization for Clinical Trials: An FDA Perspective. Cell Stem Cell. 2014 Feb 6;14(2):141-5. 

Chapter 2. Aims 
General issues regarding stem/progenitor cell therapy in the context of diseases associated with prematurity have been discussed in chapter 1 . In brief, these issues can be summarized as follows.

Very and extremely preterm infants are highly vulnerable to the detrimental effects of oxidative stress and infection, and suffer from severe diseases affecting the lungs, the brain, the bowel, and virtually every organ and tissue. In many cases, lung and brain injury eventually evolve in severe, long lasting sequelae, namely BPD and PVL.

In the last decades, the prevention and treatment of neonatal RDS with antenatal steroids and surfactant replacement has changed the epidemiology of preterm birth, allowing the survival of infants born at extremely low gestational ages. These extremely preterm infants, who received steroids prenatally and surfactant postnatally, are still prone to tissue and organ injury, but usually suffer from less severe RDS and, in many cases, develop milder forms of BPD and PVL: the "new BPD" and the diffuse, non-cystic form of PVL, as opposed to old BPD and cystic PVL, respectively. Tissue simplification and developmental arrest with larger and fewer alveoli and hypomyelination in lungs and brain, respectively, appear to be the key features of these emerging, new sequelae, while necrosis and scarring (fibrosis/astrogliosis), the hallmarks of the old forms of BPD and PVL, are usually less pronounced and contribute to a lesser extent to their pathogenesis.

Recent data suggest that loss of stem/progenitor cell populations in the developing brain and lungs may underlie tissue simplification.

These observations constitute the rationale bases for two lines of research aiming at:

- further investigating the role of stem/progenitor cell loss in the development of diseases and sequelae associated with preterm birth, and

- developing safe and effective stem cell-based protocols for the prevention and treatment of tissue injury following extremely preterm birth.

Transplantation of different cell types (including, but not limited to, mesenchymal stromal cells -MSCs -, endothelial progenitor cells - EPCs -, human amnion epithelial cells - hAECs -) could be beneficial in preterm infants for the prevention and/or treatment of BPD, PVL, and other major sequelae of prematurity. However, before this new knowledge can be translated into clinical practice, several issues still need to be addressed in preclinical in vitro and in vivo models.

Accordingly, the PhD project was developed along two lines of research.

\section{Specific aims}

1) The first research line aimed at investigating the role of angiogenic cells in the development of the lung vascular bed during late pregnancy and after preterm 
birth, and at looking for correlations suggesting their involvement in the development of the lung and in the lung vascular disruption characteristic of BPD. To this aim, clinical studies were conducted to search for correlations between the circulating levels of different populations of angiogenic cells or EPCs and the subsequent development of BPD.

- Chapter 3. This clinical research study aimed at finding correlations between circulating cord blood endothelial colony forming cells (ECFCs), a subtype of EPCs enumerated by clonogenic assay, and the subsequent development of BPD (primary outcome) or other diseases of prematurity (secondary outcomes) in preterm infants; in parallel, other cell populations of hemopoietic origin, considered "angiogenic cells" or "angiogenic macrophages", and enumerated by flow cytometry (CD34+CD133+VEGFR-2+ triple positive cells and other VEGFR-2+cell populations), were studied for correlation as well.

- Chapter 4. On the hint of the preliminary study, a second study aimed at confirming the lack of correlation between VEGFR-2+ cells and BPD or other outcomes of prematurity. It was designed as an incremental work on angiogenic cells studied by flow cytometry (CD34+CD133+VEGFR-2+ triple positive cells and other VEGFR-2+cell populations).

2) The second research line aimed at assessing, in a preclinical setting, the safety of cell products destined to clinical use and to clinical protocols for clinical trials; more specifically, the ultimate goal was to find a "biosafety profile" of the cell products to be used in clinical trials.

- Chapter 5. In vitro study on umbilical cord (UC)-derived MSCs. This study aimed at assessing the genetic stability and the risk of tumorigenicity in UCMSCs; we looked for genomic alterations - copy number variations - by arraycomparative genomic hybridization, and studied the cellular phenotype of two clones who proved to carry genomic alterations. 

Part 2. Investigating the role of endothelial progenitor cells as biomarkers 



\section{Chapter 3. Circulating endothelial progenitor cells in preterm infants with bronchopulmonary dysplasia}

Borghesi A, Massa M, Campanelli R, Bollani L, Tzialla C, Figar TA, Ferrari G, Bonetti E, Chiesa G, de Silvestri A, Spinillo A, Rosti V, Stronati M. Am J Resp Crit Care Med. 2009 Sep 15;180(6):540-6. 


\begin{abstract}
RATIONALE: The new form of bronchopulmonary dysplasia (BPD) is characterized by lung immaturity with disrupted alveolar and capillary development after extremely premature birth, but the mechanism of impaired lung vascular formation is still not completely understood. Objectives: We tested the hypothesis that reduced numbers of circulating endothelial progenitor cells at birth are associated with the development of BPD.
\end{abstract}

METHODS: We studied ninety-eight preterm infants with gestational age of less than 32 weeks or a birth weight less than 1,500 g. Endothelial colony-forming cells (ECFCs) were assessed by clonogenic analysis in infants for whom cord blood was available. The proportion of circulating endothelial and hematopoietic cells was measured by flow cytometry at birth, at 48 hours, and at 7 days of life.

MEASUREMENTS AND MAIN RESULTS: ECFCs in cord blood were lower in infants who later developed BPD (median [range]: 0.00 [0.00-0.48] vs. 2.00 [0.00-21.87]; P $=0.002)$. ECFCs decreased with decreasing gestational age $(\mathrm{r}=0.41 ; \mathrm{P}=0.02)$, but even at extremely low gestational ages, infants with higher numbers of ECFCs were protected from BPD. The endothelial and hematopoietic cell subsets studied by flow cytometry were comparable in infants with and without BPD and rapidly decreased after birth.

CONCLUSIONS: ECFCs are low at extremely low gestational ages and increase during gestation; extremely preterm infants who display lower numbers at birth have an increased risk of developing BPD. Our findings suggest that decreased ECFCs following extremely preterm birth may be associated with the risk for developing lung vascular immaturity characteristic of new BPD. 


\section{Introduction}

Bronchopulmonary dysplasia (BPD) is a chronic lung disease of prematurely born infants, with a reported incidence of up to $43 \%$ in infants with birth weight $<1500$ $\mathrm{g}$ (1). Very premature birth is characterized by surfactant deficiency, defective growth of the distal air spaces and immaturity of the alveolar capillary bed that often lead to the development of respiratory distress syndrome requiring mechanical ventilation.

Risk factors that predispose ventilated preterm infants with respiratory distress syndrome to the development of BPD include exposure to high airway pressures and high inspired oxygen concentrations, the presence of a symptomatic patent ductus arteriosus (PDA), and systemic infections $(1,2)$. In addition to environmental risk factors, genetic susceptibility also plays a major role (3).

Experimental models and clinical data support the hypothesis that structural changes of the capillaries and decreased angiogenesis in the lung vasculature contribute, together with infection/inflammation, to the pathogenesis of BPD (4-7).

An important question remains the mechanism for impaired lung capillary formation observed in infants with BPD.

Circulating endothelial progenitor cells (EPCs), first isolated in 1997 (8), comprise a small fraction of circulating mononuclear cells that can be identified by either expression of endothelial surface markers (9) or functional analysis of cultured cells (10).

Very little is known about the physiologic role that circulating EPCs play during normal lung vasculature formation.

In a mouse model of BPD, Balasubramaniam et al. found that hyperoxia decreases pulmonary vascular density, simplifies distal lung structure, and reduces EPCs in blood, bone marrow and lungs. This finding suggests a role of mobilization, recruitment and engraftment of these cells to the lung in maintaining or repairing lung structure, and points out an impairment of EPC number and function in mice exposed to hyperoxia (11).

However, it is unknown whether variations of the frequency of EPCs at birth, before oxygen exposure, may be related to the subsequent development of BPD in humans.

The aim of this study is to evaluate the association of the frequency of circulating EPCs at birth with the development of BPD in preterm infants. As the surface phenotype that specifically permits to distinguish EPCs from hematopoietic progenitor cells (HPCs) is yet unknown, different cell populations expressing markers of both the endothelial and the hematopoietic lineages were studied for correlation with BPD. 


\section{Methods}

\section{Study population}

Ninety-eight consecutive inborn preterm infants with gestational age $<32$ weeks and/or birth weight $<1500 \mathrm{~g}$ admitted within the first three hours of life to our single tertiary neonatal intensive care unit at the Fondazione IRCCS Policlinico San Matteo di Pavia (Italy) between June 2006 and January 2009 were included in the study. Infants dead before 28 days of life for whom diagnosis of BPD couldn't be established, infants for whom parental informed consent was not available, and infants with congenital/chromosomal anomalies were excluded from the study.

The study protocol was approved by the Ethic Committee of the Institution. Written parental informed consent was obtained before blood collection according to the Declaration of Helsinki. Umbilical cord blood of preterm infants is not used for donation and its collection does not interfere with umbilical cord blood collection for blood banks. Peripheral blood samples were never more abundant than $300 \mu \mathrm{l}$, and were obtained during routine withdrawal for blood count.

\section{Study design}

Peripheral blood samples for flow cytometric analysis of different CD34+ cell subsets were collected for each infant: at birth (within the first 3 hours of life), at 48 hours and at 7 days of life.

Umbilical cord blood, when available, was used for clonogenic analysis of endothelial colony forming cells (ECFCs) as described later.

The primary outcome was the association of baseline cell numbers with the development of BPD. BPD was defined as oxygen dependence for at least 28 postnatal days and graded at 36 weeks' postmenstrual age according to the fraction of inspired oxygen $\left(\mathrm{FiO}_{2}\right)$ and the requirement of respiratory support at this time: mild BPD was diagnosed if the infant was in room air, moderate BPD if the $\mathrm{FiO}_{2}$ was $0.22-0.29$ and severe $\mathrm{BPD}$ if the $\mathrm{FiO}_{2}$ was $\geq 0.30$ or the infant was receiving respiratory support $(12,13)$.

As secondary outcomes we studied the association of cell numbers at birth with the development of necrotizing enterocolitis (NEC) (14), retinopathy of prematurity (ROP) (15), intraventricular hemorrhage (IVH) (16) and periventricular leukomalacia (PVL) defined as cystic degeneration of the periventricular white matter.

To investigate the effect of birth on different cell populations studied by flow cytometry, cell percentages at 48 hours and at 7 days of life were compared with percentages at birth. 
Maternal medical records were reviewed for pregnancy and delivery characteristics. Clinical and outcome data of the study population were prospectively collected. PDA was diagnosed by echocardiogram. The clinical risk index for babies (CRIB) score for the prediction of neonatal mortality and morbidity was calculated as previously described (17). The diagnosis of early-onset sepsis, within the first 72 hours of life, was based on signs of infection accompanied by abnormal laboratory studies and/or positive cultures.

\section{Flow cytometry and in vitro cultures}

The percentages of cell populations expressing markers of both endothelial and hematopoietic lineages in different combinations were assessed by flow cytometry.

For ECFC cultures, mononuclear cells (MNCs) were plated according to Ingram et al. (18). The number of ECFCs is expressed as frequency of ECFCs $/ 10^{7}$ plated MNCs.

A detailed description of the methods used for all these measurements is provided in the online data supplement. An example of the gating strategy for identification and enumeration of CD34+ cell subsets is displayed in Figure 7.
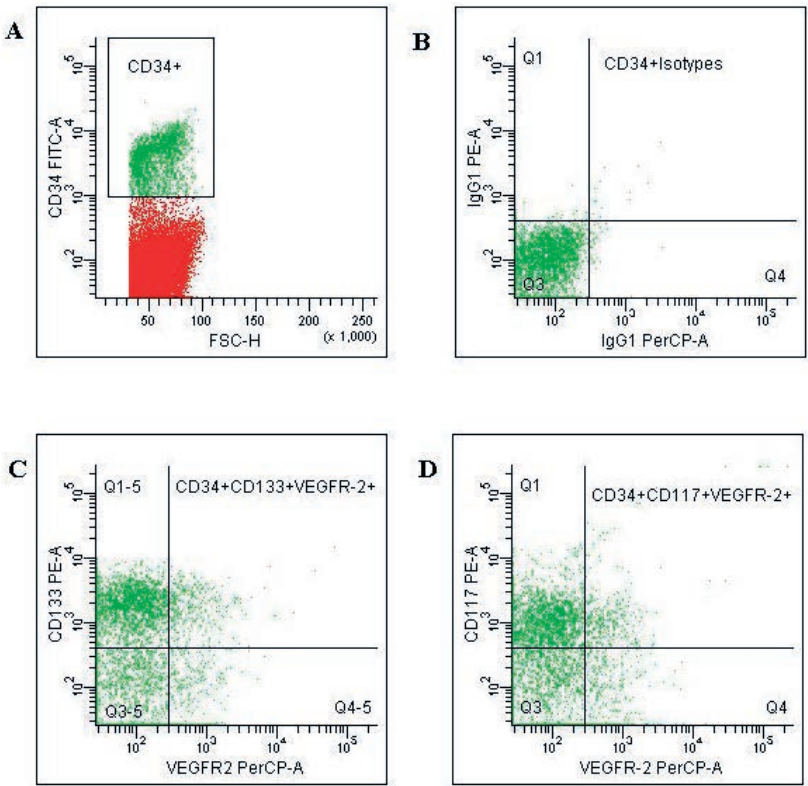

Figure 7. Gating strategy for identification and enumeration of CD34+CD133+VEGFR$2+$ and CD34+CD133-VEGFR$2+$ cells.

The analysis was performed as follows: peripheral blood mononuclear cells were gated based on their physical characteristics (FSC and SSC). CD34+ cells were then electronically gated (panel A), and markers defining the aspecific staining were set according to the isotype controls (panel B). The staining with moAbs allowed the evaluation of the cell subsets as percentage of the CD34+ cells (panel C and D). 


\section{Results}

Maternal, perinatal, and neonatal characteristics of the study infants

Twenty-four neonates (24.5\%) developed BPD and seventy-four (75.5\%) did not. Twenty-five infants were born at $<28$ weeks' gestational age; seventeen of those infants developed BPD and eight did not. The characteristics of the study infants are displayed in Table 2. Gestational age and birth weight were significantly lower $(\mathrm{P}<0.001$ and $\mathrm{P}<0.001$, respectively) and CRIB scores during the first 12 hours were significantly higher $(\mathrm{P}<0.001)$ in infants who later developed BPD than in infants who did not. The incidence of PDA and early-onset sepsis was significantly higher in infants who developed BPD ( $\mathrm{P}<0.001$ and $\mathrm{P}=0.002$, respectively). Patients with BPD had longer duration of oxygen $(\mathrm{P}<0.001)$, nasal continuous positive airway pressure ( $\mathrm{n}-\mathrm{CPAP}, \mathrm{P}<0.001)$ and ventilatory support $(\mathrm{P}<0.001)$ and were more likely to develop ROP $(\mathrm{P}<0.001)$.

ECFCs in cord blood at birth are lower in infants who subsequently develop BPD

In order to evaluate whether circulating numbers of EPCs at birth are associated with the development of BPD, the frequency of EPCs in cord blood was assessed by analysis of in vitro growth of circulating ECFCs in 9 infants with BPD and 23 infants without BPD. Infants who later developed BPD had significantly lower frequencies of ECFCs than infants without BPD ( $\mathrm{P}=0.002$; Table 3, Figure 8). In addition, if oxygen dependence at 36 weeks' postmenstrual age was considered as the primary outcome, infants who were in room air at this postmenstrual age (including both infants without BPD and infants with mild BPD; $n=26$ ) had significantly higher frequencies of ECFCs in cord blood at birth compared to infants who were still oxygen dependent at this age (i.e. infants with moderate-to-severe BPD; $n=6$ ) (median [range]: 1.63 [0.00-21.87] vs 0.00 [0.00-0.48], $\mathrm{P}=0.02$; Figure 8). Furthermore, ECFC frequency in cord blood inversely correlated with the duration of oxygen supplementation ( $\mathrm{r}=-0.60, \mathrm{P}<0.001)$, $\mathrm{n}-\mathrm{CPAP}(\mathrm{r}=-0.52, \mathrm{P}=0.003)$ and mechanical ventilation $(r=-0.59, P<0.001)$. Thus, infants with lower numbers of ECFCs in cord blood at birth were more likely to subsequently develop BPD. 
Table 2. Maternal, perinatal, and neonatal characteristics of the study infants.

\begin{tabular}{|c|c|c|c|c|}
\hline Characteristic & $\begin{array}{c}\text { All } \\
n=98\end{array}$ & $\begin{array}{c}\text { BPD } \\
24(24.5)\end{array}$ & $\begin{array}{c}\text { No BPD } \\
74(75.5)\end{array}$ & $\begin{array}{c}\text { BPD vs no BPD } \\
\text { P value* }\end{array}$ \\
\hline Gestational age - wk, mean \pm SD & $29.5 \pm 2.6$ & $26.6 \pm 1.8$ & $30.5 \pm 2.0$ & $<0.001$ \\
\hline Birth weight, g, mean \pm SD & $1169.9 \pm 382.2$ & $759.7 \pm 216.0$ & $1302.9 \pm 325.7$ & $<0.001$ \\
\hline \multicolumn{5}{|l|}{ Mode of delivery } \\
\hline Cesarean section/Vaginal delivery & $75(76.5) / 23(23.5)$ & $16(66.7) / 8(33.3)$ & $59(79.7) / 15(20.3)$ & 0.39 \\
\hline Gestational diabetes mellitus & $7(7.1)$ & $1(4.2)$ & $6(8.1)$ & 0.68 \\
\hline Maternal hypertension & $30(30.6)$ & $8(33.3)$ & $22(29.7)$ & 0.80 \\
\hline Chorioamnionitis & $16(16.3)$ & $6(25.0)$ & $10(13.5)$ & 0.21 \\
\hline Antenatal steroids & $65(66.3)$ & $17(70.8)$ & $48(64.8)$ & 0.63 \\
\hline Gender, Male/Female & $41(53.9) / 35(46.1)$ & $18(75.0) / 6(25.0)$ & $40(54.0) / 34(46.0)$ & 0.09 \\
\hline SGA & $27(27.5)$ & $9(37.5)$ & $18(24.3)$ & 0.29 \\
\hline CRIB score, median (range) $\dagger$ & $1.0(0-12)$ & $7.0(1-12)$ & $1.0(0-6)$ & $<0.001$ \\
\hline PDA & $20(20.4)$ & $11(45.8)$ & $9(12.2)$ & $<0.001$ \\
\hline Early-onset sepsis & $15(15.3)$ & $9(37.5)$ & $6(8.1)$ & 0.002 \\
\hline NEC & $7(7.1)$ & $2(8.3)$ & $5(6.7)$ & 1.00 \\
\hline IVH: grade I-IV & $13(15.3)$ & $7(29.1)$ & $8(10.8)$ & 0.05 \\
\hline PVL & $5(5.1)$ & $3(12.5)$ & $2(2.7)$ & 0.09 \\
\hline ROP & $16(16.3)$ & $13(54.1)$ & $3(4.0)$ & $<0.001$ \\
\hline Mortality & $1(1.0)$ & $1(4.2)$ & 0 & 0.24 \\
\hline Post-natal steroids $\ddagger$ & $12(12.2)$ & $12(50.0)$ & 0 & $<0.001$ \\
\hline $\mathrm{FiO}_{2}$, median (range) & $0.21(0.21-0.28)$ & $0.25(0.21-0.28)$ & $0.21(0.21-0.21)$ & $<0.001$ \\
\hline Oxygen, days, median (range) & $3(0-230)$ & $62(32-230)$ & $1(0-21)$ & $<0.001$ \\
\hline n-CPAP, days, median (range) & $5(0-66)$ & $26(0-66)$ & $2(0-39)$ & $<0.001$ \\
\hline MV, days, median (range) & $0(0-49)$ & $13(1-49)$ & $0(0-6)$ & $<0.001$ \\
\hline WBC $\times 10^{9} /$ l, median (range) & $11.2(1.7-101.0)$ & $8.2(3.0-74.6)$ & $8.3(1.7-101.0)$ & 0.89 \\
\hline
\end{tabular}

Values represent number (\%) unless otherwise specified.

*The 2 groups (BPD and no BPD) were compared by using the Student's t-test for independent samples, the MannWhitney test or the Fisher's exact test. BPD is defined as oxygen-dependence for at least 28 postnatal days. † The CRIB score ranges from 0 to 23, with higher scores indicating higher neonatal risk.

‡ The number (\%) of infants receiving postnatal steroids is indicated. Dexamethasone or methylprednisolone were used, and always administered after the $3^{\text {rd }}$ week of life.

Definitions of abbreviations: BPD = bronchopulmonary dysplasia; SGA = small for gestational age; CRIB = clinical risk index for babies; PDA = patent ductus arteriosus; NEC = necrotizing enterocolitis; IVH = intraventricular hemorrhage; $\mathrm{PVL}=$ cystic periventricular leukomalacia; $\mathrm{ROP}=$ retinopathy of prematurity; $\mathrm{FiO}_{2}=$ fraction of inspired oxygen (the value represents $\mathrm{FiO}_{2}$ at 36 weeks' postmenstrual age); n-CPAP = nasal continuous positive airway pressure; $\mathrm{MV}=$ mechanical ventilation; $\mathrm{wk}=$ weeks; $\mathrm{WBC}=$ white blood cells count at birth. 


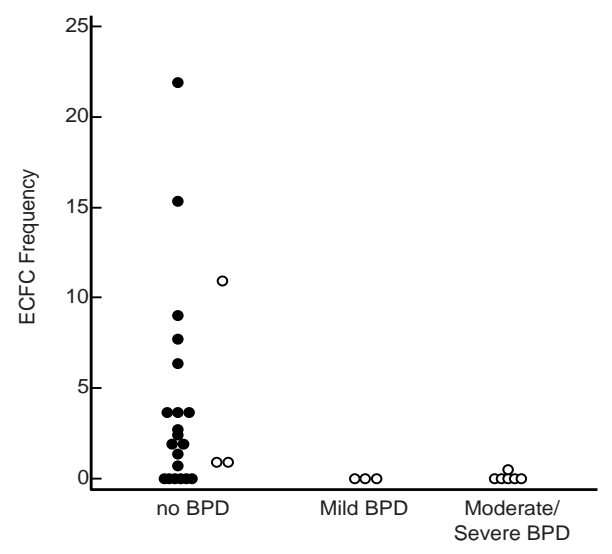

Figure 8. Frequency of endothelial colony forming cells (ECFCs) in cord blood of preterm infants with or without BPD.

Mild BPD was diagnosed in infants with oxygen-dependence for at least 28 days, but in room air at 36 weeks' postmenstrual age; BPD was graded as moderate-to-severe if $\mathrm{FiO} 2$ was $>0.21$ or the infant was receiving respiratory support at 36 weeks' postmenstrual age. ECFC frequency is expressed as number of ECFCs/107 plated mononuclear cells. Infants with gestational age at birth $>28$ weeks are indicated by closed circles, infants with gestational age at birth $<28$ weeks are indicated by open circles. Infants who later developed BPD (mild-to-severe) had significantly lower frequencies of ECFCs at birth than infants without $\mathrm{BPD}(\mathrm{P}=0.002)$.

Table 3. Median values of ECFCs in cord blood and of different CD34+ cell subsets at birth in infants with and without BPD.

\begin{tabular}{lccc}
\hline & BPD & No BPD & P value \\
\hline ECFCs/107MNCs & $0.00(0.00-0.48)$ & $2.00(0.00-21.87)$ & 0.002 \\
IQ range & $0.00-0.00$ & $0.18-5.71$ & 0.005 \\
CD34+CD45+* & $0.27(0.03-0.76)$ & $0.08(0.00-0.60)$ & \\
IQ range & $0.10-0.32$ & $0.04-0.20$ & 0.008 \\
CD34+CD45- $*$ & $0.55(0.00-3.20)$ & $0.10(0.00-1.80)$ & 0.52 \\
IQ range & $0.20-1.05$ & $0.00-0.32$ & \\
CD34+CD133+VEGFR-2+ + & $1.35(0.00-8.30)$ & $1.05(0.00-18.40)$ & 0.88 \\
IQ range & $0.31-3.05$ & $0.00-3.10$ & \\
CD34+CD117+VEGFR-2+ + & $2.20(0.00-12.70)$ & $2.65(0.00-55.90)$ & 0.005 \\
IQ range & $0.68-6.78$ & $0.55-6.30$ & \\
CD34+CD133-VEGFR-2+ $\dagger$ & $0.60(0.00-15.30)$ & $1.80(0.00-20.90)$ & 0.006 \\
IQ range & $0.00-1.00$ & $0.20-4.10$ & \\
CD34+CD117-VEGFR-2+ + & $0.30(0.00-12.00)$ & $1.40(0.00-60.00)$ & \\
IQ range & $0.00-1.28$ & $0.30-3.92$ &
\end{tabular}

All values are expressed as median (range). Interquartile (IQ) ranges are reported.

* Values represent the percentage of mononuclear cells.

† Values represent the percentage of CD34+ cells.

ECFCs = endothelial colony forming cells. The frequency of circulating ECFCs in cord blood was assessed for only 9 infants with BPD and 23 infants without BPD for whom cord blood was available; MNCs = mononuclear cells; BPD is defined as oxygen-dependence for at least 28 postnatal days. P values were calculated with the use of the nonparametric Mann-Whitney U-test. 
We studied several maternal and neonatal factors in order to identify possible determinants of ECFC levels in cord blood. At univariate analysis, ECFC frequency directly correlated with gestational age ( $r=0.41, \mathrm{P}=0.02$; Figure 9). Cord blood from infants with gestational age $<28$ weeks yielded significantly lower numbers of ECFCs than cord blood from infants with gestational age $>28$ weeks (median [range]: 0.00 [0.00-10.93] vs 2.20 [0.00-21.87], $\mathrm{P}=0.02$ ). No other maternal or neonatal characteristics (including antenatal steroids exposure, early-onset sepsis, gender, PDA, maternal hypertension, caesarean section, multiple pregnancy, SGA, chorioamnionitis, and white blood cell count at birth) predicted changes in the proportion of ECFCs in cord blood (data not shown).

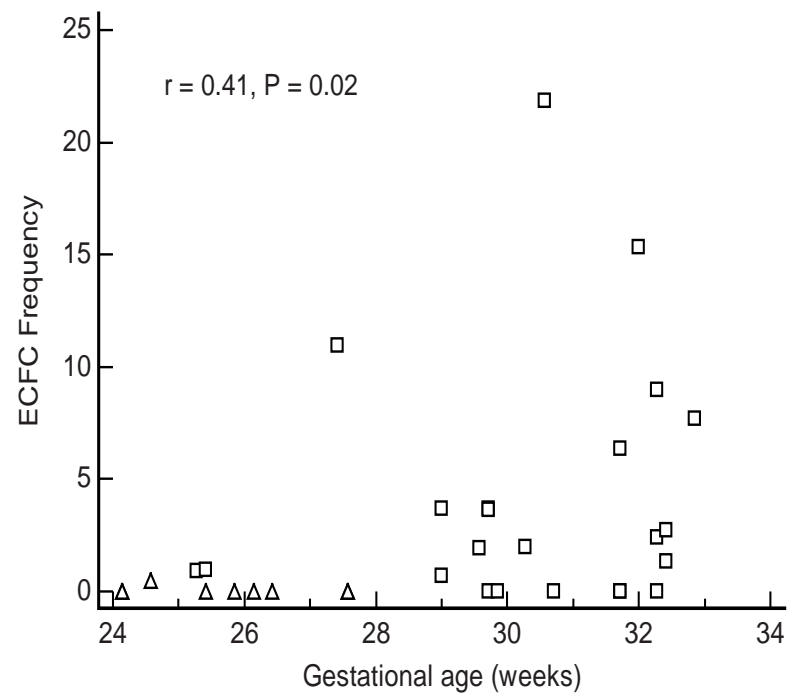

Figure 9. Correlation of endothelial colony forming cells (ECFCs) in cord blood with gestational age at birth.

Gestational age directly predicts ECFC frequencies. ECFC frequency is expressed as number of ECFCs/107 plated mononuclear cells; gestational age is expressed in weeks. Infants who subsequently developed BPD are indicated by triangles, infants without BPD are indicated by squares. BPD is defined as oxygen-dependence for at least 28 postnatal days. The number of patients shown in the graph may not correspond to that of the actual number due to overlapping of some values. The Spearman's correlation coefficient was used for correlations. $r=$ Spearman's correlation coefficient. The P value is indicated.

Lower ECFCs in cord blood are associated with the development of BPD in extremely preterm infants

To determine whether the correlation of the frequency of ECFCs with the development of BPD was an effect of gestational age, we repeated the analysis including 
only infants with gestational age $<28$ weeks at birth. Even in this small subgroup the difference remained statistically significant, and infants who developed BPD had significantly lower circulating ECFCs in cord blood at birth than infants who $\operatorname{did} \operatorname{not}(\mathrm{n}=9$ vs 3 ; median [range]: 0.00 [0.00-0.48] vs 0.92 [0.92-10.93], $\mathrm{P}=$ 0.009; Figure 8). The association of ECFCs with the development of BPD was not studied by multivariate logistic regression because too few patients could be included in the model.

\section{ECFCs and secondary outcomes}

We then studied the association of ECFC numbers with secondary outcomes and we found that infants who later developed ROP had significantly lower frequencies of ECFCs in cord blood at birth than infants who did not ( $\mathrm{n}=7$ vs 25 ; median [range]: 0.00 [0.00-0.48] vs 1.92 [0.00-21.87], $\mathrm{P}=0.01$ ), although this difference did not remain statistically significant in the subgroup of infants with gestational age $<28$ weeks ( $\mathrm{n}=7$ vs 5; median [range]: 0.00 [0.00-0.48] vs 0.92 [0.00-10.93], $\mathrm{P}$ $=0.15)$. Conversely, ECFCs were not significantly different in infants with and without PVL (P = 0.45) and IVH (P = 0.81); none of the infants for whom cord blood was available developed NEC.

CD34+ cell subsets at birth in infants who subsequently develop BPD

We used flow cytometry to investigate the percentage of distinct cell populations expressing cell surface proteins specific for the hematopoietic or the endothelial lineage in different combinations.

We first studied the correlation between the percentages of different CD34+ cell subsets at birth and the development of BPD. Both CD34+CD45- and CD34+CD45+ cells were increased at birth in infants who later developed BPD (Table 3). CD34+CD133+VEGFR-2+ triple-positive cells were comparable in infants with and without BPD, as were CD34+CD117+VEGFR-2+ cells; conversely, two cell populations (CD34+CD133-VEGFR-2+ and CD34+CD117-VEGFR-2+ cells) were reduced at birth in infants who later developed BPD (Table 3). However, the cell subsets that correlated with BPD also correlated with gestational age, and differences between infants with and without BPD did not remain significant in the subgroup of neonates with gestational age at birth $<28$ weeks (data not shown). Therefore, our data showed no correlation of any of the studied CD34+ cell subsets with the development of BPD. 
The frequency of different CD34+ cell subsets at birth does not correlate with ECFC numbers

We then analyzed the subgroup of infants for whom ECFC cultures were available to determine if any correlation exists between the percentage of different CD34+ cells and ECFC numbers. The frequency of ECFCs did not correlate with CD34+CD133+VEGFR-2+ triple-positive cells ( $\mathrm{r}=-0.12, \mathrm{P}=0.51$ ). In addition, we found no correlation between the percentages of any of the studied CD34+ cell subsets (including CD34+CD45-, CD34+CD117+VEGFR-2+, CD34+CD133-VEGFR2+, CD34+CD117-VEGFR-2+ cells, and CD34+CD45+ HPCs,) and the frequency of ECFCs (data not shown).

\section{CD34+ cell susbets and secondary outcomes}

When we assessed whether different circulating CD34+ cells correlate with the presence of other diseases of prematurity (secondary outcomes), we found that CD34+CD45+ cells were increased in infants who later developed ROP compared to infants who did not (median [range]: 0.29 [0.03-0.76] vs 0.09 [0.00-0.6], P = 0.002). Among several maternal and neonatal factors included in a multiple regression analysis to identify predictors of changes in cell counts (gestational age, antenatal steroids exposure, chorioamnionitis, early-onset sepsis, gender, PDA, maternal hypertension, caesarean section, multiple pregnancy, SGA, and white blood cell counts at birth) only gestational age independently predicted the percentage of CD34+CD45+ cells $(r=-0.34, P=0.01)$. Although infants who developed ROP had significantly lower gestational ages than infants without ROP (26.35 vs 30.28; $\mathrm{P}<0.001)$, CD34+CD45+ cells were significantly higher also in the small subgroup of neonates with gestational age at birth < 28 weeks (median [range]: 0.29 [0.12-0.76] vs 0.10 [0.05-0.38], $\mathrm{P}=0.004$ ). In addition, CD34+CD45+ cells were also increased in five infants who developed PVL compared to infants who did not (median [range]: 0.34 [0.29-0.76] vs 0.1 [0.00-0.6], $\mathrm{P}=0.002$ ). The two groups had comparable gestational age at birth. Conversely, there were no significant differences in any of the studied cell subsets between infants with and without IVH and NEC.

\section{CD34+ cell subsets during the first week of life}

We finally assessed whether preterm birth leads to changes in the proportion of circulating total CD34+ cells, of CD34+CD45+ HPCs, and of CD34+CD45- cells (the ECFC-containing cell subset) in the neonatal blood over the first week of life. Percentages of total CD34+ cells and of both CD34+CD45+ and CD34+CD45- cells were significantly lower at 48 hours of life compared to percentages at birth $(\mathrm{P}<0.001$, 
$\mathrm{P}<0.001$, and $\mathrm{P}=0.002$, respectively); at 7 days of life cell values were significantly lower than at birth $(\mathrm{P}<0.001, \mathrm{P}<0.001$, and $\mathrm{P}<0.001$, respectively) and comparable to values at 48 hours of life $(\mathrm{P}=0.43, \mathrm{P}=0.84$, and $\mathrm{P}=0.10$, respectively). These data demonstrate a rapid and stable decrease after birth of CD34+ cells due to a decrease of both the CD45+ and of the CD45- cell subpopulations.

\section{Discussion}

This is the first study showing that the more immature preterm infants that subsequently develop BPD display at birth reduced numbers of circulating EPCs assessed in cord blood by clonogenic analysis of circulating ECFCs. This finding was confirmed by the correlation of cell values with the duration of oxygen supplementation and respiratory support. Furthermore, infants with higher frequencies of ECFCs at birth were less likely to be oxygen dependent at 36 weeks' postmenstrual age.

Among several pre- and perinatal factors, gestational age was the only predictor of ECFC frequency (with lower frequencies of ECFCs at lower gestational ages). A previous study demonstrated that ECFC levels are lower in cord blood at 24-31 weeks' gestational age compared to higher gestational ages (19). A more recent study reports that cord blood from preterm infants (28-35 weeks' gestational age) yields higher numbers of ECFCs compared to cord blood from term infants (20), but samples from infants with gestational age $<28$ weeks were not included. Here we show that ECFCs in cord blood are low at extremely low gestational ages $(<28$ weeks) and are higher at higher gestational ages ( $>28$ weeks), but we did not collect cord blood from term infants for comparison. We speculate that the increase of ECFCs during a specific temporal window may contribute to the maturation of vascular beds in several districts, including the lung vascular district.

No other maternal, perinatal or neonatal characteristic (including known risk factors for BPD) predicted the frequency of circulating ECFCs, thus excluding that differences in ECFC numbers may be the byproduct of other factors.

To address whether the correlation of ECFC numbers with the development of BPD was only an effect of gestational age, we separately analyzed neonates at higher risk for developing BPD, i.e. infants with gestational age at birth $<28$ weeks. The small number of extremely preterm infants without BPD is an important limitation of our study to definitely establish a protective role of ECFCs. Nevertheless, even in this small subgroup, neonates whose cord blood yielded ECFC colonies were less likely to develop BPD than neonates without ECFCs. Thus, although not conclusively clarifying the role of EPCs in lung vascular development, our data suggest that higher circulating numbers of ECFCs in cord blood have a protective role from BPD; since the more immature infants $(<28$ weeks gestational age) are 
more likely to display lower or absent circulating ECFCs, the increased risk of extremely preterm infants to develop BPD may be linked to this finding. Accordingly, extremely preterm infants suffer from the new form of BPD (as opposed to the classic form of the disease) (1), in which impaired lung capillary development, together with alveolar simplification, is a major feature. Some infants, whose cord blood did not yield ECFCs, did not develop BPD. Since BPD is a multifactorial disease, it is possible that lack or low circulating numbers of ECFCs are not sufficient per se to determine the development of the disease. However it is of interest that all infants whose cord blood yielded ECFCs did not develop BPD (with the exception of one infant whose cord blood yielded ECFCs at a very low frequency and who developed BPD).

No relation was found between ECFC frequency and PVL or IVH, and none of the infants for whom cord blood was available developed NEC. Higher numbers of ECFCs seemed to be protective from the development of ROP, a vascular disease of the retina, although not in the subgroup of extremely premature infants $(<28$ weeks gestational age). This finding may not necessarily reflect a role of EPCs in the maturation of retinal vasculature, but rather clinical overlap among diseases, as infants with BPD are exposed to longer duration of supplemental oxygen, an important risk factor for ROP. Further data are needed to clarify this issue.

To date, no consensus has yet been reached on which is the cell surface phenotype that specifically permits to distinguish EPCs from HPCs (10). In many studies EPCs are identified by flow cytometry as triple-positive circulating CD34+CD133+ VEGFR-2+ MNCs (9). Although these triple-positive cells seem to play an important role in angiogenesis, they have been recently shown to be HPCs, while ECFCs have been demonstrated to be comprised in the CD34+CD45- fraction of circulating MNCs (21). Therefore, by flow cytometry we studied different cell subsets expressing markers of both the endothelial and hematopoietic lineages for correlation with BPD.

Neither triple-positive CD34+CD133+VEGFR-2+ cells nor CD34+CD117+ VEGFR-2+ cells correlated with the development of BPD. Although some cell populations were found to be increased, and other to be decreased in infants with BPD, these variations in cell counts were mainly an effect of gestational age, and differences did not remain significant in the subgroup of infants with gestational age at birth $<28$ weeks.

The finding of higher percentages of CD34+CD45- cells is not in contrast with the observation of lower frequencies of ECFCs in infants who developed BPD, as ECFCs probably represent only a small fraction of circulating CD34+CD45- cells. Moreover, we do not conclusively exclude a role for CD34+CD133+ VEGFR-2+ triple-positive cells in the development of BPD. Our data show that triple-positive cells are not different at birth in infants with and without BPD, suggesting that their contribution to lung vascular development during fetal life is not different in 
infants who later develop or not BPD. At present, we do not have human data to confirm or to exclude that an impairment of these cells and/or other more specific subpopulations (i.e. CD45-CD34+CD133+ VEGFR-2+ cells) are implicated in the development of BPD during later stages of the disease (e.g. in the repair of the damaged endothelium after oxygen exposure), as suggested by a mouse model of BPD (11).

Of interest, we found no correlation between any of the studied cell subset identified by FACS and the frequency of ECFCs. Similar observations have recently been reported (20). Our findings further confirm that CD34+ CD133+VEGFR-2+ triple-positive cells, although important in angiogenic processes, are probably not reflective of ECFCs, and that ECFCs are enriched in the CD34+CD45- fraction of MNCs, but probably not all CD34+CD45- cells are ECFCs.

Unexpectedly, we found that infants with ROP and PVL had significantly higher circulating proportions of CD34+CD45+ HPCs. The release of soluble growth factors able to mobilize HPCs from fetal hematopoietic organs in infants at higher risk of developing both diseases is a possible explanation for this observation; however, we did not evaluate plasma or serum factors that could corroborate this hypothesis.

Finally, we found that total CD34+ cells decrease during the first 48 hours of life, and remain stable at low levels at least during the first week of life. The decrease of total CD34+ cells was due to a decrease of both CD34+CD45+ HPCs and of the ECFC-containing CD34+CD45- fraction of MNCs. It was not possible to directly measure ECFCs in peripheral blood of preterm infants at 48 hours and at 7 days because a sufficient quantity of peripheral blood was not available for ECFC culture (minimum $5 \mathrm{ml} /$ sample). However, although total CD34+ or CD34+CD45- cells do not actually represent ECFCs, their rapid and persistent decrease after birth suggests that the physiologic increase of ECFCs with increasing postmenstrual age may be disrupted following extremely preterm birth. We speculate that the appearing or the increase of EPCs in the systemic fetal circulation may be a key developmental process, important for the maturation of lung vasculature, occurring between 24 to 30 weeks, although more frequently after 28 weeks' gestational age. Decreased EPC levels following extremely preterm birth may be associated with the persistent immaturity of lung vascular growth observed in infants with new BPD. Moreover, as suggested by recent works, oxygen exposure after preterm birth may further impair lung vascular development by directly affecting ECFC functionality in vivo (20) or by reducing the numbers of other circulating cells with angiogenic properties as CD45-CD34+CD133+VEGFR-2+ cells (11).

In conclusion, EPCs are reduced at birth in extremely premature infants who subsequently develop BPD. To the best of our knowledge, this is the first study that investigates the role of EPCs in the development of BPD in humans. The actual function of EPCs in promoting or modulating lung growth during fetal life or under 
stress conditions as after premature birth remains unknown. Further studies are needed to clarify the exact mechanism of impaired new blood vessels growth and the role of EPCs in infants with BPD. 


\section{References}

1. Bancalari E, Claure N, Sosenko IR. Bronchopulmonary dysplasia: changes in pathogenesis, epidemiology and definition. Semin Neonatol. 2003 Feb;8(1):63-71.

2. Gonzalez A, Sosenko IR, Chandar J, Hummler H, Claure N, Bancalari E. Influence of infection on patent ductus arteriosus and chronic lung disease in premature infants weighing 1000 grams or less. J Pediatr. 1996 Apr;128(4):470-8.

3. Lavoie PM, Pham C, Jang KL. Heritability of bronchopulmonary dysplasia, defined according to the consensus statement of the national institutes of health. Pediatrics. 2008 Sep;122(3):479-85.

4. Bhatt AJ, Pryhuber GS, Huyck H, Watkins RH, Metlay LA, Maniscalco WM. Disrupted pulmonary vasculature and decreased vascular endothelial growth factor, Flt-1, and TIE-2 in human infants dying with bronchopulmonary dysplasia. Am J Respir Crit Care Med. 2001 Nov 15;164(10 Pt 1):1971-80.

5. Maniscalco WM, Watkins RH, Pryhuber GS, Bhatt A, Shea C, Huyck H. Angiogenic factors and alveolar vasculature: development and alterations by injury in very premature baboons. Am J Physiol Lung Cell Mol Physiol. 2002 Apr;282(4):L811-23.

6. Thebaud B. Angiogenesis in lung development, injury and repair: implications for chronic lung disease of prematurity. Neonatology. 2007;91(4):291-7.

7. Thebaud B, Abman SH. Bronchopulmonary dysplasia: where have all the vessels gone? Roles of angiogenic growth factors in chronic lung disease. Am J Respir Crit Care Med. 2007 May 15;175(10):978-85.

8. Asahara T, Murohara T, Sullivan A, Silver M, van der Zee R, Li T, et al. Isolation of putative progenitor endothelial cells for angiogenesis. Science. 1997 Feb 14;275(5302):964-7.

9. Peichev M, Naiyer AJ, Pereira D, Zhu Z, Lane WJ, Williams M, et al. Expression of VEGFR-2 and AC133 by circulating human CD34(+) cells identifies a population of functional endothelial precursors. Blood. 2000 Feb 1;95(3):952-8.

10. Hirschi KK, Ingram DA, Yoder MC. Assessing identity, phenotype, and fate of endothelial progenitor cells. Arterioscler Thromb Vasc Biol. 2008 Sep;28(9):1584-95.

11. Balasubramaniam V, Mervis CF, Maxey AM, Markham NE, Abman SH. Hyperoxia reduces bone marrow, circulating, and lung endothelial progenitor cells in the developing lung: implications for the pathogenesis of bronchopulmonary dysplasia. Am J Physiol Lung Cell Mol Physiol. 2007 May;292(5):L1073-84.

12. Jobe AH, Bancalari E. Bronchopulmonary dysplasia. Am J Respir Crit Care Med. 2001 Jun;163(7):1723-9.

13. Walsh MC, Szefler S, Davis J, Allen M, Van Marter L, Abman S, et al. Summary proceedings from the bronchopulmonary dysplasia group. Pediatrics. 2006 Mar;117(3 Pt 2):S52-6.

14. Walsh MC, Kliegman RM. Necrotizing enterocolitis: treatment based on staging criteria. Pediatr Clin North Am. 1986 Feb;33(1):179-201.

15. An international classification of retinopathy of prematurity. Prepared by an international committee. Br J Ophthalmol. 1984 Oct;68(10):690-7.

16. Papile LA, Burstein J, Burstein R, Koffler H. Incidence and evolution of subependymal and intraventricular hemorrhage: a study of infants with birth weights less than 1,500 gm. J Pediatr. 1978 Apr;92(4):529-34.

17. The CRIB (clinical risk index for babies) score: a tool for assessing initial neonatal risk and comparing performance of neonatal intensive care units. The International Neonatal Network. Lancet. 1993 Jul 24;342(8865):193-8.

18. Ingram DA, Mead LE, Tanaka H, Meade V, Fenoglio A, Mortell K, et al. Identification of a novel hierarchy of endothelial progenitor cells using human peripheral and umbilical cord blood. Blood. 2004 Nov 1;104(9):2752-60. 
19. Javed MJ, Mead LE, Prater D, Bessler WK, Foster D, Case J, et al. Endothelial colony forming cells and mesenchymal stem cells are enriched at different gestational ages in human umbilical cord blood. Pediatr Res. 2008 Jul;64(1):68-73.

20. Baker CD, Ryan SL, Ingram DA, Seedorf GJ, Abman SH, Balasubramaniam V. Endothelial Colony Forming Cells from Preterm Infants are Increased and More Susceptible to Hyperoxia. Am J Respir Crit Care Med. 2009 May 29.

21. Case J, Mead LE, Bessler WK, Prater D, White HA, Saadatzadeh MR, et al. Human CD34+AC133+VEGFR-2+ cells are not endothelial progenitor cells but distinct, primitive hematopoietic progenitors. Exp Hematol. 2007 Jul;35(7):1109-18. 



\section{Chapter 4. Different subsets of circulating angiogenic cells do not predict bronchopulmonary dysplasia or other diseases of prematurity in preterm infants}

Borghesi A, Massa M, Campanelli R, Garofoli F, Longo S, Cabano R, Mazzucchelli I, Tzialla C, Gavilanes AWD, Gazzolo D, Manzoni P, Bollani L, Spinillo A, Rosti V, Stronati M. Int J Immunopathol Pharmacol. 2013 Jul-Sep;26(3):809-16. 


\begin{abstract}
Bronchopulmonary dysplasia (BPD) is a chronic lung disease occurring in very and extremely preterm infants undergoing mechanical ventilation. Given the altered lung vascular growth characterizing BPD, circulating angiogenic cells could be useful biomarkers to predict the risk. The objective of the study was to determine whether the percentages of circulating angiogenic cells (CD34+VEGFR-2+, CD34+CD133+VEGFR-2+, and CD45-CD34+CD133+VEGFR-2+ cells), assessed in the peripheral blood at birth by flow cytometry, could be used as markers of the risk of BPD. In one-hundred and forty-two preterm neonates (gestational age $<32$ weeks and/or birth weight $<1500 \mathrm{~g}$ ) admitted to our tertiary care Neonatal Intensive Care Unit between 2006 and 2009, we evaluated the percentages of circulating angiogenic cells at birth, at 7 days, and, in a subset of infants $(n=40)$, at 28 days of life. The main outcome was the correlation between cell counts at birth and the subsequent risk of developing BPD. In our study, all the three cell populations failed to predict the development of BPD or other diseases of prematurity. We suggest that these cells cannot be used as biomarkers in preterm infants, and that research is needed to find other early predictors of BPD.
\end{abstract}




\section{Introduction}

Bronchopulmonary dysplasia (BPD) is a chronic, severe, and often invalidating lung disease of preterm infants characterized by arrested alveolar and lung vascular growth (1), leading to chronic need of oxygen supplementation until late in infancy and detrimental consequences on lung function and neurodevelopment in older children and adults.

Not all very or extremely preterm infants develop BPD. It is well known that some risk factors may increase the risk, but, to date, it is still unexplained why some infants develop BPD and others do not. The identification of an early marker to predict the risk is a major challenge.

Arrested vascular growth, one of the hallmarks of BPD, strongly contributes to the clinical outcome in preterm neonates. Experimental (2) and initial clinical data (3) suggest that circulating angiogenic cells may also be involved in the pathogenesis of BPD.

Circulating double positive CD34+VEGFR-2+ and triple positive CD34+ CD133+VEGFR-2+ mononuclear cells are thought to be angiogenic cells of hematopoietic origin able to promote angiogenic processes (4-7). Indeed, in clinical observational studies, these cell populations have been demonstrated to correlate with a number of diseases with a major vascular component, including cardiovascular disease, systemic sclerosis, and idiopathic myelofibrosis (8-11). More specifically for BPD, mouse CD45-Sca-1+CD133+VEGFR-2+ cells were found to be decreased, in an experimental model of BPD (2). We speculated that the same three populations of cells could be implicated in lung vascular development, and that levels at birth could represent a biomarker of angiogenesis that may predict the risk of developing BPD in preterm infants.

We previously found no correlation between CD34+CD133+VEGFR-2+ cells and the development of BPD in a cohort of ninety-eight preterm infants (3). Here we present incremental data of a previously reported cohort, and definitely demonstrate the lack of association between the three above mentioned cell populations and the risk of BPD in preterm infants.

\section{Materials and methods}

\section{Study population and study design}

Infants were included if they had gestational age $<32$ weeks and/or birth weight $<$ $1500 \mathrm{~g}$, admitted within the first three hours of life to our single tertiary care neonatal intensive care unit at the Fondazione IRCCS Policlinico San Matteo di Pavia (Italy). Exclusion criteria were lack of parental informed consent, presence of 
known congenital/chromosomal abnormalities, and first blood sample not collected within the first three hours of life. The years of recruitment were 2006-2009.

Four infants died before 28 days of life, before diagnosis of BPD could be established, and before cystic PVL could be conclusively ruled out. Thirty-five infants (of which 3 died before 28 days of life) were excluded from the study because of lack of parental informed consent (1 infant), presence of known congenital/chromosomal abnormalities ( 1 infant), and first blood sample not collected within the first three hours of life (33 infants).

The final cohort consisted of ninety-eight preterm infants included in a previous study (3), together with forty-four newly recruited infants. The percentages of triple positive CD34+CD133+VEGFR-2+ cells at birth had been already reported for the ninety-eight infants included in the previous study (3). In these patients, flow cytometric data were retrospectively analyzed for other two cell populations, namely CD34+VEGFR-2+ and CD45-CD34+CD133+ VEGFR-2+ cells. The newly recruited neonates were studied for all the three cell populations at birth (within the first 3 hours of life), at 7 days, and at 28 days of life. A total of one hundred and forty-two preterm neonates were studied for the three cell populations at birth and 7 days of life; for a subset of infants $(n=40)$, data of cell values at 28 days of life were also available.

The study protocol was approved by the Ethic Committee of the Institution. Written parental informed consent was obtained before blood collection according to the Declaration of Helsinki. Peripheral blood samples were never more abundant than $400 \mu \mathrm{l}$, and were obtained during routine withdrawal for blood count.

The primary outcome was the association of baseline cell numbers with the development of BPD. BPD was defined as oxygen dependence for at least 28 postnatal days and graded at 36 weeks' postmenstrual age according to the fraction of inspired oxygen $\left(\mathrm{FiO}_{2}\right)$ and the requirement of respiratory support at this time: mild BPD was diagnosed if the infant was in room air, moderate BPD if the $\mathrm{FiO}_{2}$ was 0.22-0.29 and severe $\mathrm{BPD}$ if the $\mathrm{FiO}_{2}$ was $\geq 0.30$ or the infant was receiving respiratory support $(12,13)$.

Other diseases of prematurity share common risk factors and common pathogenic mechanisms with BPD. Thus, to further understand the role of these cells in neonatal and fetal biology, we studied, as secondary outcomes, the association of cell numbers at birth with the development of necrotizing enterocolitis (NEC) (14), retinopathy of prematurity (ROP) (15), early- and late-onset sepsis, patent ductus arteriosus (PDA), intraventricular hemorrhage (IVH) (16), and cystic periventricular leukomalacia (PVL).

Infant and maternal medical records were reviewed for pregnancy and delivery characteristics and for clinical data and outcomes. Cranial ultrasound imaging was routinely obtained within the first 24 hours of admission for all infants. Subsequently, serial cranial ultrasound examinations were carried out weekly until 31 
weeks postmenstrual age, and at 36 and 40 weeks postmenstrual age for all infants, or when clinically indicated; infants with gestational age $<27$ weeks had an additional cranial ultrasound at 48-72 hours. The same protocol had been used for the ninety-eight infants included in the previous study. Cystic periventricular leukomalacia (PVL) was defined as echodensity in the white matter dorsal and lateral to the lateral ventricles with evolution into echolucent cysts. Intraventricular haemorrhage (IVH) was graded according to Papile et al. (16). PDA was diagnosed by echocardiogram. The clinical risk index for babies (CRIB) score, for the prediction of neonatal mortality and morbidity, was calculated as previously described (17). The diagnosis of early-onset sepsis (within the first 72 hours of life) and lateonset sepsis (after the first 72 hours of life), was based on signs of infection accompanied by abnormal laboratory studies and/or positive cultures.

\section{Flow cytometry}

The percentages of circulating cell populations were assessed by flow cytometry (Figure 10 for one representative patient). The staining procedure was performed in all the neonates on 50 $\mu$ l of EDTA-whole blood samples. The isotype control was performed staining the blood cells with $5 \mu$ l of FITC-IgG1, biotin-conjugated-IgG1 revealed with PerCp-streptavidin, PE-IgG1, and APC-IgG1. An additional blood sample was stained with FITC-anti-CD34 antibody, biotin-conjugated-IgG1 revealed with PerCp-streptavidin, PE-IgG1, and APC-IgG1; this tube allowed to electronically gate the CD34+ cells to be analysed in a PE-IgG1 versus PerCP-IgG1 dot plot. The percentage of CD34+CD133+ VEGFR-2+CD45- cells was then evaluated by staining the blood sample with $10 \mu \mathrm{l}$ of fluorescein-conjugated (FITC)-antiCD34 (Becton Dickinson Pharmingen, San Josè, CA), $6 \mu \mathrm{l}$ of biotin-conjugated-antiVEGFR-2 (Sigma Chemical, St Louis, MO) revealed using peridinin-chlorophyllprotein (PerCp)-streptavidin (Becton Dickinson Pharmingen, San Josè, CA), $5 \mu \mathrm{l}$ of phycoerythrin-conjugated (PE)-anti-CD133 (Miltenyi Biotec, Bergisch Gladbach, Germany) (Becton Dickinson Pharmingen, San Josè, CA), and $5 \mu$ of allophycocyanin-conjugated (APC)-anti-CD45 (Becton Dickinson Pharmingen, San Josè, CA). All the incubation with monoclonal antibodies were performed in ice for 30 minutes. After red cell lysis $(8.3 \mathrm{~g} / \mathrm{l} \mathrm{NH} 4 \mathrm{Cl}, 1 \mathrm{~g} / \mathrm{l} \mathrm{KHCO3}, 0.04 \mathrm{~g} / \mathrm{l}$ EDTANa2, $\mathrm{pH} 7.3)$ the samples were centrifuged and the pellets resuspended in $300 \mu$ of phosphate buffer with $0.5 \%$ of fetal calf serum (FCS). Seven x $10^{5}$ cells were acquired by flow cytometer (FACScanto Becton Dickinson), and analysed by Diva software (BD Biosciences).

The percentage of CD34+VEGFR-2+ cells was calculated on electronically gated mononuclear cells. Differently, the evaluation of CD34+CD133+VEGFR-2+, and CD45-CD34+CD133+VEGFR-2+ cells was calculated as percentage of electronically gated CD34+ cells as shown for one representative patient (Figure 10). 
The cytofluorimeter is validated according to the UKNECAS external quality control for leukocyte immunophenotyping. The percentage of positive cells was obtained by subtracting the value of the appropriate isotype controls.

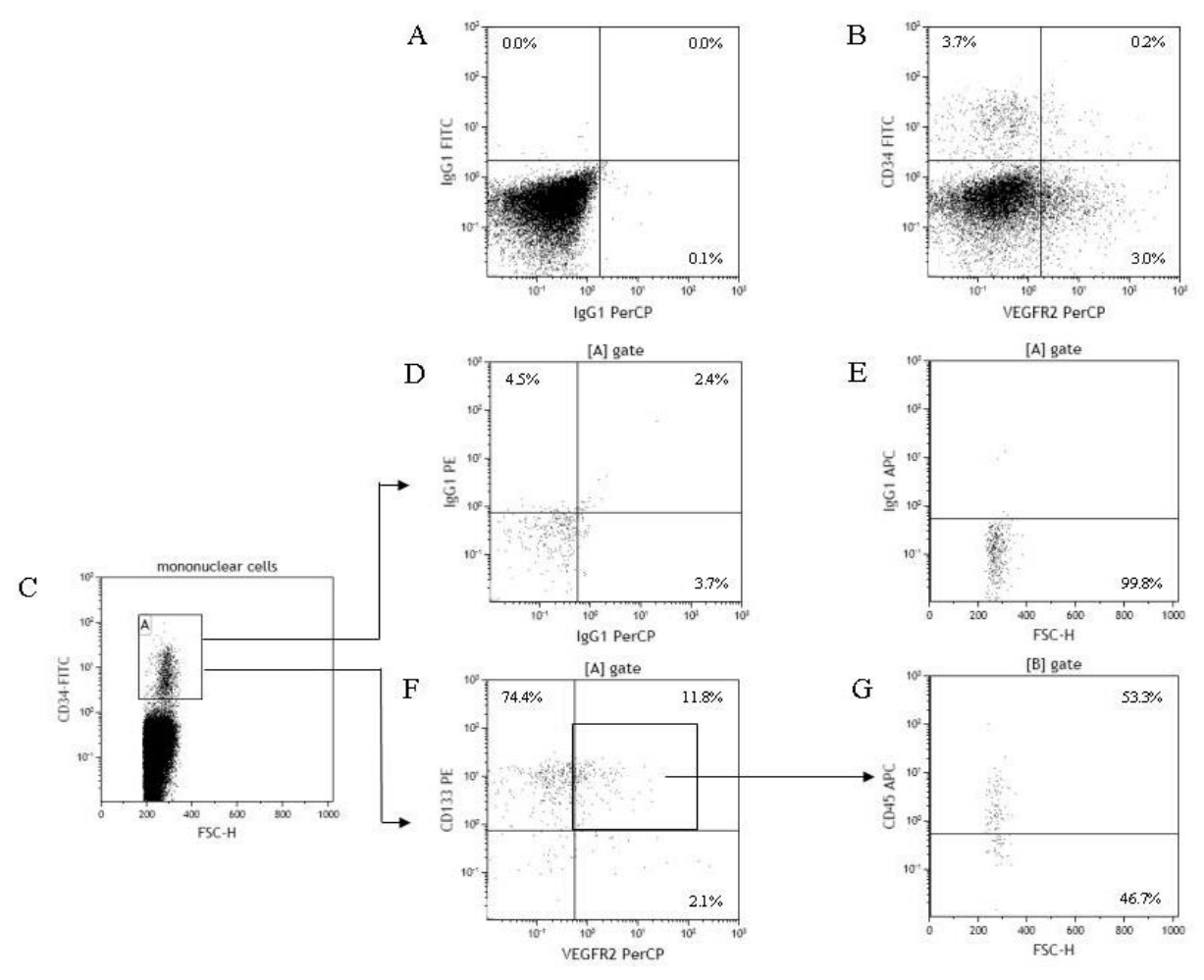

Figure 10. One representative example of the gating strategy for assessment of the percentages of CD34+VEGFR-2+, CD34+CD133+VEGFR-2+, and CD45-CD34+CD133+VEGFR-2+ cells.

\section{Statistical analysis}

The frequencies of parametric and nonparametric continuous variables are reported as mean \pm standard deviation (SD) and median and range, respectively. Categorical variables are described by count and relative frequency (\%). Comparison between groups of continuous parametric and nonparametric variables was carried out using the Student's t-test for independent samples and the nonparametric Mann-Whitney U-test, respectively. Categorical variables were compared between groups using the Fisher's exact test. The Spearman's correlation coefficient was used for univariate correlations.

Analysis of correlation of cell percentages with clinical outcomes (diseases of prematurity) was performed excluding infants dead before 28 days of life (that is, on a 
population of one-hundred and thirty-eight infants); correlation of cell percentages at birth with perinatal factors, CRIB score, white blood cell counts at birth, erythroblasts at birth, and mortality, was performed on the entire population of onehundred and forty-two infants. A P value $<0.05$ was considered statistically significant for all analyses. All analyses were performed using MedCalc ${ }^{\circledR}$ v9.5.1.0 software.

\section{Results}

\section{Lack of correlation between cell populations and clinical outcomes}

Maternal, perinatal, and neonatal characteristics of the study infants are reported in Table 4. We first analyzed whether circulating levels of CD34+ VEGFR-2+, CD34+CD133+VEGFR-2+, and CD45-CD34+CD133+VEGFR-2+ cells at birth correlate with the subsequent development of BPD or other diseases of prematurity.

At univariate analysis, CD34+VEGFR-2+, CD34+CD133+VEGFR-2+, and CD45CD34+CD133+VEGFR-2+ cell counts were comparable in infants with and without $\mathrm{BPD}(\mathrm{P}=0.91, \mathrm{P}=0.71$, and $\mathrm{P}=0.71$, respectively; Figure 11).

When infants with no BPD where analyzed together with infants with mild BPD and compared to infants with moderate-to-severe BPD, we found no significant differences in cell percentages between the two groups $(\mathrm{P}=0.56, \mathrm{P}=0.45$, and $\mathrm{P}=0.77$; Figure 11).

Similarly, no correlation was found between cell percentages and any disease of prematurity, including cystic PVL, IVH, ROP, NEC, early- or late-onset sepsis, or PDA (Data not shown).

\section{Cell populations and maternal/perinatal factors}

We then asked whether a correlation existed between cell percentages at birth and the presence of perinatal factors, some of which are known to influence the development of BPD. In our study, circulating levels of CD34+VEGFR-2+, CD34+CD133+ VEGFR-2+, and CD45-CD34+CD133+VEGFR-2+ cells at birth did not correlate with the presence of maternal hypertension, chorioamnionitis, gestational age and birth weight, gender, multiple pregnancy, cesarean section, and small for gestational age; only a slight increase in triple-positive CD34+CD133+VEGFR-2+ cells but not CD34+VEGFR-2+ and CD45-CD34+CD133+VEGFR-2+ cells was observed in infants who had received antenatal steroids. Further, we found no correlation between CD34+CD133+ VEGFR-2+ and CD45-CD34+CD133+VEGFR-2+ cells and white blood cell counts at birth, and only a small correlation was found between CD34+ VEGFR-2+ and white blood cell counts at birth (Data not shown). 

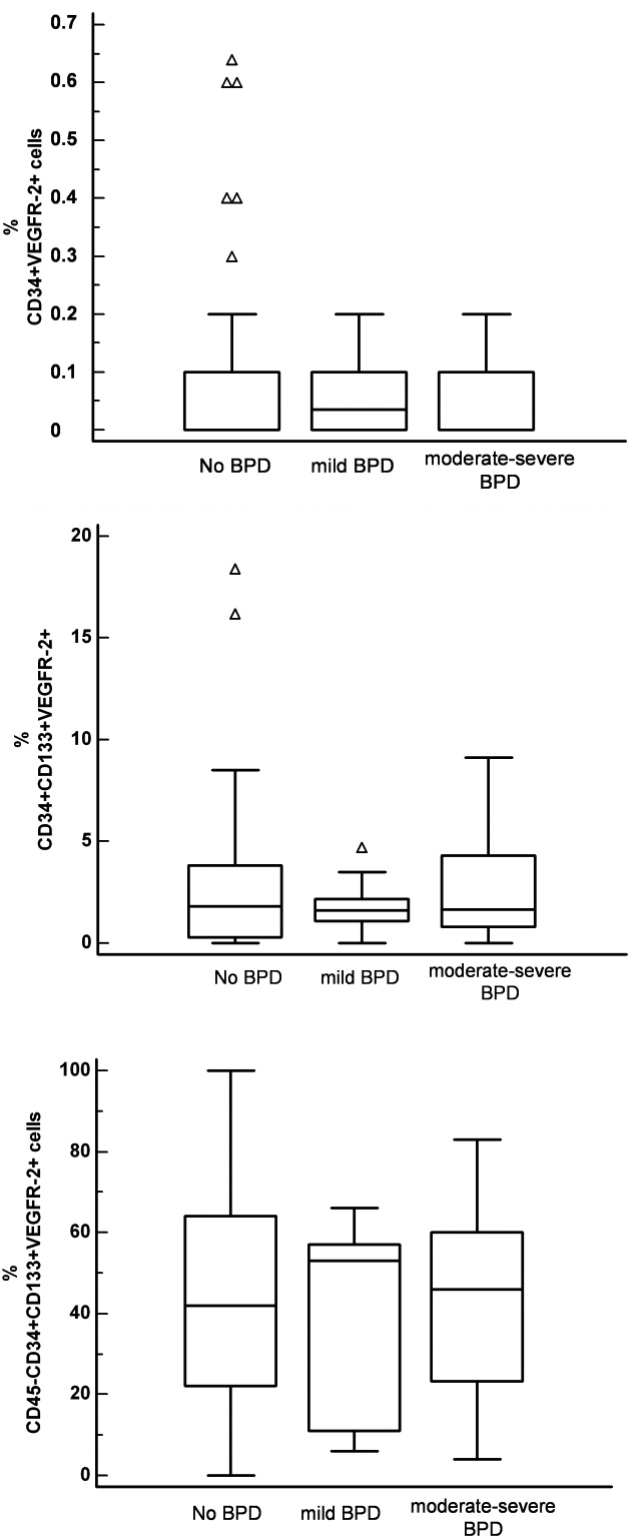

Figure 11. CD34+VEGFR-2+, CD34+CD133+VEGFR-2+, and CD45-CD34+CD133+VEGFR-2+ cells in infants without BPD and in infants with mild or moderatesevere BPD. 
Table 4. Maternal, perinatal, and neonatal characteristics of the study infants.

\begin{tabular}{|c|c|c|c|c|}
\hline Characteristic & $\begin{array}{c}\text { All } \\
\mathrm{n}=142\end{array}$ & $\begin{array}{c}\text { BPD } \\
38(27.5)\end{array}$ & $\begin{array}{c}\text { No BPD } \\
100(72.5)\end{array}$ & $\begin{array}{c}\text { BPD vs no BPD } \\
\text { P value* }\end{array}$ \\
\hline Gestational age - wk, mean \pm SD & $29.1 \pm 2.6$ & $26.5 \pm 1.9$ & $30.3 \pm 1.9$ & $<0.001$ \\
\hline Birth weight, g, mean \pm SD & $1146.3 \pm 392.5$ & $762.5 \pm 223.7$ & $1308.9 \pm 329.9$ & $<0.001$ \\
\hline \multicolumn{5}{|l|}{ Mode of delivery } \\
\hline Cesarean section/Vaginal delivery & $105(73.9) / 37$ (26.1) & $26(68.4) / 12(31.6)$ & $76(76.0) / 24(24.0)$ & 0.43 \\
\hline Gestational diabetes mellitus & $10(7.0)$ & $4(10.5)$ & $6(6.0)$ & 0.59 \\
\hline Maternal hypertension & $42(29.6)$ & $11(28.9)$ & $30(30.0)$ & 0.93 \\
\hline Chorioamnionitis & $33(23.2)$ & $16(42.1)$ & $17(17.0)$ & 0.02 \\
\hline Antenatal steroids & $99(69.7)$ & $29(76.3)$ & $67(67.0)$ & 0.39 \\
\hline Gender, Male/Female & $89(62.7) / 53(37.3)$ & $25(65.8) / 13(34.2)$ & $62(62.0) / 38(38.0)$ & 0.83 \\
\hline SGA & $37(26.1)$ & $11(28.9)$ & $24(24.0)$ & 0.71 \\
\hline CRIB score, median (range) † & $1.0(0-14)$ & $7(1-14)$ & $1.0(0-6)$ & $<0.001$ \\
\hline PDA & $33(23.2)$ & $18(47.4)$ & $13(13.0)$ & $<0.001$ \\
\hline Early-onset sepsis & $3(2.1)$ & $1(2.6)$ & $2(2.0)$ & 0.67 \\
\hline NEC & $12(8.5)$ & $2(5.3)$ & $10(10.0)$ & 0.58 \\
\hline IVH: grade I-IV & $21(14.8)$ & $12(31.6)$ & $8(8.0)$ & 0.001 \\
\hline PVL & $7(4.9)$ & $5(13.2)$ & $2(2.0)$ & 0.03 \\
\hline ROP & 28 (19.7) & $23(60.5)$ & $5(5.0)$ & $<0.001$ \\
\hline Mortality & $4(2.8)$ & $1(2.6)$ & $3(3.0)$ & 0.13 \\
\hline Post-natal steroids $\ddagger$ & $16(11.3)$ & $16(42.1)$ & 0 & $<0.001$ \\
\hline $\mathrm{FiO}_{2}$, median (range) & $0.21(0.21-0.35)$ & $0.25(0.21-0.35)$ & $0.21(0.21-0.21)$ & $<0.001$ \\
\hline Oxygen, days, median (range) & $2(0-230)$ & $71(32-230)$ & $1(0-47)$ & $<0.001$ \\
\hline n-CPAP, days, median (range) & $0(0-68)$ & $29(1-68)$ & $2(0-40)$ & $<0.001$ \\
\hline MV, days, median (range) & $2(0-54)$ & $13(0-54)$ & $0(0-6)$ & $<0.001$ \\
\hline WBC $\times 10^{9} / \mathrm{l}$, median (range) & $11.7(1.5-101.0)$ & $8.0(2.8-74.6)$ & $8.4(1.5-101.0)$ & 0.92 \\
\hline
\end{tabular}

Values represent number (\%) unless otherwise specified.

When infants with BPD were compared to infants without BPD, neonates dead before 28 days of life were excluded from the analysis.

*The 2 groups (BPD and no BPD) were compared by using the Student's t-test for independent samples, the MannWhitney test, or the Fisher's exact test. BPD is defined as oxygen-dependence for at least 28 postnatal days.

† The CRIB score ranges from 0 to 23, with higher scores indicating higher neonatal risk.

‡ The number (\%) of infants receiving postnatal steroids is indicated. Dexamethasone or methylprednisolone were used, and always administered after the $3^{\text {rd }}$ week of life.

Definitions of abbreviations: BPD = bronchopulmonary dysplasia; SGA = small for gestational age; $\mathrm{CRIB}=$ clinical risk index for babies; PDA = patent ductus arteriosus; $\mathrm{NEC}=$ necrotizing enterocolitis; $\mathrm{IVH}=$ intraventricular hemorrhage; $\mathrm{PVL}=$ cystic periventricular leukomalacia; $\mathrm{ROP}=$ retinopathy of prematurity; $\mathrm{FiO}_{2}=$ fraction of inspired oxygen (the value represents $\mathrm{FiO}_{2}$ at 36 weeks' postmenstrual age); n-CPAP = nasal continuous positive airway pressure; $\mathrm{MV}=$ mechanical ventilation; $\mathrm{wk}=$ weeks; $\mathrm{WBC}=$ white blood cells count at birth. 


\section{Cell populations and severity of the clinical conditions}

In order to determine whether the three cell populations may represent a marker of severity of the clinical conditions of preterm infants, we studied the cell percentages for correlation with the CRIB score, erythroblast counts at birth (a marker of illness severity), and mortality risk. However, we did not detect any correlation between these variables and cell percentages (Data not shown).

\section{Cell populations after the first week of life}

When we analyzed the counts of the three cell populations at 7 days and, in a subset of infants ( $n=40,14$ with BPD and 26 without BPD), at 28 days of life, we found no association with BPD or with the risk of any other disease of prematurity (data not shown). Importantly, cell percentages at 28 days of life did not correlate with FiO2 values at 28 days $(\mathrm{r}=0.08, \mathrm{P}=0.59 ; \mathrm{r}=0.03, \mathrm{P}=0.66$; and $\mathrm{r}=0.138, \mathrm{P}=0.43$, for the three cells populations) or at 36 weeks postmenstrual age ( $\mathrm{r}=-0.17, \mathrm{P}=0.24$; $\mathrm{r}=$ -0.11, $\mathrm{P}=0.44$; and $\mathrm{r}=0.18, \mathrm{P}=0.28$ ), and were not different in infants exposed to oxygen for more than 15 days compared to infants exposed to oxygen for less than 15 days $(\mathrm{P}=0.63, \mathrm{P}=0.50$, and $\mathrm{P}=0.37)$.

\section{Discussion}

We studied, by flow cytometry, the percentages at birth, at 7 days and at 28 days of life, of three circulating cell populations of hematopoietic progenitors with angiogenic properties in preterm infants, for correlation with BPD, a pulmonary disease of the premature infant characterized by impaired lung vascular development; in our study we did not find any correlation between the enumerated cell populations and BPD or any other disease associated with premature birth.

We chose to study CD34+VEGFR-2+ and CD34+CD133+VEGFR-2+ cells, because both cells had been previously associated with diseases with vascular dysfunction (8-10), and had been proposed as biomarkers of cardiovascular risk (18). In addition, the mouse counterpart of CD45-CD34+CD133+VEGFR-2+ cells was demonstrated to be reduced in circulating blood of neonatal mice after exposure to oxygen (2). In an attempt to identify early predictors of BPD, we correlated cell percentages at birth with the subsequent risk of developing BPD. Indeed, BPD is characterized by dysmorphic vascular changes $(19,20)$, and circulating angiogenic cells may be implicated in pulmonary angiogenesis.

However, CD34+VEGFR-2+, CD34+CD133+VEGFR-2+, and CD45-CD34+CD133 +VEGFR-2+ cells at birth identified with our flow cytometry protocol failed to predict the risk of BPD. This finding is in agreement with our previous report on a 
lower number of patients (3) and with a recent report (21). Other polychromatic flow cytometry protocols (PFC) may be more useful for the identification and enumeration of specific cell populations directly involved in lung vascular development $(22,23)$. Interestingly, a recent clinical study by Baker et al. conducted using this novel PFC protocol showed a significantly lower ratio of angiogenic circulating progenitors to non-angiogenic circulating progenitors in cord blood samples of preterm infants who subsequently developed moderate or severe BPD (24).

Further, the three cell populations do not seem to be implicated in the pathogenesis of any outcome or neonatal disease of prematurity and are not influenced by perinatal factors.

In conclusion, CD34+VEGFR-2+, CD34+CD133+VEGFR-2+, and CD45-CD34+ CD133+VEGFR-2+ cells at birth failed to predict the subsequent development of BPD or any other disease of prematurity, and we discourage further studies. Research is needed to find other markers or predictors able to early identify infants at risk of BPD. Our study also underlines the importance of human studies (as opposed to animal studies) to understand the pathogenesis of BPD and to improve its clinical management. 


\section{References}

1. Bancalari E, Claure N, Sosenko IR. Bronchopulmonary dysplasia: changes in pathogenesis, epidemiology and definition. Semin Neonatol. 2003 Feb;8(1):63-71.

2. Balasubramaniam V, Mervis CF, Maxey AM, Markham NE, Abman SH. Hyperoxia reduces bone marrow, circulating, and lung endothelial progenitor cells in the developing lung: implications for the pathogenesis of bronchopulmonary dysplasia. Am J Physiol Lung Cell Mol Physiol. 2007 May;292(5):L1073-84.

3. Borghesi A, Massa M, Campanelli R, Bollani L, Tzialla C, Figar TA, et al. Circulating endothelial progenitor cells in preterm infants with bronchopulmonary dysplasia. Am J Respir Crit Care Med. 2009 Sep 15;180(6):540-6.

4. Hirschi KK, Ingram DA, Yoder MC. Assessing identity, phenotype, and fate of endothelial progenitor cells. Arterioscler Thromb Vasc Biol. 2008 Sep;28(9):1584-95.

5. Prater DN, Case J, Ingram DA, Yoder MC. Working hypothesis to redefine endothelial progenitor cells. Leukemia. 2007 Jun;21(6):1141-9.

6. Yoder MC, Ingram DA. The definition of EPCs and other bone marrow cells contributing to neoangiogenesis and tumor growth: is there common ground for understanding the roles of numerous marrow-derived cells in the neoangiogenic process? Biochim Biophys Acta. 2009 Aug;1796(1):504.

7. Case J, Mead LE, Bessler WK, Prater D, White HA, Saadatzadeh MR, et al. Human CD34+AC133+VEGFR-2+ cells are not endothelial progenitor cells but distinct, primitive hematopoietic progenitors. Exp Hematol. 2007 Jul;35(7):1109-18.

8. Werner N, Kosiol S, Schiegl T, Ahlers P, Walenta K, Link A, et al. Circulating endothelial progenitor cells and cardiovascular outcomes. N Engl J Med. 2005 Sep 8;353(10):999-1007.

9. Massa M, Rosti V, Ferrario M, Campanelli R, Ramajoli I, Rosso R, et al. Increased circulating hematopoietic and endothelial progenitor cells in the early phase of acute myocardial infarction. Blood. 2005 Jan 1;105(1):199-206.

10. Massa M, Rosti V, Ramajoli I, Campanelli R, Pecci A, Viarengo G, et al. Circulating CD34+, CD133+, and vascular endothelial growth factor receptor 2-positive endothelial progenitor cells in myelofibrosis with myeloid metaplasia. J Clin Oncol. 2005 Aug 20;23(24):5688-95.

11. Avouac J, Meune C, Ruiz B, Couraud PO, Uzan G, Boileau C, et al. Angiogenic biomarkers predict the occurrence of digital ulcers in systemic sclerosis. Ann Rheum Dis. 2012 Mar;71(3):394-9.

12. Jobe AH, Bancalari E. Bronchopulmonary dysplasia. Am J Respir Crit Care Med. 2001 Jun;163(7):1723-9.

13. Walsh MC, Szefler S, Davis J, Allen M, Van Marter L, Abman S, et al. Summary proceedings from the bronchopulmonary dysplasia group. Pediatrics. 2006 Mar;117(3 Pt 2):S52-6.

14. Walsh MC, Kliegman RM. Necrotizing enterocolitis: treatment based on staging criteria. Pediatr Clin North Am. 1986 Feb;33(1):179-201.

15. An international classification of retinopathy of prematurity. Prepared by an international committee. Br J Ophthalmol. 1984 Oct;68(10):690-7.

16. Papile LA, Burstein J, Burstein R, Koffler H. Incidence and evolution of subependymal and intraventricular hemorrhage: a study of infants with birth weights less than 1,500 gm. J Pediatr. 1978 Apr;92(4):529-34.

17. The CRIB (clinical risk index for babies) score: a tool for assessing initial neonatal risk and comparing performance of neonatal intensive care units. The International Neonatal Network. Lancet. 1993 Jul 24;342(8865):193-8.

18. Rosenzweig A. Circulating endothelial progenitors--cells as biomarkers. N Engl J Med. 2005 Sep 8;353(10):1055-7. 
19. Thebaud B, Abman SH. Bronchopulmonary dysplasia: where have all the vessels gone? Roles of angiogenic growth factors in chronic lung disease. Am J Respir Crit Care Med. 2007 May 15;175(10):978-85.

20. Abman SH. The dysmorphic pulmonary circulation in bronchopulmonary dysplasia: a growing story. Am J Respir Crit Care Med. 2008 Jul 15;178(2):114-5.

21. Paviotti G, Fadini GP, Boscaro E, Agostini C, Avogaro A, Chiandetti L, et al. Endothelial progenitor cells, bronchopulmonary dysplasia and other short-term outcomes of extremely preterm birth. Early Hum Dev. 2011 Jul;87(7):461-5.

22. Estes ML, Mund JA, Ingram DA, Case J. Identification of endothelial cells and progenitor cell subsets in human peripheral blood. Curr Protoc Cytom. 2010 Apr;Chapter 9:Unit 933 1-11.

23. Mund JA, Estes ML, Yoder MC, Ingram DA, Jr., Case J. Flow Cytometric Identification and Functional Characterization of Immature and Mature Circulating Endothelial Cells. Arterioscler Thromb Vasc Biol. 2012 Jan 26.

24. Baker CD, Balasubramaniam V, Mourani PM, Sontag MK, Black CP, Ryan SL, et al. Cord blood angiogenic progenitor cells are decreased in bronchopulmonary dysplasia. Eur Respir J. 2012 Dec;40(6):1516-22. 



\section{Valorisation: ECFCs for early prediction of BPD}

The works reported in chapters 3 and 4 identify circulating endothelial colony forming cells (ECFCs), an endothelial progenitor cell population, as a biomarker for bronchopulmonary dysplasia (BPD), a disease of preterm infants whose pulmonary and extra-pulmonary consequences may last all life long.

RELEVANCE. In the field of neonatology, as in other fields of medicine, tools for early, reliable and reproducible diagnosis or prediction of diseases as well as prognostic stratification and prediction of long term sequelae are fundamental for decision taking in clinical practice. With an accurate and reliable biomarker, physicians can confirm their therapeutic choices and inform patients during counselling, reporting robust data to justify their clinical decision.

TARGET GROUPS. The biomedical science and the clinical practice are moving towards the delivery of an individualized medicine, in which therapeutic choices are personalized for single patients. Therefore, should a biomarker work and be validated for clinical use, clinicians could take advantage from it, for instance, during the decision process about drugs to use (e.g. corticosteroids) or about the selection of patients for novel treatments (e.g. stem cells) to be used in clinical practice or in clinical trials. This would be a direct benefit for families of preterm infants too: medical counselling with parents could be facilitated, and the communication of the clinical decisions will rely not only on the clinical experience of the attending physician and on his/her feeling that the clinical conditions are predictive of long term outcomes, but also on measurable and objective markers.

INNOVATION. Currently, there is no way to predict the development of BPD at birth. The risk of BPD may be statistically estimated on the basis of few clinical data, but this statistics-based tool becomes more accurate some days after birth when disease changes are already established. A laboratory biomarker for prediction of BPD at birth does not exist and is needed.

ACTIVITIES/PRODUCTS. Although ECFCs do not seem, so far, to be sufficient to predict BPD, data from the literature suggest that a combination of clinical data, 
circulating growth factors (e.g. VEGF, known from clinical and experimental studies to be altered in BPD) together with changes in ECFCs at birth, and, possibly, with data from high throughput tools (next generation sequencing, metabolomics) may allow the development of a "biomarker profile", predictive for the development of BPD in single individuals.

SCHEDULE and IMPLEMENTATION. To achieve the ambitious goal of a biomarker profile predictive of premature infants at risk for short and long-term morbidity and mortality associated with BPD, much work is needed. The inclusion of ECFC in the biomarker profile will require additional studies to define the appropriate timing, collection, and processing of samples to measure cytokines and growth factors and to analyze cells for the consistent identification of circulating ECFCs. Once all this will be done, in the future, ECFC analysis could be automated with instruments for ECFC analysis produced at the industry level, and routinely used in diagnostic laboratories in hospitals. "Kits for BPD prediction" may be produced as well, and may include materials for ECFC analysis and for the analysis of other biomarkers of BPD included in the profile. 
Part 3. Biosafety profile of

\author{
umbilical \\ cord-mesenchymal \\ stromal cells
}



Chapter 5. Genomic alterations in human umbilical cord-derived mesenchymal stromal cells call for stringent quality control before any possible therapeutic approach

Borghesi A, Avanzini MA, Novara F, Mantelli M, Lenta E, Achille V, Cerbo RM, Tzialla C, Longo S, De Silvestri A, Zimmermann LJI, Manzoni P, Zecca M, Spinillo A, Maccario R, Zuffardi O, Stronati M. Cytotherapy. 2013 Nov;15(11):1362-73. 


\section{Abstract}

BACKGROUND. The umbilical cord (UC) is a promising source of mesenchymal stromal cells (MSCs). UC-MSCs display very similar in vitro characteristics to bone marrow-MSCs, and could represent a valuable alternative for cell-based therapies. However, it is still unclear whether UC-MSCs are prone or not to acquire genomic imbalances during in vitro expansion.

METHODS. Using array-comparative genomic hybridization (aCGH), we compared copy number variations of early (P2-P3) and late (>P5) passages of in vitro expanded UC-MSCs.

RESULTS. In two out of eleven long term UC-MSCs cultures, we observed the appearance of clones carrying genomic imbalances, and generating genetic mosaicism at intermediate passages. Although still able to reach the senescence phase, the cells carrying the genomic imbalance acquired a proliferative advantage, as demonstrated by the increase in frequency during long term culture.

DISCUSSION. Altogether, our results suggest that caution should be kept in designing UC-MSC-based clinical protocols; their clinical use should be preceded by aCGH screening for the acquisition of genomic imbalances during in vitro expansion. 


\section{Introduction}

Mesenchymal stromal cells (MSCs) are cells of mesenchymal origin able to differentiate into multiple lineages (1). Given their regenerative potential and their immunomodulatory properties (2-4), MSCs have found, in recent years, vast and diverse applications in clinical and experimental protocols (5-8).

Recent reports suggest that novel, promising applications of MSC therapy include neonatal, chronic, non-malignant diseases (9-12). For these and other diseases, attention has focused on umbilical cord (UC)-derived MSCs (13-19). The UC can be easily collected from healthy pregnant women during delivery, without the need for invasive procedures and without raising ethical issues related to the obtainment of bone marrow (BM)- and adipose tissue-derived adult MSCs.

A fundamental still unanswered question is whether UC-MSCs are prone to the acquisition of genomic abnormalities and/or to undergo oncogenic transformation during in vitro expansion. Adult human MSCs, different from adult mouse MSCs, are apparently resistant to transformation (4, 20-23); Capelli et al. report that, similarly to adult-MSCs, UC-MSCs are not prone to acquire genomic abnormalities (17). However, in their study, the comparison of the genomic profiles obtained from array-comparative genomic hybridization (aCGH) analysis of cells at passage (P) 0 with cells at passage P3 may have missed the presence of clones carrying genomic alterations that were present at low percentages (less than 15-20\%) and therefore not detectable by aCGH. Indeed, cell clones carrying a genomic abnormality conferring a proliferative advantage may be undetectable at early passages, and become evident at later passages (>P5).

Thus, we investigated whether, during in vitro expansion, UC-MSCs may acquire genomic alterations, detectable by aCGH at late passages (>P5), and if these confer a proliferative advantage to the anomalous clone.

\section{Materials and methods}

Isolation and culture of UC- and BM-MSCS

Human UCs (10-20 cm length) were collected in sterility from eleven healthy pregnant women at full term (37-40 weeks gestational age), who underwent elective caesarean section at the Department of Obstetrics and Gynecology of the Fondazione IRCCS Policlinico San Matteo, Pavia. The protocol was approved by the Ethics Committee of the Institution, and written informed consent was obtained from all women before delivery. The UCs were cut into 1-2 $\mathrm{mm}^{3}$ fragments, incubated in serum-free $\alpha$ MEM (Gibco Invitrogen, Germany) supplemented with gentamicin 50 $\mu \mathrm{g} / \mathrm{ml}$ (Gibco), penicillin $100 \mathrm{U} / \mathrm{ml}$ (Sigma Aldrich, Germany) and collagenase type 
II $1 \mathrm{mg} / \mathrm{ml}$ (Sigma Aldrich) at $37^{\circ} \mathrm{C}$ in a humidified atmosphere containing $5 \% \mathrm{CO}_{2}$ for 30 minutes. Digestion was continued for an additional $30 \mathrm{~min}$. with trypsinEDTA $1 \mathrm{U} / \mathrm{ml}$ (Lonza, Switzerland). Cell suspension was collected and MNCs were isolated by density gradient centrifugation (Ficoll $1.077 \mathrm{~g} / \mathrm{ml}$; Lymphoprep, Nycomed Pharma) and plated in non-coated $75-175 \mathrm{~cm}^{2}$ polystyrene culture flasks (Corning Costar, Celbio) at a density of $160,000 / \mathrm{cm}^{2}$ in complete culture medium: D-MEM (Gibco) supplemented with L-glutamine 2mM, gentamycin $50 \mu \mathrm{g} / \mathrm{ml}$ (Gibco) and Mesencult 10\% (StemCell Technologies, Canada), as previously described (4). Cultures were maintained at $37^{\circ} \mathrm{C}$ in a humidified atmosphere containing $5 \%$ $\mathrm{CO}_{2}$. After 48 hour adhesion, non-adherent cells were discarded and culture medium was replaced twice a week. At day 7, MSC clones (colony forming unitfibroblast, CFU-F) were counted. Cells reaching confluence were harvested using Trypsin (Sigma-Aldrich, Italy), re-plated for expansion at a density of 4,000 cells $/ \mathrm{cm}^{2}$ and propagated in culture for several passages until reaching a senescence phase. Senescent cells were monitored for up to 8 weeks, in order to reveal any change in morphology and/or proliferation rate. UC-MSCs were stained using a senescence $\beta$-galactosidase (SA- $\beta$-gal) Stainig Kit (Ozyme, France) following the manufacturer's instructions and microscopically analyzed. Cell growth was analyzed by direct cell count and the doubling time was determined. The mean doubling time (TD) was calculated by the formula: TD=t $\log _{10}(2) /\left(\log _{10} \mathrm{~N}-\log _{10} \mathrm{~N} 0\right)$ where $\mathrm{N}=$ cells harvested, $\mathrm{N} 0=$ cells seeded, and $\mathrm{t}=$ time of the culture (in hours) (24). The population doubling (PD) of cultured MSCs was calculated at every passage according to the equation $\mathrm{PD}=\log _{10}(\mathrm{~N} / \mathrm{N} 0) / \log _{10}(2)$ where $\mathrm{N}=$ number of harvested cells and $\mathrm{N} 0=$ number of seeded cells).

BM-MSC were generated from bone marrow aspirates of 10 healthy donors, as previously described $(4,23)$.

\section{UC-MSC multilineage differentiation potential}

The adipogenic and osteogenic differentiation capacity of UC-MSCs was determined at early (P2 or P3) and late (P8 or P10) passages, as previously described $(4,25)$. To detect osteogenic differentiation, cells were stained for alkaline phosphatase activity using Fast Blue (Sigma-Aldrich) and for calcium deposition using Alzarin Red (Sigma-Aldrich). Adipogenic differentiation was evaluated through the morphological appearance of lipid droplets stained with Oil Red 0 staining (SigmaAldrich). In order to quantify osteogenic and adipogenic differentiation, optical density was measured spectrophotometrically $(550 \mathrm{~nm}$ ) after extraction of Alizarin Red and Oil Red from cells by adding $400 \mu \mathrm{l}$ of $0.05 \mathrm{~N} \mathrm{NaOH}$ in Ethanol. Results were calculated by extrapolation from a standard curve and expressed as $\mathrm{pg} / \mathrm{ml}$ and $\mathrm{U} / \mathrm{ml}$, respectively. 
UC-MSCs at early and late passages were phenotipically characterized by flowcytometry. Fluorescein isothiocyanate (FITC) or phycoerythrin (PE)-conjugated monoclonal antibodies specific for the following antigens were used: CD45, CD14, CD33, CD34, CD13, CD80, CD31, HLA A-B-C, HLA-DR, CD90 (BD PharMingen, CA), CD73, CD105 (Serotec, UK). Appropriate, isotype-matched, non-reactive fluorocrome-conjugated antibodies were used as controls.

The intracellular expression of p16INK4A protein was evaluated using an antiCDK2A/p16INK4A monoclonal antibody (Abcam, Cambridge, UK) and a goat antimouse PE-conjugate as the secondary antibody (SouthernBiotech, Birmingham, AL, USA), following the manufacturer's instructions. Appropriate, isotype-matched, non-reactive fluorocrome-conjugated antibodies were used as controls. Cells were acquired by a FACSCanto flow cytometer (BD PharMingen) and analysis was performed using the Diva software (BD Biosciences) $(4,25)$.

\section{Molecular karyotyping}

Molecular karyotyping of UC-MSCs at early and late passages was performed through aCGH with the Agilent kit 60K (Human Genome CGH Microarray, Agilent Technologies, Santa Clara, CA, USA) according to the manufacturer's protocol. Male Coriell DNA (NA10851 from Coriell Institute for Medical Research) was used as control DNA for all experiments. Data analysis was performed using Agilent Genomic Workbench Standard Edition 6.5.0.58. Quality control parameters for all experiments were valuated using the Agilent Genomic Workbench QC tool. Oligo positions are referred to hg19.

Mosaic percentages were evaluated by in house experiments on the basis of the $\log 2$ ratios obtained from artificial mosaics with known percentages of abnormal DNA.

\section{Mycrosatellite analysis}

Mycrosatellite analysis was performed using primers specific for polymorphic loci mapping in all the genome. Primers were labeled with fluorescent probes (ABI 6Fam and 8-Hex) followed by analysis on an ABI 3100 Genetic Analyzer (Applied Biosystems). 
FISH was performed on MSC interphase nuclei with the CHR10 CEP SureFISH probe (Agilent Technologies, Santa Clara, CA, USA) according to the manufacturer's protocol. CHR9p telomere SureFish probe was used as the control probe.

\section{Methylcellulose-based colony formation assay}

A suspension of 200,000 cells in D-MEM low glucose (Gibco), 0.9\% methylcellulose (StemCell Technologies), 30\% (vol/vol) FBS (StemCell Technologies) was plated in six-well plates. After 4 weeks incubation at $37^{\circ} \mathrm{C}$ in a humidified atmosphere with $5 \% \mathrm{CO}_{2}$, plates were examined for formation of colonies using an inverted microscope (Leitz, Germany). A rat MSC line was used as a positive control.

Real-time quantitative polymerase chain reaction ( $q P C R$ )

Five primer couples covering the entire $C D K N 2 A / p 16 I N K 4 A$ gene were selected for qPCR on genomic DNA using Primer 3 software (http://frodo.wi.mit.edu/primer3/). A control amplicon was selected with the same parameters in the $M A P K 1$ gene on 22q11.2; size (approximately $60 \mathrm{bp}$ ) and $\mathrm{Tm}\left(60^{\circ} \mathrm{C}\right)$ were the same for all amplicons. Amplification, detection and data analysis were performed with Mx3005P (Stratagene) using SYBR Green QPCR Master Mix Brilliant III Ultra Fast (Agilent).

\section{Statistical analysis}

The frequencies of parametric and nonparametric continuous variables are reported as the mean \pm standard deviation (SD) and median and interquartile range (IQR), respectively. Comparison between groups of continuous parametric and nonparametric variables was carried out using the Student's t-test for independent samples and the nonparametric Mann-Whitney U-test, respectively. A P value < 0.05 was considered statistically significant for all analyses. All analyses were performed using MedCalc $®$ v9.5.1.0 software.

\section{Results}

Morphology, surface phenotype, and differentiation potential of UC-MSCs

MSCs able to expand and differentiate ex vivo were obtained from all eleven human UC samples (10-20 cm length) collected in sterility from healthy pregnant women 
at full term (37-40 weeks gestational age), who underwent elective caesarean section. Data from UC-MSCs were compared with previously reported data from ten BM-MSC samples $(4,23,25)$.

UC-MSCs displayed the typical spindle-shaped morphology similar to that of BM-MSCs differentiated under the same culture conditions (Figure 12). Surface phenotyping performed by flow cytometry every second passage (at P1, P3, P5, and on until senescence), confirmed that UC-MSCs were positive for CD90, CD73, CD105, CD13 and HLA-A-B-C and negative for CD34, CD45, CD14, CD80, CD31, CD33 and HLA-DR surface antigens (typical panel of MSC markers) $(4,23,25)$ (Figure 13).

The capacity of UC-MSCs to differentiate in vitro to osteoblasts and adipocytes was demonstrated by histological staining and measured by spectrophotometry. Microscopic examination of stained cells demonstrated the absence of nodules and smaller fat droplets in UC-derived osteoblasts and adipocytes, respectively, compared to BM-derived cells. At spectrophotometric analysis, the quantification of Alizarin Red (osteoblasts) and Oil Red (adipocytes) of differentiated UC-MSCs was lower than that of BM-MSCs (mean \pm SD: $37 \pm 22 \mathrm{pg} / \mathrm{ml}$ vs $240 \pm 323 \mathrm{pg} / \mathrm{ml}, \mathrm{P}=0.01$; and $60 \pm 30 \mathrm{U} / \mathrm{ml}$ vs $173 \pm 71 \mathrm{U} / \mathrm{ml}, \mathrm{P}=0.04$, respectively) (Figure 12).

Clonogenic capacity, proliferative potential, and senescence of UC-MSCS

After plating UC-derived mononuclear cells, CFU-F formation was assessed by microscopic examination of cultures at day 7, according to our protocol in use for BM-MSCs. The clonogenic efficiency was calculated as the number of colonies per $10^{6}$ mononuclear seeded cells. At day 7, in 8 out of 11 UC-MSC lots we observed a disseminated pattern of growth, suggesting the earlier appearance of CFU-F. In the remaining 3 lots, we observed the presence of $\mathrm{CFU}-\mathrm{F}$ at day 7 , with higher frequencies in UC-MSC cultures compared to BM-MSC cultures $\left(22 \pm 8 / 10^{6}\right.$ seeded cells vs $5 \pm 2 / 10^{6}$, respectively). 

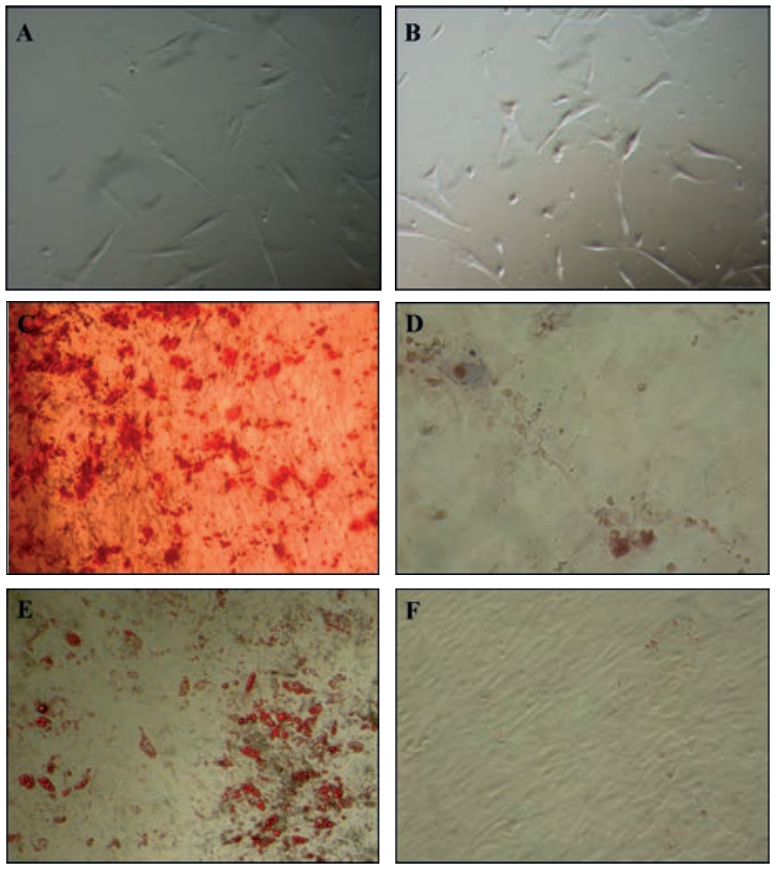

Figure 12. Morphology and differentiation potential of BM- and UCMSCs.

Morphologic appearance of BM(Panel A) and UC-MSCs (Panel B) grown in D-MEM. Panels $\mathrm{C}$ and D show the differentiation potential in osteogenic conditions of BM- and UC-MSCs, respectively, and panels E and $\mathrm{F}$ show the differentiation potential in adipogenic conditions of BM- and UC-MSCs, respectively.

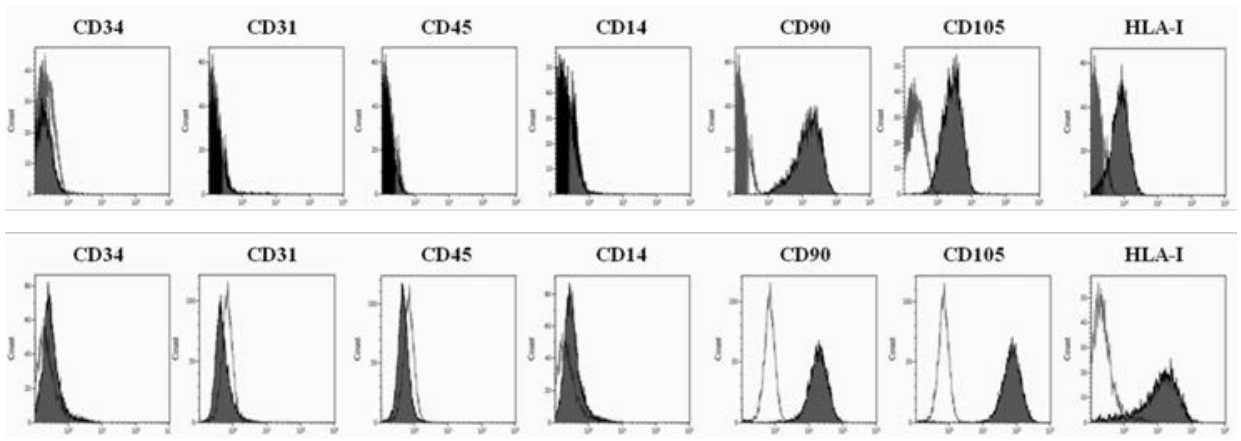

Figure 13. A representative flow cytometric analysis of UC-MSCs (top row) surface proteins and BMMSCs (bottom row) at early passages.

UC-MSCs grew more rapidly in culture than BM-MSCs. The median time to reach $80 \%$ confluence in four consecutive passages (from P1 to P4) was lower for UCMSC than for BM-MSCs (44.0 days [IQR: 41-46 days] vs 78.5 days [IQR: 68-113 days], $\mathrm{P}=0.001)$. After passage $\mathrm{P} 3$, the $\mathrm{BM}$-MSC proliferative rate progressively slowed, as demonstrated by the progressive increase in the doubling time, compared to that of UC-MSCs (Figure 14). Cell growth was also evaluated as population doubling; the cumulative population doublings of UC- and BM-MSCs from P1 to P6 were comparable, and are reported in Figure 14. 
The senescence phase was defined as a decrease in MSC proliferative capacity, eventually leading to cell cycle arrest. MSCs ceased their growth at variable passages. In general, UC-MSCs reached senescence earlier than BM-MSCs (P10 [IQR: P8-P12] vs P17 [IQR: P14-P20], P<0.001). After monitoring for eight weeks, neither UC-MSCs nor BM-MSCs escaped senescence and recommenced proliferation.

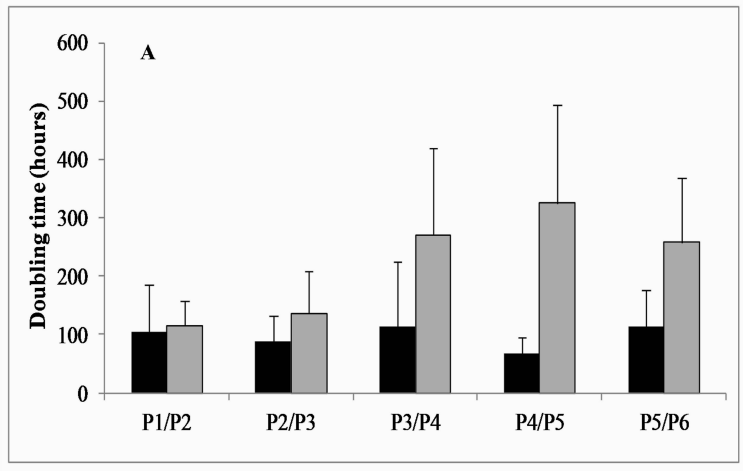

Figure 14. Proliferative potential of BM- and UC-MSCs.

Panel A: doubling time of UC-MSCs ( $n=11$, black bars) or BM-MSCs $(n=10$, gray bars). Values are reported as the mean and standard deviation. Panel B: cumulative population doubling (PD); reported values represent the mean cumulative $\mathrm{PD}$ of 11 UC-MSCs and 10 BM-MSCs.

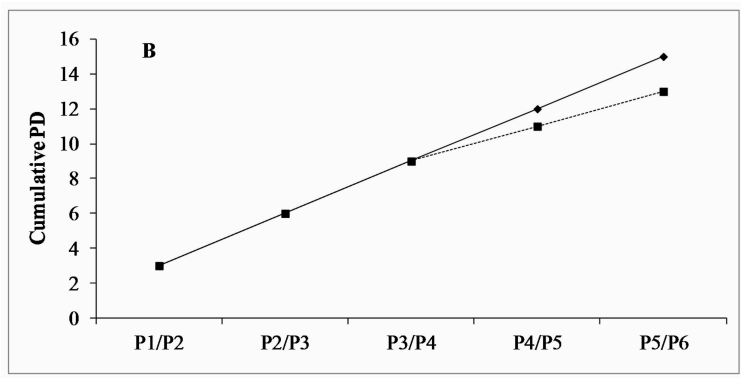

\section{Molecular karyotyping of UC-MSCS}

Molecular karyotyping was performed by aCGH analysis on 11 lots of UC-MSCs. In 9 out of 11 UC-MSCs, comparison of late versus early passages of parallel experiments did not evidence any chromosomal anomalies, except for CNVs (Copy Number Variations) present in the Database of Genomic Variants (DGV, available at http://projects.tcag.ca/variation/. Accessed June 6, 2012) or genomic variations attributable to control DNA.

In one UC-MSC sample we detected a chromosome 10 trisomy (Figure 15). The whole chromosome imbalance was present in about $70 \%$ of analyzed cells at P8 and in $100 \%$ of analyzed cells at P10, but was not detectable at previous passages (P1, P4, P6).

In a second lot, a $7 \mathrm{q} 35$ deletion of about $245 \mathrm{~Kb}$ (minimal deleted region chr7:146,856,474-147,101,307 referring to hg19) partially involving the CNTNAP2 gene and the MIR548F4 gene was identified (Figure 16). The chromosomal imbal- 
ance, not detectable at P1, was present in about 50\% of analyzed cells at P3, in about $70 \%$ at $\mathrm{P} 5$ and about $80 \%$ at $\mathrm{P} 6$.

In order to demonstrate that the clones presenting with genomic imbalances were not the result of contamination from other laboratory cultures, the donor origin of the abnormal clones was demonstrated by genome-wide microsatellite analysis (26), performed both at early and late passages (data not shown).
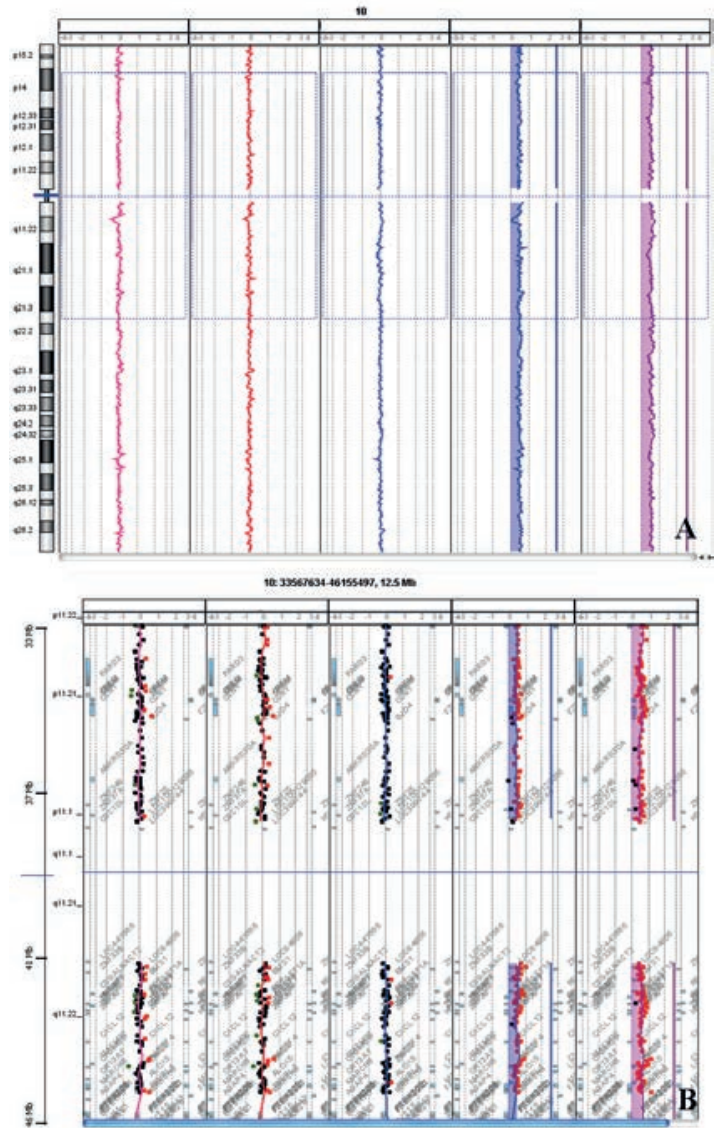

Figure 15. Array-comparative genomic hybridization profile of the UC-MSC sample with chromosome 10 trisomy detected at late passages and not at the early ones.

A. The whole chromosome 10 in all analyzed passages: from left to right P1, P4, P6, P8 and P10 (each color identifies an individual experiment). The imbalance was not present at early passages but only at P8 and P10.

B. A particular of the pericentromeric region of chromosome 10 at all passages: where the consecutive red spots at P8 and P10 show the duplicated region. 

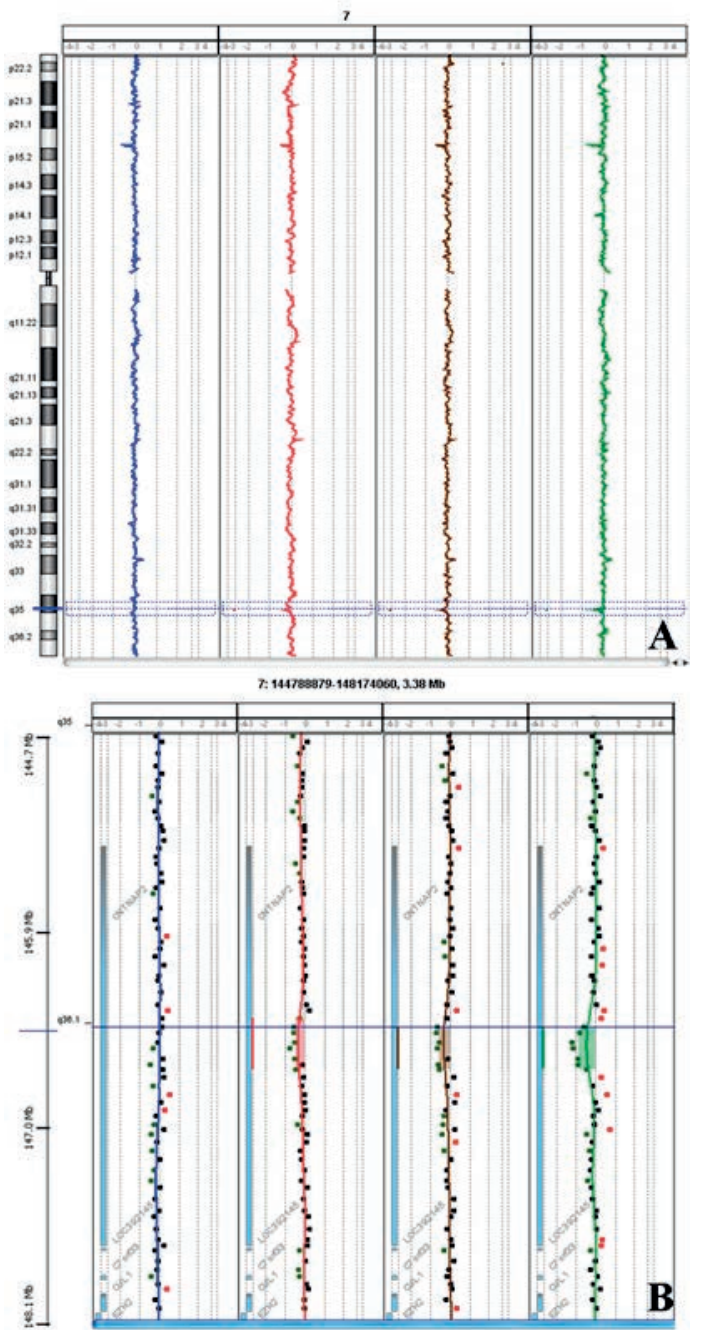

Figure 16. Array-comparative genomic hybridization profile of the UC-MSC sample with 7q35 deletion of about $245 \mathrm{~Kb}$ [arr 7q35(146,856,474-147,101,307)x1 genomic assembly: hg19].

A. The whole chromosome 7 in all analyzed passages: from left to right P1, P3, P5 and P6 (each color identifies an experiment). The imbalance was not present at P1 but only at P3, P5 and P6.

B. A particular of $7 q 35$ deletion at all passages: the consecutive green spots at P3, P5 and P6 show the deleted region with an increment in cell percentage carrying the imbalance from P3 to P6.

\section{FISH analysis of chromosome 10 trisomy}

FISH analysis was performed on interphase nuclei of the UC-MSC lot with the chromosome 10 trisomy, as evidenced by aCGH. The FISH was performed on UCMSCs at P3 and P5 (after thawing and re-expansion cells frozen at P2 and P4, respectively) using the probe for chromosome 10 centromere and one control probe mapping to the chromosome 9p telomere. 200 interphase nuclei were counted for each analyzed culture passage. The chromosome 10 trisomy was not detected at passage P2 but, surprisingly, it was present in 179/200 (approximately 90\%) nuclei at P4. It was not possible to perform FISH analysis on the second lot with the 
7q35 deletion because BAC probes were not present within the deleted region (Figure 17).

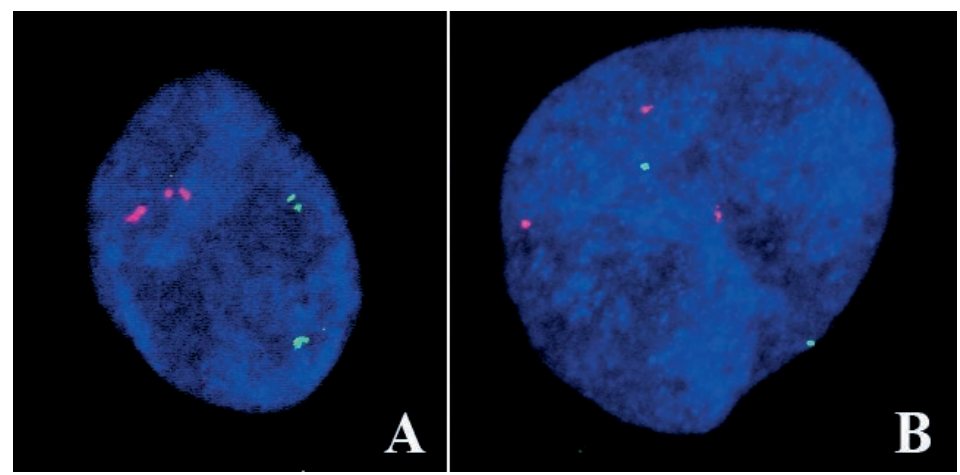

Figure 17. FISH analysis performed on the lot with chromosome 10 trisomy. The green spots indicate the control probes used for the analysis (CHR9p telomere SureFISH probes), while the red spots the chromosome 10 centromere (CHR10 CEP SureFISH probes). On the left (Panel A) it is possible to note the red spots at P2 indicating the two normal chromosomes 10, while on the right (Panel B) the three different red spots indicating the chromosome 10 trisomy at $\mathrm{P} 4$.

In vitro characteristics of the unbalanced clones

Both UC-MSC cultures carrying a genomic imbalance reached the senescence phase at passages comparable to those of other lots of UC-MSCs, and, after eight weeks of monitoring, none of the two cell clones escaped senescence and recommenced proliferation.

However, the proliferative advantage that we observed in the two unbalanced clones raised the question of whether the clones were undergoing tumor transformation. To address this issue, we used a methylcellulose-based colony formation assay to test UC-MSCs for anchorage-independent growth, at early, intermediate, and late passages. After four weeks culture in semisolid medium, we did not observe any colony formation from UC-MSCs, either from the two lots bearing genomic imbalances, or from non altered UC-MSC lots. Conversely, a rat MSC line, used as a positive control, formed several colonies under the same culture conditions (Figure 18).

1 The results of this assay, serving as an in vitro surrogate of in vivo tumor formation, suggest that the two unbalanced clones, albeit harboring genomic alterations conferring a proliferative advantage, did not acquire a full tumor phenotype. 

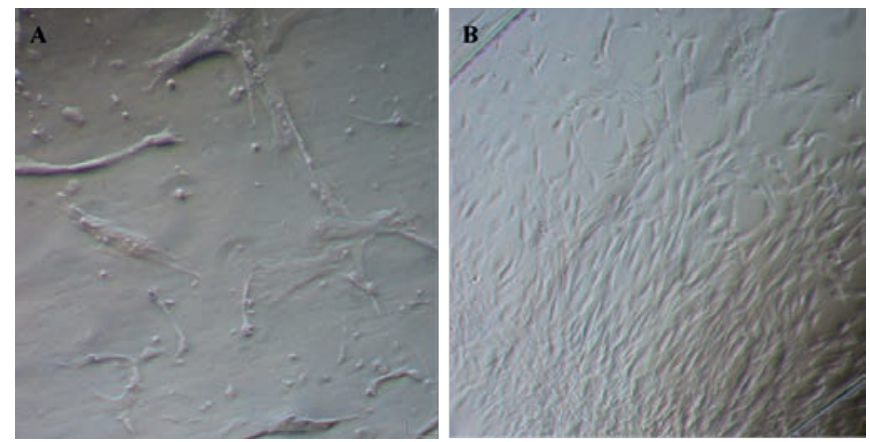

Figure 18. Methylcellulose-based anchorage-independent mesenchymal stromal cell growth assay.

Magnification 40X. Panel A shows UC-MSCs from the lot carrying a chromosome 10 trisomy; a scattered pattern of growth was observed, and cells underwent cell death after 4 weeks in culture. Panel B shows a rat MSC line forming colonies during growth in semisolid medium. Rat MSCs are typically smaller than human cells.

\section{Assessment of CDKN2A/p16INK4A in the unbalanced clones}

Previous works demonstrated that a critical step in the acquisition of an increased proliferative capacity without anchorage independence in MSCs is the deletion of the $C D K N 2 A / p 16 I N K 4 A$ gene $(27,28)$. Therefore, we confirmed aCGH data by qPCR using primers spanning the entire $C D K N 2 A / p 16 I N K 4 A$ gene on genomic DNA from the two lots of UC-MSCs bearing chromosomal anomalies (one early and one late passage of culture for each clone). The same analysis was performed in parallel on other control UC-MSCs at the same culture passages and on two different DNA controls from healthy individuals. The analysis performed on all studied UC-MSCs showed that CDKN2A/p16INK4A gene was never found deleted both in the heterozygous and in the homozygous state. This experiment definitively excluded that a deletion of $C D K N 2 A / p 16 I N K 4 A$ was responsible for the proliferative advantage observed in the aberrant clones (Data not shown).

We then questioned whether the detected genomic alterations may confer proliferative advantage by affecting the expression of the p16INK4A protein. To respond to this question, we evaluated, by flow cytometry, the intracellular expression of the p16INK4A protein at early and late passages of UC-MSC cultures with or without genomic alterations and of BM-MSC cultures. We found a similar percentage of cells expressing the p16INK4A intracellular protein in UC-MSCs and BM-MSCs both at an early passage (P3; mean \pm SD: $40.0 \pm 7.5$ and $46.5 \pm 33$, respectively) and late passage (P8; mean \pm SD: $58.0 \pm 13.0$ and $58.0 \pm 38.0$, respectively). Similarly, we observed comparable percentages of expression of the p16INK4A intracellular protein in UC-MSCs bearing genomic alterations: $36.0 \%$ 
(lot with trisomy 10) and 49.0\% (lot with 7q35 deletion) at P3 and 67.0\% (lot with trisomy 10) and 64.0\% (lot with 7q35 deletion) at P8 (Data not shown).

\section{Discussion}

The UC is a promising source of MSCs. While many studies have focused on MSCs of adult origin, much less research has been performed on UC-MSCs, and very little is known about the genetic stability of UC-MSCs. In the present study, we fully characterized UC-MSCs from different donors, and compared the results with those obtained from BM-MSCs expanded under the same culture conditions; more importantly, we investigated the genomic stability of UC-MSCs during long term cultures, and we report here novel data on comparative aCGH analysis of UC-MSC cultures at early (P2 or P3) and late (>P5) passages.

In agreement with previous reports, we were able to efficiently isolate UCMSCs from all UC samples; in vitro expanded UC-MSCs displayed the typical spindle-shaped morphology and immunophenotype, with UC-MSCs displaying higher proliferative rates compared to BM-MSCs $(15,16)$.

In 8 out of 11 samples a disseminated pattern of growth with a high proliferative rate was observed. When present, CFU-F colonies from UC-MSCs were detected at higher numbers per $10^{6}$ seeded cells compared to those from BM-MSCs, in line with previous reports (15).

In addition, the adipogenic and osteogenic differentiation, hallmarks of MSCs, although detectable in all experiments, were less efficient in UC-MSCs compared to BM-MSCs as demonstrated by both microscopic examination and spectrophotome-

try. Contrasting data are available in the literature, with different studies reporting a comparable, higher or lower differentiation capacity between UC-MSCs and BMMSCs $(16,24,29)$. Although we are not able to conclusively explain these contrasting results among studies, including ours, we speculate that, as suggested by Can and Karahuseyinoglu (14), UC-MSCs may contain more than one set of stem cells; however, this possible heterogeneity was not evident using our CD panel for MSC characterization by flow cytometry. Differences in the protocols used for the isolation of starting cell populations, as well as different methods used for the quantification of the degree of differentiation $(16,29)$, may account for differences among studies.

Similarly, the diversity of the starting cell population may also explain differences in the number of passages needed to reach the senescence phase. Indeed, in our experiments UC-MSCs reached the senescence phase in a lower number of passages than BM-MSCs, and this observation is in contrast with reports showing higher number of passages (30) and a greater proliferative potential (16) for UCMSCs compared to BM-MSCs. 
Our study also addresses the important issue of the genetic stability of UCMSCs expanded in long term cultures. Karyotype analysis had previously shown that UC-MSCs are genetically stable during in vitro expansion up to passage P13 $(29,31)$. However, conventional karyotype analysis does not detect subchromosomal genomic CNVs which may confer a proliferative advantage to the affected clone. Therefore, the use of aCGH for the detection of CNVs may represent a sensitive and reproducible technology to perform a deeper genomic screening before the use of UC-MSCs for cell therapy protocols.

In one study, Capelli et al. showed, by aCGH analysis performed at passage 3 of culture, that UC-MSCs are not prone to the acquisition of CNVs (17). However, the analysis of early passages may have missed the detection of genomic alterations present at low rates that become more frequent at later stages of in vitro expansion.

In our study, molecular karyotyping performed by aCGH analysis at early and late passages allowed the detection of a chromosome 10 trisomy in one lot and a 7 q35 deletion in a second one, that, in both cases, increased in frequency in subsequent passages; with genome-wide microsatellite analysis we were able to demonstrate that these genomic imbalances were not the result of culture contamination. This observation raised the question whether the detected alterations were donordependent or culture-driven. Indeed, by aCGH, the lowest level of mosaic whole chromosome aneuploidy detectable is about $20 \%$, and the clones carrying the genomic alterations could have already been present at low percentages in the starting cell population or at early passages. We therefore performed FISH analysis in the lot of UC-MSCs in which the clone with the chromosome 10 trisomy was discovered, and we found that, as expected, the chromosome 10 trisomy was not detectable at P3, thus suggesting a culture-associated appearance of the aberration. However, in contrast with aCGH results, by FISH analysis we found the chromosome 10 trisomy at a frequency of $90 \%$ at P5. These FISH experiments were performed on UC-MSC aliquots thawed and re-expanded in vitro. Therefore, we cannot exclude that the trisomy was already present at a low frequency $(<20 \%)$ at P4 before freezing, and that the aberrant clone proliferated at high rates upon thawing and re-expansion.

Both cell cultures reached the senescence phase at passages comparable to those of other lots of UC-MSCs and were not capable of anchorage independent growth when cultured in semisolid medium. These observations, together with the maintenance of the classical MSC phenotype at early and late passages, suggest that the unbalanced cell clones did not acquire a full tumor phenotype. Nevertheless, the increase in frequency over passages demonstrated that the cell clones carrying the genomic alterations acquired a proliferative advantage.

A growing number of observations demonstrate that stem cells, including adult MSCs, may acquire chromosomal or subchromosomal aberrations (32). How- 
ever, the exact significance of these genomic imbalances is still controversial. Chromosomal aberrations, either donor-dependent or acquired during in vitro MSC expansion from fetal or adult tissues, may confer a growth advantage or disadvantage. Tarte et al. identified, by conventional karyotype analysis, donordependent chromosomal abnormalities in BM-MSCs (recurring trisomy of chromosome 5 with occasional trisomy of chromosomes 8 and 20) which seemed to be deleterious for cell survival as demonstrated by the disappearance of the aneuploid cells in almost all cultures at P2 (33). Less clear seems to be the effect of other described aneuploidy states on in vitro cell growth and survival, including trisomies of chromosomes $7 \mathrm{q}$ and $17 \mathrm{q}$, monosomy of chromosome $6 \mathrm{q}$, monosomy of chromosome 13 and trisomy of chromosome $19(32,34)$. In our study, we were not able to determine whether the genomic imbalances were mechanistically implicated in the gain of proliferative advantage, or were simply markers of the clones displaying high proliferation rates. In particular, the chromosome 10 trisomy, occurring in tumors of various origin, is not a frequent finding in tumors of mesenchymal origin (as reported in the National Cancer Institute "Recurrent Chromosomal Aberrations in Cancer Database Searcher"; http://cgap.nci.nih.gov/Chromosomes/Mitel_Search\#MARK; accessed June 05, 2013 ), and its possible role in promoting proliferation of UC-MSCs remains to be elucidated. Similarly, the CNTNAP2 gene (present in the 7q35 region) is located in a common fragile site which has been demonstrated to be inactivated in different types of cancers such as brain, ovarian and breast tumors (35), but it has not been demonstrated to be a tumor suppressor gene. Therefore, any link with accelerated MSC proliferation would be merely speculative so far. Future studies, including genome-wide methylation analysis and gene expression profiling may clarify these issues.

In order to gain some insight into the biological mechanisms driving the increased proliferation rate observed in the unbalanced clones, we also confirmed by qPCR that $p 16 I N K 4 A$, a proliferation modulator gene whose deletion had been previously associated with high cell proliferation of MSC lines (27), was not deleted in the anomalous clones. Then, we assessed the $p 16 I N K 4 A$ gene expression at the protein level by flow cytometry to detect any changes in $p 16 I N K 4 A$ expression that may drive higher cell proliferation. We found comparable expression between BM-MSCs and UC-MSCs and between UC-MSCs with or without genomic imbalances, thus excluding the involvement of p16INKA in the acquisition of a high proliferation rate in the unbalanced clones.

Our observations raise several questions. First, whether clones with a genomic imbalance not detectable at early passages, although able to reach the senescence phase in vitro, may acquire a tumor phenotype in vivo. Second, whether genomic alterations are randomly acquired or whether specific genomic regions are more prone to instability in UC-MSCs. Third, whether other genomic alterations, including single nucleotide substitutions possibly occurring during UC-MSC expansion, 
may confer a full tumor phenotype to the anomalous clone in some lots. Fourth, whether UC-MSCs are prone to gain chromosomal anomalies at frequencies of $\sim 4 \%$, comparable to those described in other studies for MSCs (32-34) (in our small study the appearance of genomic imbalances occurred in two out of eleven lots, which corresponds to a frequency of $18 \%$; thus, larger studies are needed). Finally, the best combination of analytical techniques, among those nowadays available, for testing of genetic stability in MSC lots expanded for clinical use needs to be defined (36).

In conclusion, our observations suggest that aCGH is an invaluable tool to detect CNVs in in vitro expanded UC-MSCs; however, analysis limited to early passages may miss alterations becoming more frequent and evident at late passages. The use of UC-MSCs in regenerative medicine, specially for neonatal patients with chronic, non-malignant diseases, should be preceded by full evaluation of a biosafety profile of the lots prepared for cell therapy. An aliquot of the lot destined for clinical use should be expanded and replated until senescence. Moreover, aCGH analysis for comparison of late $v s$ early passages should become a routine procedure when establishing the biosafety profile of a cell product prepared for clinical use. 


\section{References}

1. Dominici M, Le Blanc K, Mueller I, Slaper-Cortenbach I, Marini F, Krause D, et al. Minimal criteria for defining multipotent mesenchymal stromal cells. The International Society for Cellular Therapy position statement. Cytotherapy. 2006;8(4):315-7.

2. Bernardo ME, Pagliara D, Locatelli F. Mesenchymal stromal cell therapy: a revolution in Regenerative Medicine? Bone Marrow Transplant. 2012 Feb;47(2):164-71.

3. Le Blanc K. Mesenchymal stromal cells: Tissue repair and immune modulation. Cytotherapy. 2006;8(6):559-61.

4. Avanzini MA, Bernardo ME, Cometa AM, Perotti C, Zaffaroni N, Novara F, et al. Generation of mesenchymal stromal cells in the presence of platelet lysate: a phenotypic and functional comparison of umbilical cord blood- and bone marrow-derived progenitors. Haematologica. 2009 Dec;94(12):1649-60.

5. Le Blanc K, Frassoni F, Ball L, Locatelli F, Roelofs H, Lewis I, et al. Mesenchymal stem cells for treatment of steroid-resistant, severe, acute graft-versus-host disease: a phase II study. Lancet. 2008 May 10;371(9624):1579-86.

6. Matthay MA, Thompson BT, Read EJ, McKenna DH, Jr., Liu KD, Calfee CS, et al. Therapeutic potential of mesenchymal stem cells for severe acute lung injury. Chest. 2010 0ct;138(4):965-72.

7. Salem HK, Thiemermann C. Mesenchymal stromal cells: current understanding and clinical status. Stem Cells. 2010 Mar 31;28(3):585-96.

8. Sensebe L, Bourin P. Mesenchymal stem cells for therapeutic purposes. Transplantation. 2009 May 15;87(9 Suppl):S49-53.

9. van Velthoven CT, Kavelaars A, van Bel F, Heijnen CJ. Mesenchymal stem cell treatment after neonatal hypoxic-ischemic brain injury improves behavioral outcome and induces neuronal and oligodendrocyte regeneration. Brain Behav Immun. 2010 Mar;24(3):387-93.

10. van Haaften T, Byrne R, Bonnet S, Rochefort GY, Akabutu J, Bouchentouf M, et al. Airway delivery of mesenchymal stem cells prevents arrested alveolar growth in neonatal lung injury in rats. Am J Respir Crit Care Med. 2009 Dec 1;180(11):1131-42.

11. Aslam M, Baveja R, Liang OD, Fernandez-Gonzalez A, Lee C, Mitsialis SA, et al. Bone marrow stromal cells attenuate lung injury in a murine model of neonatal chronic lung disease. Am J Respir Crit Care Med. 2009 Dec 1;180(11):1122-30.

12. Dalous J, Larghero J, Baud O. Transplantation of umbilical cord-derived mesenchymal stem cells as a novel strategy to protect the central nervous system: technical aspects, preclinical studies, and clinical perspectives. Pediatr Res. 2012 Apr;71(4 Pt 2):482-90.

13. Montemurro T, Andriolo G, Montelatici E, Weissmann G, Crisan M, Colnaghi MR, et al. Differentiation and migration properties of human foetal umbilical cord perivascular cells: potential for lung repair. J Cell Mol Med. 2011 Apr;15(4):796-808.

14. Can A, Karahuseyinoglu S. Concise review: human umbilical cord stroma with regard to the source of fetus-derived stem cells. Stem Cells. 2007 Nov;25(11):2886-95.

15. Sarugaser R, Lickorish D, Baksh D, Hosseini MM, Davies JE. Human umbilical cord perivascular (HUCPV) cells: a source of mesenchymal progenitors. Stem Cells. 2005 Feb;23(2):220-9.

16. Baksh D, Yao R, Tuan RS. Comparison of proliferative and multilineage differentiation potential of human mesenchymal stem cells derived from umbilical cord and bone marrow. Stem Cells. 2007 Jun;25(6):1384-92.

17. Capelli C, Gotti E, Morigi M, Rota C, Weng L, Dazzi F, et al. Minimally manipulated whole human umbilical cord is a rich source of clinical-grade human mesenchymal stromal cells expanded in human platelet lysate. Cytotherapy. 2011 Aug;13(7):786-801.

18. Troyer DL, Weiss ML. Wharton's jelly-derived cells are a primitive stromal cell population. Stem Cells. 2008 Mar;26(3):591-9.

19. Weiss ML, Troyer DL. Stem cells in the umbilical cord. Stem Cell Rev. 2006;2(2):155-62. 
20. Aguilar S, Nye E, Chan J, Loebinger M, Spencer-Dene B, Fisk N, et al. Murine but not human mesenchymal stem cells generate osteosarcoma-like lesions in the lung. Stem Cells. 2007 Jun;25(6):1586-94.

21. Vilalta M, Degano IR, Bago J, Gould D, Santos M, Garcia-Arranz M, et al. Biodistribution, long-term survival, and safety of human adipose tissue-derived mesenchymal stem cells transplanted in nude mice by high sensitivity non-invasive bioluminescence imaging. Stem Cells Dev. 2008 Oct;17(5):993-1003.

22. Lange C, Cakiroglu F, Spiess AN, Cappallo-Obermann H, Dierlamm J, Zander AR. Accelerated and safe expansion of human mesenchymal stromal cells in animal serum-free medium for transplantation and regenerative medicine. J Cell Physiol. 2007 Oct;213(1):18-26.

23. Bernardo ME, Zaffaroni N, Novara F, Cometa AM, Avanzini MA, Moretta A, et al. Human bone marrow derived mesenchymal stem cells do not undergo transformation after long-term in vitro culture and do not exhibit telomere maintenance mechanisms. Cancer Res. 2007 Oct 1;67(19):9142-9.

24. Lu LL, Liu YJ, Yang SG, Zhao QJ, Wang X, Gong W, et al. Isolation and characterization of human umbilical cord mesenchymal stem cells with hematopoiesis-supportive function and other potentials. Haematologica. 2006 Aug;91(8):1017-26.

25. Bernardo ME, Avanzini MA, Perotti C, Cometa AM, Moretta A, Lenta E, et al. Optimization of in vitro expansion of human multipotent mesenchymal stromal cells for cell-therapy approaches: further insights in the search for a fetal calf serum substitute. J Cell Physiol. 2007 Apr;211(1):121-30.

26. Novara F, Beri S, Giorda R, Ortibus E, Nageshappa S, Darra F, et al. Refining the phenotype associated with MEF2C haploinsufficiency. Clin Genet. 2010 Nov;78(5):471-7.

27. Serakinci N, Guldberg P, Burns JS, Abdallah B, Schrodder H, Jensen T, et al. Adult human mesenchymal stem cell as a target for neoplastic transformation. Oncogene. 2004 Jun 24;23(29):5095-8.

28. Novara F, Beri S, Bernardo ME, Bellazzi R, Malovini A, Ciccone R, et al. Different molecular mechanisms causing 9p21 deletions in acute lymphoblastic leukemia of childhood. Hum Genet. 2009 Oct;126(4):511-20.

29. Karahuseyinoglu S, Cinar 0, Kilic E, Kara F, Akay GG, Demiralp DO, et al. Biology of stem cells in human umbilical cord stroma: in situ and in vitro surveys. Stem Cells. 2007 Feb;25(2):319-31.

30. Lund RD, Wang S, Lu B, Girman S, Holmes T, Sauve Y, et al. Cells isolated from umbilical cord tissue rescue photoreceptors and visual functions in a rodent model of retinal disease. Stem Cells. 2007 Mar;25(3):602-11.

31. Weiss ML, Medicetty S, Bledsoe AR, Rachakatla RS, Choi M, Merchav S, et al. Human umbilical cord matrix stem cells: preliminary characterization and effect of transplantation in a rodent model of Parkinson's disease. Stem Cells. 2006 Mar;24(3):781-92.

32. Ben-David U, Mayshar Y, Benvenisty N. Large-scale analysis reveals acquisition of lineage-specific chromosomal aberrations in human adult stem cells. Cell Stem Cell. 2011 Aug 5;9(2):97-102.

33. Tarte K, Gaillard J, Lataillade JJ, Fouillard L, Becker M, Mossafa H, et al. Clinical-grade production of human mesenchymal stromal cells: occurrence of aneuploidy without transformation. Blood. 2010 Feb 25;115(8):1549-53.

34. Sensebe L, Tarte K, Galipeau J, Krampera M, Martin I, Phinney DG, et al. Limited acquisition of chromosomal aberrations in human adult mesenchymal stromal cells. Cell Stem Cell. 2012 Jan 6;10(1):9-10; author reply -1 .

35. McAvoy S, Ganapathiraju SC, Ducharme-Smith AL, Pritchett JR, Kosari F, Perez DS, et al. Nonrandom inactivation of large common fragile site genes in different cancers. Cytogenet Genome Res. 2007;118(2-4):260-9.

36. Barkholt L, Flory E, Jekerle V, Lucas-Samuel S, Ahnert P, Bisset L, et al. Risk of tumorigenicity in mesenchymal stromal cell-based therapies-Bridging scientific observations and regulatory viewpoints. Cytotherapy. 2013 Apr 18. 



\section{Valorisation: Biosafety of umbilical cord-derived mesenchymal stromal cells (MSCs)}

The study reported in chapter 5 concerns the biosafety of stem cells, specifically MSCs isolated from the umbilical cord, to be used in cell therapy in the setting of neonatal medicine.

RELEVANCE. The umbilical cord is a promising source of MSCs, but studies on the genetic stability of umbilical cord-derived MSCs were lacking. In a historical moment in which stem cells occupy a substantial part of the medical news in the media, it seems important to accurately study the potential risks associated with a specific cell therapy.

TARGET GROUPS. MSCs are polyvalent cells with different behaviors in different environments, and could be suitable for treating a series of diseases affecting all ages, from the neonatal age to adulthood, ranging from graft versus host disease in bone marrow transplant recipients, to inflammatory bowel diseases, neuroinflammatory diseases, and diseases of the preterm infant. All the people (patients) that could benefit from therapies with MSCs may be interested in our results.

ACTIVITIES/PRODUCTS. In the context of cell factories, specialized laboratories dedicated to the production of cell products destined to clinical use, the identification of genomic imbalances through array-comparative genomic hybridization should become a routine procedure for every lot of MSCs, in order to exclude from clinical use the lots with cells carrying imbalances.

INNOVATION. Similar studies had been carried out for other stem/progenitor cell populations, but not for umbilical cord-derived MSCs. Our study adds this important information regarding a cell population isolated from the umbilical cord, a promising source given its availability and the few ethical issues related to its collection.

SCHEDULE/IMPLEMENTATION. In the setting of neonatal medicine, one experimental work suggests that umbilical cord-derived MSCs may mitigate the phe- 
notype of experimental BPD. If these results will be confirmed and umbilical cordderived MSCs will be object of a clinical trial in preterm newborn infants, routine screening for genomic imbalances of the lots to be used in trials will be performed before the cell products are administered to the patients. 
Part 4. Discussion, future perspectives and
conclusive remarks 

Chapter 6. Discussion 
The experimental and clinical data reported in the previous chapters may be summarized into the following headlines:

1) Major diseases associated with prematurity include (although are not limited to) BPD, PVL and NEC;

2) The pathogenesis of these diseases is largely unknown; initial evidence suggests that endogenous, tissue resident stem cells may be lost or disrupted in these conditions (due to exposure to risk factors), leading to tissue simplification, and tissue susceptibility to injury;

3) Stem/progenitor cells display properties making them suitable for therapy (aiming at replacement of lost or disrupted endogenous stem cells, or aiming at protection of tissue resident stem/progenitor cells and differentiated cells);

4) Stem/progenitor cells that are of interest in the preterm infant include ECFCs and MSCs;

5) ECFCs and MSCs can be isolated in vitro from fetal/neonatal tissues, enumerated, and expanded for in vitro studies; ECFC and MSC technology can be exploited in order to:

i) perform clinical studies in which ECFCs and/or MSCs work as biomarkers of disease(s) associated with prematurity, aiming at understanding the pathogenesis and at finding early predictors of disease;

ii) perform in vitro safety studies which are preliminary to a safe use of in vitro expanded ECFCs and MSCs for therapy; and

iii) perform in vitro studies for the understanding of their biology and their role during development.

Specifically, in our studies, we:

- Investigated the potential role of different subtypes of EPCs (including ECFCs and other angiogenic cells) as biomarkers or predictors of BPD (chapter 3 and chapter 4);

- Performed in vitro studies to characterize UC-MSCs and define their biosafety profile in the perspective of their use in the clinical setting of neonatal diseases associated with prematurity (chapter 5 ).

\section{Chapter 3 and chapter 4: investigating the role of EPCs as biomarkers}

In chapter 3, a clinical research study is reported, showing a negative correlation between circulating cord blood ECFCs, a subtype of EPC, and the subsequent development of BPD in preterm infants; ECFCs were enumerated by a clonogenic assay. On the contrary, other cell populations considered "angiogenic cells" or "angiogenic macrophages", enumerated by flow cytometry (CD34+CD133+VEGFR-2+ triple positive cells and other VEGFR-2+cell populations), did not correlate with any disease of prematurity. These findings were confirmed in a second study, re- 
ported in chapter 4, showing the lack of correlation between VEGFR-2+ cells enumerated by flow cytometry and BPD.

The first scientific question was whether the depletion, in the lung, of ECFCs (the EPC subtype representing true EPCs with vasculogenic potential and endothelial colony forming ability) is a main contributor to BPD in preterm infants; that is, we questioned whether a depletion of ECFCs in the pulmonary vascular bed was pathogenically implicated in the development of BPD. As there is no way, presently, to study lung resident ECFCs in humans during the neonatal age in vivo, we decided to study circulating ECFCs. Taking advantage of a clonogenic assay, we enumerated the number of colonies yielded from a cord blood sample of prematurely born infants, and we subsequently studied this number for correlation with the development of BPD (primary outcome) or other diseases of prematurity (secondary outcomes) (Figure 19).

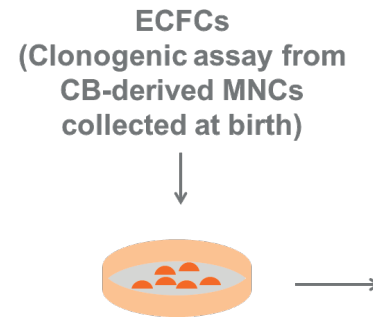

Figure 19. Enumeration of cord blood ECFCs. The number of ECFC colonies was correlated with the subsequent development of BPD and other diseases of prematurity. ECFCs = endothelial colony forming cells; MNCs = mononuclear cells.

In our study, we found that infants who subsequently developed BPD had lower numbers of ECFCs in cord blood compared to infants who did not develop BPD.

One limitation of our study is the low number of patients in which we were able to assess ECFC colonies. Interestingly, however, similar results were found in another, larger and independent, study conducted by Baker et al. (1).

Clinical and experimental data suggest that ECFCs have a physiologic role during fetal development. A study by Javed et al. first reported that ECFC levels are low in cord blood at 24 to 31 weeks gestational age, and subsequently increase with increasing gestational age (2). However, a more recent study reported that cord blood from preterm infants (28-35 wk gestational age) yields higher numbers of ECFCs compared with cord blood from term infants (3). Our group showed that ECFCs in cord blood are low at extremely low gestational ages $(<28 \mathrm{wk})$ and are higher at higher gestational ages ( $>28 \mathrm{wk}$ ), suggesting (although not demonstrating) that the increase of ECFCs during a specific temporal window (28-35 weeks gestational age) may have the specific function of contributing to the maturation of vascular beds in several districts, including the lung vascular district (4).

The disruption of ECFC function may therefore have implications for neonatal disease, and may specifically play a role in the specific subgroup of infants with gestational age $<28$ weeks. Indeed, our study (4) together with the study by Baker 
et al. (1) suggests that higher numbers of ECFCs at birth protect preterm infants from the development of BPD; thus, the appearance or the increase of ECFCs in the systemic fetal circulation may be a key developmental process, important for the maturation of lung vasculature, occurring between 24 to 30 weeks, and lasting until 35 weeks gestational age. Along with this speculation, our working hypothesis, corroborated by initial data $(1,4)$, is that, during gestation or at least during a specific temporal window, ECFC contribution to lung vascular growth is not dispensable (Figure 4). As preterm birth leads to a stable postnatal decline in all CD34+ cell subsets, including the ECFC-containing CD34+CD45- cell subset (4), it is possible (but still has to be experimentally confirmed) that the deprivation of the contribution of ECFCs to lung maturation following extremely preterm birth may play a role in the developmental arrest of the lung vascular bed and, as a consequence, on the pathogenesis of BPD. Alternatively, ECFC decline after birth could be a mirror of the decline of resident ECFCs in tissues and organs (that is, a marker of tissue-angiogenic potential), including the lungs.

Of interest, ECFCs are exquisitely sensitive to oxidative stress and oxygen exposure, known major risk factors for neonatal diseases associated with prematurity. Ingram et al. demonstrated that oxidative treatment (i.e. exposure to $\mathrm{H}_{2} \mathrm{O}_{2}$ ) decreases the clonogenic capacity of ECFCs by increasing apoptosis and by diminishing capillary-like tube forming ability in vitro and in vivo (5), and more recently Fujinaga et al. showed that hyperoxia decreases growth and disrupts VEGF-NO signaling in human preterm ECFCs (6).

Importantly, all these studies do not provide mechanistic explanations of physiological and pathological processes; however, they hint that tight links may exist between oxygen exposure, oxidative stress, circulating ECFC reduction and impairment following preterm birth, vascular disease, and development of BPD, and prompt additional studies to confirm the above speculations and to elucidate the exact interactions among all these factors.

In favor of a role for ECFC disruption in the pathogenesis of BPD, a recently published experimental work by Alphonse et al. demonstrates, in rats, the existence of lung resident ECFCs $(7,8)$, as previously demonstrated both in rats and mice (9-11). Their data show that ECFCs from hyperoxic lungs (95\%02 rats, BPD model) have compromised proliferative, clonogenic and in vitro vessel forming potential, suggesting that oxygen-induced depletion of vessel forming progenitors may be a possible mechanism underlying arrested lung vascular growth in BPD. In addition, in their study, the authors intra-jugularly administered human umbilical cord blood-ECFCs at day 14, and observed improved lung function and preserved alveolar development, and attenuated pulmonary hypertension (improved pulmonary artery acceleration times and decreased right ventricular hypertrophy) in ECFC-treated hyperoxia-exposed mouse pups compared to the non-treated controls, suggesting that human umbilical cord blood-ECFCs may offer a new thera- 
peutic option for BPD $(7,8)$ (see also chapter 1, paragraph 1.7.2., EPC-based treatments).

Advantages of studying ECFCs with the clonogenic assay. The study of ECFCs over other subtypes of EPCs has the great advantage to focus on true endothelial progenitors with in vitro endothelial colony forming capacity. Indeed, ECFCs display spontaneous vasculogenic properties both in vitro (human vessel formation in a matrigel assay) and in vivo (when implanted into immunodeficient mice) (12, 13). The study of ECFCs in the newborn infant has, therefore, the potential to provide important insights into the processes of vasculogenesis and angiogenesis in preterm and full-term human neonates, and, when correlated to disease states (as $\mathrm{BPD}$ ), has the potential to unravel the cellular mechanisms underlying the pathologic changes of the vascular beds in different districts.

Limitations of studying ECFCs with the clonogenic assay. The study of ECFCs with the clonogenic assay has limitations that are intrinsic to the methodology itself. Indeed, the reproducibility of the results of a single test is probably poor due to a series of reasons, as follows:

i) different amounts of cord blood are collected for each infant (although the results are reported as number $/ 10^{7} \mathrm{MNCs}$, the ECFC population is very rare, and even small amounts of blood in excess or defect could change the results);

ii) different amounts of MNCs are recovered for each cord blood sample and, again, ECFCs represent a rare population whose count may be influenced by MNC counts;

iii) to overcome the previous problems, the assay should be performed in duplicate or triplicate, but the amount of cord blood that can be recovered from a tiny umbilical cord of a preterm infant could be not always sufficient;

iv) the cord blood collected from a tiny umbilical cord of a preterm infant could be not always of good quality, and even a small blood clot could change the counts of the rare ECFC population;

v) the method takes at least 14 days to give the results; at 14 days of life, other clinical parameters may be more useful for the prediction of BPD, and, at this stage, the results of ECFC culture may be not useful;

vi) the method allows just association studies, not mechanistic links.

Our findings on ECFCs, together with data from the literature, raise additional questions and generate novel hypotheses. Future studies should aim at addressing the following issues: first, whether low circulating levels of cord blood-ECFCs are mechanistically linked to low amounts of lung resident ECFCs at birth, with circulating cord blood-ECFCs being therefore the direct expression of lung vascular immaturity at birth in infants who subsequently develop BPD, or, alternatively, whether levels and function of circulating ECFCs just mirror the amount and function of tissue (lung) resident ECFCs; second, which kind of relationship exists between circulating and lung resident ECFCs during the first weeks of life, and 
whether the disruption of circulating ECFCs due to preterm birth and oxidative stress may cause deprivation of their contribution to lung vascular maturation following preterm birth; finally, whether circulating ECFCs can be included in a biomarker profile for the prediction of BPD, and whether ECFCs as biomarkers could be useful in predicting which infants may need ECFC-based progenitor cell therapy.

The second scientific question was whether other specific subtypes of EPCs, different from ECFCs, may be taken as biomarkers of BPD.

By flow cytometry, many cell populations with angiogenic properties can be studied. At the time we performed the study, mononuclear cells expressing in different combinations the surface antigens CD34, CD133 (AC133) and VEGFR-2 were thought to be EPCs; it became clear only later that these putative EPCs are actually of hematopoietic (not endothelial) origin, although the great amount of published article describing their correlation with several diseases with a vascular components in adult humans is undeniable, and identifies these cells as angiogenic cells of hematopoietic origin.

We studied the cord blood or the peripheral blood for enumeration, by flow cytometry, of the following putative-EPC populations:

- CD34+CD133+VEGFR-2+ (triple-positive) cells and CD34+CD117+ VEGFR-2+ cells (98 infants studied);

and

- CD34+VEGFR-2+, CD34+CD133+VEGFR-2+, CD34+CD133+VEGFR-2+ CD45cells (142 infants studied).

Advantage of studying angiogenic cells by flow cytometry. Enumeration by cell surface phenotype using different combinations of surface markers is quick and the results readily available and well reproducible (14).

Disadvantage of studying angiogenic cells by flow cytometry. As stated above, in studying these cell populations it is important to keep in mind that the study is not focusing on true endothelial progenitors, but rather on angiogenic cells of hematopoietic origin. This consideration is fundamental to avoid any wrong speculation on the involvement of these cells in the pathogenesis of human diseases.

In origin, triple positive cells were promising, because: i) correlated with vascular diseases (including cardiovascular disease and type 2 diabetes mellitus) in adult humans (15-17), and ii) a neonatal mouse model of BPD suggested the involvement of CD45-/Sca-1+/CD133+/VEGFR-2+ in lung vascular disruption of hyperoxia-exposed mice (18).

However, in several studies, including two from our group (chapter 3 and chapter 4), a robust correlation between cell counts and major diseases of prematurity has not been detected, and triple-positive cells or other related cell populations are not useful in predicting $\operatorname{BPD}(4,19,20)$. 
Indeed, in our studies, triple-positive cells and other CD34+ subsets at birth did not predict BPD or other outcomes of prematurity (4). Our findings suggest that the contribution of these cell populations to lung vascular development during fetal life is not different in infants who may or may not develop BPD later. The discrepancy with adult cardiovascular diseases, in which baseline low percentages of CD34+VEGFR-2+ cells predict the risk for subsequent cardiovascular events, is easily explainable by the fact that the two diseases are pathogenically very different. Indeed, CD34+VEGFR-2+ cells may be important in vascular turnover and repair but not in pulmonary vascular development during late pregnancy. Although not conclusively excluding that CD34+VEGFR-2+, CD34+CD133+VEGFR-2+, and CD45-CD34+CD133+VEGFR-2+ cells contribute to vascular development during fetal life, we definitely demonstrate that cells identified with our flow cytometry protocol are not the key factor that is reduced in human infants at higher risk of BPD, and that they cannot be taken as a surrogate marker for defective pulmonary vascular development and for prediction of BPD. Finally, cell values at 7 and 28 days of life were comparable in infants with or without BPD, suggesting that, in humans, the three cell populations are not subject to the detrimental effects of oxygen, as it conversely happens in an experimental setting for CD45-Sca1+CD133+VEGFR-2+ cells in neonatal mice (18).

Other polychromatic flow cytometry protocols may be more useful for the identification and enumeration of specific cell populations directly involved in lung vascular development or in the pathogenesis of $\operatorname{BPD}(21,22)$. These include:

1) A population of circulating progenitor cells (CPCS) which are hematopoietic elements with a role in the growth and maintenance of the vasculature origin. These cells are CD34+CD45dim cells, represent functional circulating hematopoietic stem and progenitor cells (CHSPCs), and can be separated in two functional subsets (pro-angiogenic and non-angiogenic) on the basis of AC133 expression. The AC133+ subset of the CHSPCs enhances the growth of tumor blood vessels in vivo in immunodeficient mice. In addition, the ratio of AC133+ proangiogenic CHSPCs (enumerated as CD34brightAC133+CD45dimCD31+) to AC133- nonangiogenic CHSPCs (enumerated as CD34brightAC133-CD45dimCD31+) (also called CPC:nonCPC ratio) unambiguously correlates with the severity of the clinical state of patients with peripheral arterial disease $(21,23)$, is elevated in patients with different solid tumors before treatment (24), and is reduced in cord blood of infants born to mothers with gestational diabetes mellitus (25). Interestingly, a recent clinical study by Baker et al. conducted using this novel polychromatic flow cytometry protocol showed a significantly lower ratio of angiogenic circulating progenitors to non-angiogenic circulating progenitors in cord blood samples of preterm infants who subsequently developed moderate or severe BPD (1); a more recent study shows that, during infancy, there is a parallel increase in the membrane and vascular components of pulmonary diffusion, consistent with alveolari- 
zation during this period of rapid lung growth, and that CHSPCs correlate with the pulmonary capillary blood volume, suggesting that pro-angiogenic CHSPCs may contribute to lung vascularization during alveolarization (26).

2) Circulating ECFCs, enumerated by flow cytometry. Recently, in a paper from the same group describing CPCs, Mund et al. described a polychromatic flow cytometry protocol able to identify a population of cells containing both bona fide ECFCs and mature circulating endothelial cells, by varying expressions of CD34, CD31, and CD146 but not AC133 and CD45. After immunomagnetic separation, the putative ECFCs failed to form hematopoietic colonies, yet clonogenic endothelial colonies with proliferative potential were obtained, thus verifying their identity as ECFCs; consistent with clonogenic assays, the frequency of ECFCs were increased in cord blood and were extremely rare in the peripheral blood of healthy adults (22). This protocol will be extremely useful in future clinical studies, both to investigate the correlation between ECFCs identified by the clonogenic and the flow cytometric method, and to reproducibly describe the behavior of ECFCs in health and disease. Indeed, ECFCs identified with this protocol fulfill the definition of an EPC according to Yoder (a circulating cell that gives rise to progeny displaying clonal proliferative potential and differentiation restricted to the endothelial lineage, ability to form lumenized capillary-like tubes in vitro; cells must display cytoplasmic vacuolation capacity and ability to form stable human blood vessels; cells must secrete a basement membrane when implanted into tissues with or without a scaffold that become an integrated part of the host circulatory system; and display potential to undergo remodeling to form the intima of arterial, venous, and capillary structures) (13). At present, the rare circulating ECFCs display these features while most other bone marrow-derived cells currently called EPCs fail to do so (13). Additional studies are needed to find a unique cell surface marker that would permit prospective isolation and enrichment of cells displaying the above listed characteristics of an EPC (13).

3) Bone marrow-derived cells. Monocytes expressing the Tie2 receptor (Tie2expressing monocytes, TEMS) are a distinct hematopoietic lineage of pro-angiogenic cells, that have been implicated in promoting tumor angiogenesis in a paracrine manner (27) (it is worth here to recall the comment suggested by De Palma et al. that, besides TEMs and endothelial cells (ECs), Tie2 expression distinguished a rare population of tumor stroma-derived mesenchymal progenitors representing a primary source of tumor pericytes; therefore, Tie2 expression characterizes three distinct cell types required for tumor neovascularization: ECs, proangiogenic cells of hematopoietic origin, and pericyte precursors of mesenchymal origin) (27).

TEMs account for $2 \%$ to $7 \%$ of blood mononuclear cells in the peripheral blood of adult healthy donors and are easily identifiable by flow cytometry (28). The function, if any, of TEMs during development and during the neonatal age is currently unknown. 


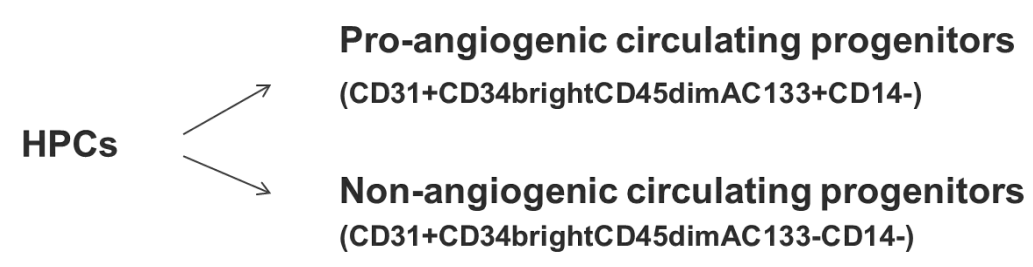

EPCs $\longrightarrow$ Endothelial colony forming cells (CD31+CD34brightCD45-AC133-CD14- cells)

Figure 20. Cell surface phenotype of ECFCs, pro-angiogenic and non-angiogenic CPCs.

These new protocols, possibly integrated with clonogenic assays, will help to clarify the complex interactions between different angiogenic cells and true EPCs during gestation and after birth, both in physiological and pathological conditions, and will possibly allow to get closer to the understanding of the pathogenesis of BPD and other preterm and term neonatal diseases characterized by a prominent defect in vascular growth, including retinopathy of prematurity and persistent pulmonary hypertension of the newborn. The relative contribution of the distinct cells with a paracrine or permissive action (paracrine role) and with endothelial capacity (building block role) (29) during gestation and after preterm birth remains to be elucidated.

\section{Chapter 5: biosafety profile of UC-MSCs}

In chapter 5 , in vitro study on umbilical cord (UC)-derived MSCs. This study aimed at assessing the genetic stability and the risk of tumorigenicity in UC-MSCs; we looked for genomic alterations - copy number variations - by array-comparative genomic hybridization, and studied the cellular phenotype of two clones carrying genomic alterations (namely, a trisomy 10 in one clone and a 7q25 deletion in one clone).

Whether MSCs, and specifically UC-MSCs could be beneficial in preventing or treating human infants with BPD is currently unknown.

A rationale for using MSCs comes from the observation, in a mouse model of BPD (30), that oxygen-induced lung injury is associated with a reduction of lung resident MSCs; however, if a similar reduction occurs in humans is less clear (31). We think that MSCs have the potential to counteract tissue injury associated with preterm birth, in virtue of: 
- their in vitro properties (immunomodulatory - antiapoptotic - antiscarring proangiogenic - supporting proliferation and differentiation of stem and progenitor cells);

- previous clinical experience on different (pediatric and adult) inflammatory diseases;

In two animal models (mouse and rat, respectively), BM-MSCs or their conditioned medium were effective in reducing lung changes associated with hyperoxia $(30,32$, 33); similar results were obtained with UC-MSCs (34).

Therefore, UC-MSCs may be equivalent to BM-MSCs, but are much less studied. When expanded in vitro, MSCs are forced to grow at a high rate in presence of several growth factors; these are potential conditions to induce culture-driven malignant transformation.

BM-MSCs seem resistant to oncogenic transformation, and undergo genetic imbalance at a low frequency $(4 \%)(35,36)$. Until our study was performed, the only study on UC-MSCs (37) reported resistance to genetic imbalance, but the authors only compared very early (P0) with early (P3) passages of UC-MSCs. Thus, we questioned whether checking for genetic imbalances at later passages (>P5) could allow the detection of unbalanced clones (38).

In our study (chapter 5), UC-MSCs expanded until senescence, and monitored up to 8 weeks after, showed resistance to oncogenic transformation, but, by array$\mathrm{CGH}$, we demonstrated the appearance of clones with proliferative advantage carrying specific genomic imbalances in two out of eleven lots (trisomy of cr. 10 and $7 \mathrm{q} 35$ deletion).

This finding adds scientific information to the larger field of the biosafety of cell products destined to clinical use or to clinical protocols. While we are convinced that it is worth to exploit the potential of UC-MSCs for neonatal diseases, and, as demonstrated by Pierro et al. (34), we believe that the beneficial effects could be equivalent to those achievable with BM-MSCs, our study focuses the attention on the safety of using UC-MSCs. A genetic testing for CNVs of the lots destined to clinical use could become a routine test before UC-MSC infusion in clinical protocols. 
Chapter 7. Future perspectives and conclusive remarks 


\section{Unsolved issues in the field of stem cell therapy for diseases associated with preterm birth and future perspectives}

Recent studies (a phase I study on cord blood-MSCs for BPD and a feasibility study on autologous cord blood cells for hypoxic-ischemic encephalopathy) suggest that stem cell therapy may be feasible in neonates $(39,40)$. However, before stem and progenitor cell therapy become a true option for very and extremely preterm infants, the following issues should be resolved:

Which infants to treat? Infants at higher risk of sequelae of prematurity, representing the best candidates for treatment and/or prevention, should be accurately selected; it is indeed unknown which infants could be good candidates for treatment and/or prevention. Not all very and extremely preterm infants develop BPD, PVL and NEC, and, at present, we are unable to early predict the risk. Future research should focus on the identification of a marker or a group of markers able to early and accurately predict the risk of BPD (including clinical characteristics, soluble plasma factors, cellular biomarkers, and possibly genetic markers).

Hypothetically, risk stratification could follow at least two approaches, clinical and based on biomarkers; these two approaches are not mutually exclusive and could be also integrated (41).

For BPD, for instance, the risk stratification with the clinical approach could be based on few readily available data which have been shown to accurately estimate the risk of BPD outcome (gestational age, birth weight, postnatal day, gender, race/ethnicity, and ventilatory parameters - FiO2 and ongoing ventilatory strategy -) (https://neonatal.rti.org/index.cfm?fuseaction=BPDCalculator.start), or include also more complex information as, for instance, instrumental data (chest Xrays, echocardiographic findings). Similar considerations can be done for cerebral damage, whose risk estimate can be extrapolated from few clinical data (gestational age, birth weight, gender, singleton or multiple birth, antenatal corticosteroids). See: http://www.nichd.nih.gov/about/org/der/branches/ppb/programs/epbo/Pages/epbo_case.aspx?start=14:46:50 and https://neonatal.rti.org/OTEstimator/index.cfm?CFID=4387913\&CFTOKEN=80048184\&fuseaction=0TEstimator.EstimatorDE).

Risk stratification with biomarkers could include genetic markers (e.g. polymorphisms), measurement of molecules or cell counts in blood (e.g. circulating ECFCs or the CPC:nonCPCs ratio) or biological fluids (e.g. tracheal aspirate).

Which cells to use? The most suitable cell population targeted to specific diseases and/or clinical conditions should be chosen; the choice of the cell population most suitable for transplantation in infants with, or at risk of, BPD, depends on the goal of the specific therapy. For instance, therapies that aim at improving the vascularization of the lungs, could be based on angiogenic cells (bone marrow-derived pro-angiogenic CPCs, or ECFCs) (42) or on soluble factors able to improve vasculo- 
genesis, while therapies that aim at reducing epithelial injury could be better based on the protective effects of MSCs or their conditioned medium $(30,33)$. In humans, at present, both MSCs and ECFCs, although different in their function and biological behavior, seem to have the potential to be beneficial in preterm infants for the treatment or the prevention of BPD. The first ones (MSCs) by exerting their cytoprotective effects $(30,33)$, the second ones (ECFCs) with their vasculogenic potential (43). For perinatal brain injury, neural stem cells or induced pluripotent stem cells (iPSCs) have been proposed (44) for their regenerative potential; however issues regarding the source for recovery of neural stem cells and issues regarding the risks related to the genetic stability of iPSCs limit, at present, the use of these two cell types in phase I clinical trials; MSCs have been successfully tested in a hypoxic-ischemic encephalopathy animal model $(45,46)$, and particularly UC-MSCs represent a promising option for brain protection (47); conversely, in a rat model of excitotoxic brain injury, the whole mononuclear fraction of the human umbilical cord blood (UCB-MNCs intravenously or intraperitoneally), previously considered to be a promising option, was recently demonstrated to be unable to integrate into the developing brain or promote subsequent repair, and intraperitoneal injection of high amounts of UCB-MNCs aggravated white matter damage (48).

Also, the source of cells should be defined. For MSCs, for instance, using fetal tissues as a source of cells (UC-MSCs rather than BM-MSCs) will be an option only after UC-MSCs will be equally characterized and their safety demonstrated, as addressed by in vitro and in vivo non-tumorigenicity and genetic stability upon expansion and transplantation.

How many cells? Which route of administration should be used for which disease? The answer to this question directly depends on the previous one, that is, on which is the most suitable cell type to be used. Both MSCs and ECFCs can be administered intravenously, via the umbilical venous or a peripheral catheter. The infused cells will necessarily pass through the pulmonary circulation, and, at least for MSCs, it has been demonstrated that a large portion will home to (or will be stopped in) the lungs. Alternatively, for BPD, intratracheal administration could be a good option, depending, again, on the infused cell type. For perinatal brain injury, both the systemic (intravenous of intranasal) and local (intraparenchymal, intraventricular, or intrathecal) routes of administration have been proposed $(45,46$, $49,50)$.

Also, the optimal numbers of cells to be infused must be calculated in order to reduce toxicity while achieving the highest therapeutic effect.

These technical issues are of extreme importance to avoid failure of phase I clinical trials (due, for instance, to low numbers of infused cells) or side effects (due for instance to excessively high numbers of cells).

When to give the cells - which is the right timing? That is: should we aim at preventing or regenerating? These questions are directly related to the first one. 
If we know which infants are at risk, we will target this subclass of patients for prevention, rather than to cure a posteriori.

MSCs, in animal models, exert their action by protecting the developing tissues, rather than engrafting and regenerating the damaged tissues. The beneficial effects of MSC administration could be less dramatic if cells are administered after 10,20 or 30 days of mechanical ventilation and oxygen supplementation, when molecular and cellular changes already occurred.

For ECFCs, we can speculate that the time of administration could be less strictly important. ECFCs are capable of vasculogenesis, can create new vessels which anastomose with the already existing vascular network, and could probably repair, rather than prevent, the vascular damage (although this assertion still needs demonstration in animal models). The early improvement in the lung vascular circulation by early administration of ECFCs would have the potential to reduce the need for oxygen supplementation and mechanical ventilation and thus indirectly minimize epithelial lung changes in infants at risk of BPD.

Specifically for brain injury, the timing could be very different for different types of brain injury (intraventriculatr hemorrhage, periventricular leukomalacia, perinatal stroke, perinatal asphyxia) (44).

For BPD, tools for prediction are available; similarly, for encephalopathy of prematurity tools for prediction have been developed. These statistics-based tools together with biomarkers (including cell biomarkers) could help to identify infants at increased risk of specific diseases

(https://neonatal.rti.org/index.cfm?fuseaction=tools.main

https://neonatal.rti.org/index.cfm?fuseaction=BPDCalculator.start

https://neonatal.rti.org/OTEstimator/index.cfm?fuseaction=0TEstimator.start http://www.nichd.nih.gov/about/org/der/branches/ppb/programs/epbo/Pages/ epbo_case.aspx).

The best timing for administration must be exactly calculated, and may change across time with improvement in our knowledge on the pathogenesis of diseases of prematurity, and with the discovery of new biomarkers and development of new tools for prediction.

\section{Beyond BPD and encephalopathy of prematurity}

Stem/progenitor cell therapy for brain injury after hypoxic ischemic insult. Recent attention has focused on the use of MSCs for hypoxic-ischemic encephalopathy (a condition not necessarily associated with prematurity, although occurring in preterm infants as well) as a model for the repair of ischemic brain injury. Compared to other cell types, MSCs display several advantages: they can be easily obtained from different sources (bone marrow, Wharton's jelly, placenta, cord blood), while 
neural stem cells, for instance, can only be collected from deceased adults or fetuses; MSCs possess immunomodulatory activity and are not strongly immunogenic (and are therefore less likely rejected during transplantation); and they have been shown to orchestrate the repair of damaged brain by paracrine mechanisms, stimulating endogenous processes of repair (51). In particular, in animal models, MSCs have been directly implanted in the site of the cerebral lesion, leading to maturation of new neurons and oligodendrocytes (45), to a reduction of the volume of the lesion, improved functional outcome, and decreased proliferating inflammatory cells (46). These results seem the effect of the stimulation of endogenous repair processes, rather than direct differentiation of implanted cells in neural cells. Further, MSCs have been successfully delivered to the brain via the nasal route, and have been demonstrated to induce functional recovery and a reduction in brain lesion size in a mouse model; indeed, nasally administered MSCs migrate to the site of injury and are able to stimulate endogenous cerebral repair (49).

Stem/progenitor cell therapy for inflammatory diseases during the neonatal age. Other neonatal diseases, beyond pulmonary and brain diseases, could benefit from stem cell therapy. For instance, diseases of the preterm and full term infant that are accompanied by a high degree of inflammation, as NEC, could benefit from the immunomodulatory properties of MSCs. NEC is indeed characterized by a high degree of inflammation $(52,53)$, and MSCs, proven effective in chronic inflammatory bowel disease (54), could be beneficial in reducing complications and improving outcomes in human infants with NEC $(55,56)$.

Hypothetically, even diseases today not considered target for stem cell therapy, as, for instance, acute bacterial meningitis, could one day benefit from stem cell therapy, either for protection (MSC administration for immunomodulation and reduction of brain injury in the acute phase of meningitis) or regeneration (iPSCs or Neural stem cells could become candidate cells). Similarly, bacterial pneumonia could benefit from the immunomodulatory and anti-infectious action of MSCs (57). Also, far from today, genetic or congenital diseases (e.g. alveolar capillary dysplasia or congenital surfactant deficiency) could one day benefit from stem cell technology.

\section{Conclusive remarks}

Neonatal diseases associated with preterm birth still represent a burden for global health and families. The search for new tools to minimize the risk of complications associated with prematurity is urgent. Stem cell technology offers new possibilities to prevent or cure these invalidating diseases. Further understanding of the developmental biology in physiological and pathological conditions, of the multiple mechanisms underlying disruption of normal organ development after very/extremely preterm birth, and of the complex biology of stem cells, will allow 
the performance of targeted studies (starting from phase I clinical trials) and the design of appropriate preventive and treatment protocols.

While a growing body of evidence suggests that the use of stem cells could be effective for treatment of some neonatal diseases, some gaps exist in the literature, limiting the use of stem cells in regenerative medicine and the design of phase I clinical trials. All the unanswered questions must be clearly resolved before safe and appropriate protocols can be translated into clinical practice. 


\section{References}

1. Baker CD, Balasubramaniam V, Mourani PM, Sontag MK, Black CP, Ryan SL, et al. Cord blood angiogenic progenitor cells are decreased in bronchopulmonary dysplasia. Eur Respir J. 2012 Dec;40(6):1516-22.

2. Javed MJ, Mead LE, Prater D, Bessler WK, Foster D, Case J, et al. Endothelial colony forming cells and mesenchymal stem cells are enriched at different gestational ages in human umbilical cord blood. Pediatr Res. 2008 Jul;64(1):68-73.

3. Baker CD, Ryan SL, Ingram DA, Seedorf GJ, Abman SH, Balasubramaniam V. Endothelial colonyforming cells from preterm infants are increased and more susceptible to hyperoxia. Am J Respir Crit Care Med. 2009 Sep 1;180(5):454-61.

4. Borghesi A, Massa M, Campanelli R, Bollani L, Tzialla C, Figar TA, et al. Circulating endothelial progenitor cells in preterm infants with bronchopulmonary dysplasia. Am J Respir Crit Care Med. 2009 Sep 15;180(6):540-6.

5. Ingram DA, Krier TR, Mead LE, McGuire C, Prater DN, Bhavsar J, et al. Clonogenic endothelial progenitor cells are sensitive to oxidative stress. Stem Cells. 2007 Feb;25(2):297-304.

6. Fujinaga H, Baker CD, Ryan SL, Markham NE, Seedorf GJ, Balasubramaniam V, et al. Hyperoxia disrupts vascular endothelial growth factor-nitric oxide signaling and decreases growth of endothelial colony-forming cells from preterm infants. Am J Physiol Lung Cell Mol Physiol. 2009 Dec;297(6):L1160-9.

7. Alphonse RS, Rajabali S, Thebaud B. Lung injury in preterm neonates: the role and therapeutic potential of stem cells. Antioxid Redox Signal. 2012 Oct 1;17(7):1013-40.

8. Alphonse RS, Vadivel A, Fung M, Shelley WC, Critser PJ, Ionescu L, et al. Existence, Functional Impairment and Lung Repair Potential of Endothelial Colony Forming Cells in Oxygen-Induced Arrested Alveolar Growth. Circulation. 2014 Apr 7.

9. Alvarez DF, Huang L, King JA, ElZarrad MK, Yoder MC, Stevens T. Lung microvascular endothelium is enriched with progenitor cells that exhibit vasculogenic capacity. Am J Physiol Lung Cell Mol Physiol. 2008 Mar;294(3):L419-30.

10. Schniedermann J, Rennecke M, Buttler K, Richter G, Stadtler AM, Norgall S, et al. Mouse lung contains endothelial progenitors with high capacity to form blood and lymphatic vessels. BMC Cell Biol. 2010;11:50.

11. Yoder MC. Progenitor cells in the pulmonary circulation. Proc Am Thorac Soc. 2011 Nov;8(6):46670.

12. Ingram DA, Mead LE, Tanaka H, Meade V, Fenoglio A, Mortell K, et al. Identification of a novel hierarchy of endothelial progenitor cells using human peripheral and umbilical cord blood. Blood. 2004 Nov 1;104(9):2752-60.

13. Yoder MC. Human endothelial progenitor cells. Cold Spring Harb Perspect Med. 2012 Jul;2(7):a006692.

14. Peichev M, Naiyer AJ, Pereira D, Zhu Z, Lane WJ, Williams M, et al. Expression of VEGFR-2 and AC133 by circulating human CD34(+) cells identifies a population of functional endothelial precursors. Blood. 2000 Feb 1;95(3):952-8.

15. Hill JM, Zalos G, Halcox JP, Schenke WH, Waclawiw MA, Quyyumi AA, et al. Circulating endothelial progenitor cells, vascular function, and cardiovascular risk. N Engl J Med. 2003 Feb 13;348(7): 593-600.

16. Werner N, Kosiol S, Schiegl T, Ahlers P, Walenta K, Link A, et al. Circulating endothelial progenitor cells and cardiovascular outcomes. N Engl J Med. 2005 Sep 8;353(10):999-1007.

17. Tepper OM, Galiano RD, Capla JM, Kalka C, Gagne PJ, Jacobowitz GR, et al. Human endothelial progenitor cells from type II diabetics exhibit impaired proliferation, adhesion, and incorporation into vascular structures. Circulation. 2002 Nov 26;106(22):2781-6. 
18. Balasubramaniam V, Mervis CF, Maxey AM, Markham NE, Abman SH. Hyperoxia reduces bone marrow, circulating, and lung endothelial progenitor cells in the developing lung: implications for the pathogenesis of bronchopulmonary dysplasia. Am J Physiol Lung Cell Mol Physiol. 2007 May;292(5):L1073-84.

19. Paviotti G, Fadini GP, Boscaro E, Agostini C, Avogaro A, Chiandetti L, et al. Endothelial progenitor cells, bronchopulmonary dysplasia and other short-term outcomes of extremely preterm birth. Early Hum Dev. 2011 Jul;87(7):461-5.

20. Safranow K, Kotowski M, Lewandowska J, Machalinska A, Dziedziejko V, Czajka R, et al. Circulating endothelial progenitor cells in premature infants: is there an association with premature birth complications? J Perinat Med. 2012 Jun;40(4):455-62.

21. Estes ML, Mund JA, Ingram DA, Case J. Identification of endothelial cells and progenitor cell subsets in human peripheral blood. Curr Protoc Cytom. 2010 Apr;Chapter 9:Unit 933 1-11.

22. Mund JA, Estes ML, Yoder MC, Ingram DA, Jr., Case J. Flow Cytometric Identification and Functional Characterization of Immature and Mature Circulating Endothelial Cells. Arterioscler Thromb Vasc Biol. 2012 Jan 26.

23. Estes ML, Mund JA, Mead LE, Prater DN, Cai S, Wang H, et al. Application of polychromatic flow cytometry to identify novel subsets of circulating cells with angiogenic potential. Cytometry A. 2010 Sep;77(9):831-9.

24. Pradhan KR, Mund JA, Johnson C, Vik TA, Ingram DA, Case J. Polychromatic flow cytometry identifies novel subsets of circulating cells with angiogenic potential in pediatric solid tumors. Cytometry B Clin Cytom. 2011 Sep;80(5):335-8.

25. Acosta JC, Haas DM, Saha CK, Dimeglio LA, Ingram DA, Haneline LS. Gestational diabetes mellitus alters maternal and neonatal circulating endothelial progenitor cell subsets. Am J Obstet Gynecol. 2011 Mar;204(3):254 e8- e15.

26. Chang DV, Tiller CJ, Kisling JA, Case J, Mund JA, Haneline LS, et al. Membrane and Capillary Components of Lung Diffusion and Pro-Angiogenic Cells in Infants. Eur Respir J. 2013 May 16.

27. De Palma M, Venneri MA, Galli R, Sergi Sergi L, Politi LS, Sampaolesi M, et al. Tie2 identifies a hematopoietic lineage of proangiogenic monocytes required for tumor vessel formation and a mesenchymal population of pericyte progenitors. Cancer Cell. 2005 Sep;8(3):211-26.

28. Venneri MA, De Palma M, Ponzoni M, Pucci F, Scielzo C, Zonari E, et al. Identification of proangiogenic TIE2-expressing monocytes (TEMs) in human peripheral blood and cancer. Blood. 2007 Jun 15;109(12):5276-85.

29. De Palma M, Naldini L. Role of haematopoietic cells and endothelial progenitors in tumour angiogenesis. Biochim Biophys Acta. 2006 Aug;1766(1):159-66.

30. van Haaften T, Byrne R, Bonnet S, Rochefort GY, Akabutu J, Bouchentouf M, et al. Airway delivery of mesenchymal stem cells prevents arrested alveolar growth in neonatal lung injury in rats. Am J Respir Crit Care Med. 2009 Dec 1;180(11):1131-42.

31. Popova AP, Bozyk PD, Bentley JK, Linn MJ, Goldsmith AM, Schumacher RE, et al. Isolation of tracheal aspirate mesenchymal stromal cells predicts bronchopulmonary dysplasia. Pediatrics. 2010 Nov;126(5):e1127-33.

32. Ionescu L, Byrne RN, van Haaften T, Vadivel A, Alphonse RS, Rey-Parra GJ, et al. Stem cell conditioned medium improves acute lung injury in mice: in vivo evidence for stem cell paracrine action. Am J Physiol Lung Cell Mol Physiol. 2012 Dec;303(11):L967-77.

33. Aslam M, Baveja R, Liang OD, Fernandez-Gonzalez A, Lee C, Mitsialis SA, et al. Bone marrow stromal cells attenuate lung injury in a murine model of neonatal chronic lung disease. Am J Respir Crit Care Med. 2009 Dec 1;180(11):1122-30.

34. Pierro M, Ionescu L, Montemurro T, Vadivel A, Weissmann G, Oudit G, et al. Short-term, long-term and paracrine effect of human umbilical cord-derived stem cells in lung injury prevention and repair in experimental bronchopulmonary dysplasia. Thorax. 2012 Dec 15. 
35. Sensebe L, Tarte K, Galipeau J, Krampera M, Martin I, Phinney DG, et al. Limited acquisition of chromosomal aberrations in human adult mesenchymal stromal cells. Cell Stem Cell. 2012 Jan 6;10(1):9-10; author reply -1 .

36. Tarte K, Gaillard J, Lataillade JJ, Fouillard L, Becker M, Mossafa H, et al. Clinical-grade production of human mesenchymal stromal cells: occurrence of aneuploidy without transformation. Blood. 2010 Feb 25;115(8):1549-53.

37. Capelli C, Gotti E, Morigi M, Rota C, Weng L, Dazzi F, et al. Minimally manipulated whole human umbilical cord is a rich source of clinical-grade human mesenchymal stromal cells expanded in human platelet lysate. Cytotherapy. 2011 Aug;13(7):786-801.

38. Borghesi A, Avanzini MA, Novara F, Mantelli M, Lenta E, Achille V, et al. Genomic alterations in human umbilical cord-derived mesenchymal stromal cells call for stringent quality control before any possible therapeutic approach. Cytotherapy. 2013 Nov;15(11):1362-73.

39. Cotten CM, Murtha AP, Goldberg RN, Grotegut CA, Smith PB, Goldstein RF, et al. Feasibility of autologous cord blood cells for infants with hypoxic-ischemic encephalopathy. J Pediatr. 2014 May;164(5):973-9 e1.

40. Chang YS, Ahn SY, Yoo HS, Sung SI, Choi SJ, Oh WI, et al. Mesenchymal stem cells for bronchopulmonary dysplasia: phase 1 dose-escalation clinical trial. J Pediatr. 2014 May;164(5):966-72 e6.

41. Balasubramaniam V, Ingram DA. Endothelial progenitors in the risk of developing bronchopulmonary dysplasia: can we include endothelial progenitor cells in BPD risk assessment? Am J Respir Crit Care Med. 2009 Sep 15;180(6):488-90.

42. Balasubramaniam V, Ryan SL, Seedorf GJ, Roth EV, Heumann TR, Yoder MC, et al. Bone marrowderived angiogenic cells restore lung alveolar and vascular structure after neonatal hyperoxia in infant mice. Am J Physiol Lung Cell Mol Physiol. Mar;298(3):L315-23.

43. Hirschi KK, Ingram DA, Yoder MC. Assessing identity, phenotype, and fate of endothelial progenitor cells. Arterioscler Thromb Vasc Biol. 2008 Sep;28(9):1584-95.

44. Titomanlio L, Kavelaars A, Dalous J, Mani S, El Ghouzzi V, Heijnen C, et al. Stem cell therapy for neonatal brain injury: perspectives and challenges. Ann Neurol. 2011 Nov;70(5):698-712.

45. van Velthoven CT, Kavelaars A, van Bel F, Heijnen CJ. Repeated mesenchymal stem cell treatment after neonatal hypoxia-ischemia has distinct effects on formation and maturation of new neurons and oligodendrocytes leading to restoration of damage, corticospinal motor tract activity, and sensorimotor function. J Neurosci. 2010 Jul 14;30(28):9603-11.

46. van Velthoven CT, Kavelaars A, van Bel F, Heijnen CJ. Mesenchymal stem cell treatment after neonatal hypoxic-ischemic brain injury improves behavioral outcome and induces neuronal and oligodendrocyte regeneration. Brain Behav Immun. 2010 Mar;24(3):387-93.

47. Dalous J, Larghero J, Baud 0. Transplantation of umbilical cord-derived mesenchymal stem cells as a novel strategy to protect the central nervous system: technical aspects, preclinical studies, and clinical perspectives. Pediatr Res. 2012 Apr;71(4 Pt 2):482-90.

48. Dalous J, Pansiot J, Pham H, Chatel P, Nadaradja C, D’Agostino I, et al. Use of human umbilical cord blood mononuclear cells to prevent perinatal brain injury: a preclinical study. Stem Cells Dev. 2013 Jan 1;22(1):169-79.

49. van Velthoven CT, Kavelaars A, van Bel F, Heijnen CJ. Nasal administration of stem cells: a promising novel route to treat neonatal ischemic brain damage. Pediatr Res. Nov;68(5):419-22.

50. van Velthoven CT, Kavelaars A, van Bel F, Heijnen CJ. Nasal administration of stem cells: a promising novel route to treat neonatal ischemic brain damage. Pediatr Res. 2010 Nov;68(5):419-22.

51. van Velthoven CT, Kavelaars A, van Bel F, Heijnen CJ. Regeneration of the ischemic brain by engineered stem cells: fuelling endogenous repair processes. Brain Res Rev. 2009 Jun;61(1):1-13.

52. Gaudin A, Farnoux C, Bonnard A, Alison M, Maury L, Biran V, et al. Necrotizing enterocolitis (NEC) and the risk of intestinal stricture: the value of C-reactive protein. PLoS One. 2013;8(10):e76858.

53. Abreu MT. The Ying and Yang of bacterial signaling in necrotizing enterocolitis. Gastroenterology. 2010 Jan;138(1):39-43. 
54. Ciccocioppo R, Bernardo ME, Sgarella A, Maccario R, Avanzini MA, Ubezio C, et al. Autologous bone marrow-derived mesenchymal stromal cells in the treatment of fistulising Crohn's disease. Gut. 2011 Jun;60(6):788-98.

55. Weil BR, Markel TA, Herrmann JL, Abarbanell AM, Meldrum DR. Mesenchymal stem cells enhance the viability and proliferation of human fetal intestinal epithelial cells following hypoxic injury via paracrine mechanisms. Surgery. 2009 Aug;146(2):190-7.

56. Tayman C, Uckan D, Kilic E, Ulus AT, Tonbul A, Murat Hirfanoglu I, et al. Mesenchymal stem cell therapy in necrotizing enterocolitis: a rat study. Pediatr Res. 2011 Nov;70(5):489-94.

57. Lee JW, Krasnodembskaya A, McKenna DH, Song Y, Abbott J, Matthay MA. Therapeutic effects of human mesenchymal stem cells in ex vivo human lungs injured with live bacteria. Am J Respir Crit Care Med. 2013 Apr 1;187(7):751-60. 
Acknowledgements 
I wish to thank all the people who, with their skills, experience, competences, advices, support and critical discussion made it possible the conception and realization of the research projects that are now published as articles and constitute the heart of the present thesis.

The I.O. PhD represented a unique opportunity in my personal research career. During these years of training, I acquired skills and experience; the I.O. PhD program was the "place" where all the little pieces of the puzzle were organized in a consistent way, so that the single results became part of a whole picture. Not secondary, at some point I had the feeling of playing in a team. This feeling represented the frame of the picture, which is as important as the picture itself. I am honored to have been one of the first PhD students to be part of this great experience, which was a platform to test my skills, a way to open my mind to an international thinking, and a strong stimulus to keep on doing research.

For all this, I am sincerely grateful: to Prof. Diego Gazzolo, who took in charge my PhD studentship and followed it step by step; to Prof. Luc Zimmermann, for his supervision of my work, and the critical discussions we had at almost every PhD meeting; to Prof. Danilo Gavilanes and Prof. Boris Kramer, for their mentorship, help, and inputs; and to the whole I.O. PhD board.

Thanks to Prof. Mauro Stronati, who, from the first moment I started to work in his group, gave me "carte blanche", allowing me to verify my scientific hypothesis without putting any limitation. Not every boss is able to concede such a freedom to his collaborators. Also, Prof. Stronati was the one who first proposed me to apply for the I.O. PhD program.

Many thanks to all my colleagues of the NICU, and particularly to Lina Bollani, Giovanna Ferrari, and all the others colleagues, who were sometimes "tolerant", knowing that I was busy with research.

For the work on EPCs I wholeheartedly thank Vittorio Rosti and Margherita Massa. They were already working and publishing on EPCs when we met. We started setting up a collaboration, and they ended up being my mentors, both open to my proposals and rigorous in the steps to perform. Thanks to Rita Campanelli, who taught me my first notions of flow cytometry, and whose work was essential for the publication of the studies on EPCs.

For the work on MSCs, I acknowledge the important role of Maria Antonietta Avanzini and Rita Maccario, two invaluable mentors, and of Francesca Novara, for her role in the genetic studies; not least, I wish to thank Melissa Mantelli, Valentina Achille and Elisa Lenta, for their teachings, for the discussions, and for their availability.

A special thank you to the nurses and the midwives: the collection of samples would have been impossible without them. Their role in research is as essential as that of any other collaborator. 
Thanks to "Le biologhe" of the Laboratory of Neonatal Immunology, Francesca, Iolanda, Claudia and Micol.

Thanks to the people that I met during my out-of-the-PhD training periods: thanks to Jean-Laurent Casanova to host me in his lab and making me part of an outstanding scientific environment; every one of his words is a precious scientific teaching. Thanks to Jacinta, Matt, Maya, Jacqueline, Elodie; and thanks to Maria Grazia Roncarolo, Georgia, Andrea Valle, Andrea Annoni, and to all the others who supported me in my research training, and helped me to put "another brick in the wall".

Thanks to Gaia W.: a true pioneer in the Italian landscape. Now she is sunnier than I am.

Thanks to the Associazione Aiutami a Crescere ONLUS, that provided financial support for the experiments on MSCs.

A tender thank you to Roberta Maragliano. I regret that the events did not permit to go on working together.

Thanks to Stefania, for her unconditional presence.

Thanks to Angela Maria Cometa, for her constant support, earlier and today.

Thanks to Valérie, for her ability to hear me, temper my doubts, turn off my existential questions, and push me to go on with science.

Thanks to Elisa, always near.

Thanks to my family: my mother, always pushing me outside the comfort zone; to my father, who first pulled me into a "scientific comfort zone"; and to my two brothers, for they are my comfort zone.

My thinking goes to my grandparents, my aunts and uncles (zia Anna e zio Mimmo, Zia Augusta e zio Edemondo, zia Ines e zio Carlo, zia Angelina e zio Ugo, zio Mario e zia Milla), and my cousins, as their legacy is part of my present attitude to life and science.

Maybe the most important teaching that all the people cited above taught me during the past years is that research is, almost never, the effort of one single person. Although personal motivation and individual elbow grease are essential forces driving the researcher during all the steps of the scientific process, the multiplicity of methodologies and skills that are required, nowadays, to verify a hypothesis, make it impossible to rely only on ideas, a bench, a hood, and a microscope. Collaboration is one of the fundamental bases of good science.

The patients and their families were our first collaborators. To them, the most heart-felt thanks. They are the true driving force of our endeavors. 



\section{Curriculum vitae and scientific output}

Alessandro Borghesi, MD, obtained his medical degree from the University of Pavia School of Medicine (Pavia, Italy) in 2001. He completed his Pediatric Residency at the University of Pavia School of Medicine in 2006, and he currently serves as a staff member at the Neonatal Intensive Care Unit of the Fondazione IRCCS Policlinico "San Matteo" (San Matteo Research Hospital) in Pavia.

Since the years of Residency, Alessandro Borghesi developed several research projects in the field of neonatal medicine. A main area of interest is the field of stem cells (endothelial progenitor cells and mesenchymal stromal cells) in the context of prematurity. He also developed clinical and basic studies in the field of neonatal infections, with special focus on prevention of infection in the neonatal units; a major part of his experimental work aims at understanding the molecular bases of neonatal infectious diseases.

Alessandro Borghesi serves as a reviewer for numerous international journals and research grants, and he is active as a tutor for students and residents.

\section{Additional scientific activity conducted during the I.O. PhD study period}

A collaborative study on neonatal and adult ECFCs has been conducted, studying the $\mathrm{Ca}(2+)$ response to VEGF in umbilical cord blood (UCB)-ECFCs compared to that in peripheral blood (PB)-ECFCs (differentiated from the peripheral blood of adult individuals). VEGF-induced proliferation of UCB-ECFCs is faster compared with their peripheral counterpart; the present study aimed at investigating whether the higher proliferative potential of UCB-ECFCs was associated to any difference in the molecular underpinnings of their $\mathrm{Ca}(2+)$ response to VEGF. The results of this study show that the $\mathrm{Ca}(2+)$ response to VEGF in UCB-ECFCs is shaped by a different $\mathrm{Ca}(2+)$ machinery as compared with PB-ECFCs, involving canonical transient receptor potential channel 3 (TRPC3), which is expressed in UCB- but not in PB-ECFCs, and that mediates diacylglycerol-dependent $\mathrm{Ca}(2+)$ entry. 
These results were reported in one published article, attached to the present thesis:

Dragoni S, Laforenza U, Bonetti E, Lodola F, Bottino C, Guerra G, Borghesi A, Stronati $M$, Rosti V, Tanzi F, Moccia F. Canonical transient receptor potential 3 channel triggers vascular endothelial growth factor-induced intracellular Ca2+ oscillations in endothelial progenitor cells isolated from umbilical cord blood. Stem Cells Dev. 2013 oct 1;22(19):2561-80.

\section{List of lectures in scientific meetings (with abstracts or articles published in scientific journals/abstract books) during the I.O. PhD study period:}

2012, Torino (Italy). Speaker in plenary session in the "3rd International Conference on Clinical Neonatology"; topic: "Stem cells for BPD and IVH repair" (discussant: E. Bancalari)

2012, Riyadh (Saudi Arabia). Speaker in plenary session in the 12th Annual International Saudi Neonatology Society Conference; topic: "Future applications of stem cell therapy in neonatal medicine"

2011, Sorrento (Italy). Speaker in parallel session at the 17th National Congress of the Italian Society of Neonatology; topic: "Endothelial Progenitors Cells in Preterm Infants"

2010, Bari (Italy). Speaker in Parallel Session at the 16th National Congress of the Italian Society of Neonatology; topic: "Circulating Endothelial Progenitor Cells and Diseases of the Preterm Infant"

2009, Cuneo (Italy). Speaker in Plenary Session at the 3rd Congresso M.I.O.N. Meeting Internazionale Ostetrico Neonatologico delle Alpi del Mare; topic: "Circulating Endothelial Progenitor cells in Bronchopulmonary Dysplasia"

2009, Bologna (Italy). Speaker in Plenary Session at the 15th National Congress of the Italian Society of Neonatology; topic: "Endothelial Progenitor Cells and Bronchopulmonary Dysplasia" 
